\title{
Anishiniiwi bimaadisiwin: \\ Ojicree and (East) Cree Experiences of Aboriginal Literacies From Kasabonika, Mistissini, Waswanipi, and Waskaganish
}

By

\author{
Justine Macdonald \\ A thesis submitted to \\ The Faculty of Graduate Studies and Research \\ in partial fulfilment of \\ the degree requirements of \\ Masters Applied Language
}

School of Linguistics and Applied Language Studies

Department of Applied Language

Carleton University

Ottawa, Ontario, Canada

January 2011

Copyright $(\mathbb{C}$

2011 - Justine Macdonald 
Library and Archives

Canada

Published Heritage Branch

395 Wellington Street Ottawa ON K1A ON4

Canada
Bibliothèque et

Archives Canada

Direction du

Patrimoine de l'édition

395 , rue Wellington

Ottawa ON K1A ON4

Canada

Your file Votre référence

ISBN: 978-0-494-81636-3

Our file Notre référence

ISBN: 978-0-494-81636-3

NOTICE:

The author has granted a nonexclusive license allowing Library and Archives Canada to reproduce, publish, archive, preserve, conserve, communicate to the public by telecommunication or on the Internet, loan, distribute and sell theses worldwide, for commercial or noncommercial purposes, in microform, paper, electronic and/or any other formats.

The author retains copyright ownership and moral rights in this thesis. Neither the thesis nor substantial extracts from it may be printed or otherwise reproduced without the author's permission.
AVIS:

L'auteur a accordé une licence non exclusive permettant à la Bibliothèque et Archives Canada de reproduire, publier, archiver, sauvegarder, conserver, transmettre au public par télécommunication ou par l'Internet, prêter, distribuer et vendre des thèses partout dans le monde, à des fins commerciales ou autres, sur support microforme, papier, électronique et/ou autres formats.

L'auteur conserve la propriété du droit d'auteur et des droits moraux qui protège cette thèse. Ni la thèse ni des extraits substantiels de celle-ci ne doivent être imprimés ou autrement reproduits sans son autorisation.
In compliance with the Canadian Privacy Act some supporting forms may have been removed from this thesis.

While these forms may be included in the document page count, their removal does not represent any loss of content from the thesis.
Conformément à la loi canadienne sur la protection de la vie privée, quelques formulaires secondaires ont été enlevés de cette thèse.

Bien que ces formulaires aient inclus dans la pagination, il n'y aura aucun contenu manquant. 
The undersigned recommend to the Faculty of Graduate Studies and Research acceptance of the thesis

\section{Anishiniiwi bimaadisiwin: Ojicree and (East) Cree Experiences of Aboriginal Literacies From Kasabonika, Mistissini, Waswanipi, and Waskaganish}

Submitted by Justine Macdonald

in partial fulfilment of the requirements for the degree of

Masters of Applied Language

Devon Woods, Thesis Supervisor

(\# Chair's Name \#), Chair, Department of Applied Language

Carleton University

2011 


\section{Abstract}

In this study, the experiences of literacy for three Ojicree and four (East) Cree participants are discussed. Respondents reside in the communities of Kasabonika, Mistissini, Waskaganish, and Waswanipi in northern Ontario and Quebec. The research takes a qualitative approach with seven interviews in three areas of interest: 1) Aboriginal literacy development among participants who attended residential or community schools (where reading and writing in their ancestral languages was not taught), 2) Past and current uses of the syllabic and roman scripts, and 3) The relationship between Aboriginal literacy and identity. The paper includes a literature review that provides a general background to the research question and a discussion of the origins of syllabics in Ontario and Quebec. The distinction between 'Ojicree' and 'Cree', and a general description of the shared characteristics of northern communities where these languages are spoken as the L1 is discussed. A personal narrative description of life in Kasabonika is also given as context for analysis. The concluding chapter makes suggestions for further research and consolidates the findings of the study.

Keywords: Cree, Ojicree, biliteracy, Aboriginal literacy, syllabics, roman orthography, Kasabonika, Waswanipi, Mistissini, Waskaganish, East Cree, 
Our Native language embodies a value system about how we ought to live and relate to each other... it gives a name to relations among kin, to roles and responsibilities among family members, to ties with the broader clan group. There are no English words for these relationships. Now, if you destroy our language you not only break down these relationships, but you also destroy other aspects of our Indian way of life and culture, especially those that describe man's connections with nature, the Great Spirit, and the order of things. Without our languages, we will cease to exist as a separate people.

-Elder Eli Taylor (Assembly of First Nations, 1990) 
For my grade 7 student,

Lance Brown,

who reminded me once:

'there's always a chance'

and was right. 


\section{Acknowledgements}

I am deeply grateful to the many people who have supported me during the writing of this paper. My supervisor, Dr. Devon Woods, took me as his student late in September of 2010 after I returned from Kasabonika. I had the interviews and an idea, but nothing written. He helped me understand the writing process on a deeper level and transfer my thoughts to paper. I am also grateful to my initial co-supervisors: Dr. Marie-Odile Junker, who gave forum for me to think about Aboriginal languages in her culture class and who continues to do outstanding work through her collaboration with Cree Language of Instruction Program (C.L.I.P.) in support of the Cree language; and Dr. Guillaume Gentil, who gave me guidance in the beginning phase of planning this research.

My initial interests in Aboriginal culture and language stem from time spent in the north of Ontario. During 2005-2006 I worked in forestry for a Native tree-thinning company, owned by Darren Landry and based out of Shining Tree. Landry taught me many things about the animals and forest during the many hours we spent walking through the bush. In 2008, I met and interviewed four Cree women, Pearl, Ruth, Emily, and Anna, while they were involved in the creation of the online East Cree dictionary, and to whom I am very appreciative. In 2009-2010, I had the life-changing opportunity to work in Kasabonika as the grade 7 teacher. I met some fantastic kids and observed a different way of life that will always stay with me. I am deeply grateful to the Native language teachers there, Judy, John, and Saloma, who agreed at a busy time of year, to be interviewed. I am also grateful to Norman Semple for his help in recording these sessions, his insights into Native issues, and many hours of discussion in the library.

I moved to Ottawa in the winter of 2006 . I have no family here and have always worked full-time while attending school. The relationships with my friends and coworkers in this city 
have been paramount to my academic successes. The completion of this paper would not have been possible without the stable environment to write that was provided to me by the Zaine family, and the unwavering encouragement and support that were always offered. I am deeply grateful to all of you. Thank you to Fred Oxtoby for his constant reminders of the importance of education, and to Four Seasons Sunrooms in allowing me to leave the jobsite for the classroom on Tuesdays and Thursdays. Thank you to Tosh, for your spiritual support in the days before my leaving to Kasabonika. Thank you to Angela, who gave me a place to live when I came back, where I was able to write the initial proposal for this research. Thank you to Greg, who always listened and was there with me through my hard times. Thank you to Brenda for helping me manage the stress and reminding me of my priorities. Also, to Michel Robitaille, whose presence in my life since 2008 has kept me on track in achieving my goals and who taught me more skills than are possible to list here. Thank you for believing in me. Finally, to my mum and dad, thank you for always being there and ready to help.

I wrote the bulk of this paper from the $5^{\text {th }}$ floor of Macodrum library, at the corner computer of the grad room. During thoughtful moments, I would lift up my eyes and watch the geese flocking to the river. They remind me of my students in Kasabonika. It is the end of January now and the birds are still there, every time I look: flying level with the horizon, in perfect rhythm, all together. Michel says they will keep going to the water until it freezes over completely, until there is nowhere else for them to land. This is the strength of spirit those kids have. Every word in this is for them. 


\section{Table of Contents}

Abstract $\quad$ iii

Acknowledgements $\quad$ vi

Table of Contents viii

List of Tables $\quad$ ix

List of Figures $\quad$ xi

$\begin{array}{ll}\text { Chapter 1: Introduction } & 1\end{array}$

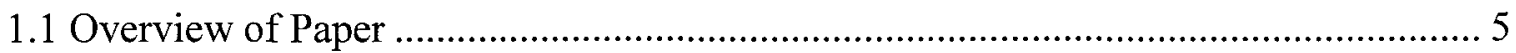

$\begin{array}{lr}\text { Chapter 2: Literature Review } & 6\end{array}$

2.1 Aboriginal Identity and Litearcy ................................................................. 7

2.2 Literacies, Bilitleracy, and Northern Bilingual Communities ................................ 13

2.2.1 'Literacies' and 'Biliteracy' ................................................................. 13

2.2.2 Aboriginal Bilingual Communities in Northern Ontario and Quebec ............ 15

2.2.3 Theoretical Framework ......................................................................... 18

2.3 Issues Related to Aboriginal Writing Systems in Northern Ontario and Quebec....... 21

2.3.1 'Ojicree', '(East) Cree', 'Cree', and 'Ojibwe' ............................................. 21

2.3.2 The Cree Syllabary: A Background ........................................................ 28

2.3.3 Indigenous Origins of the Cree Syllabics ............................................... 31

2.3.4 Modern Syllabics .............................................................................. 32

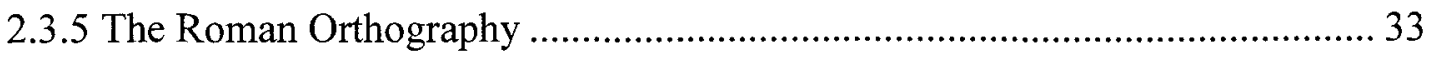

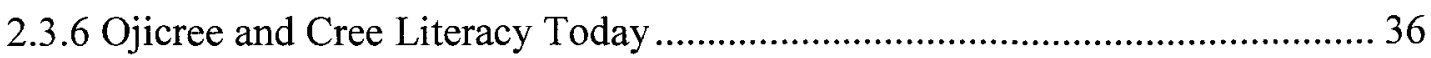

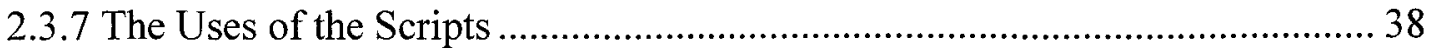

2.3.8 The Learning and Teaching of the Cree Writing Systems........................... 40

2.3.9 Residential Schools: The Generation Gab in Aboriginal Language Learning 41

2.3.10 Aboriginal Control of Aboriginal Education: The Cree School Board ......... 43 
2.3.11 A Note on the Decision Making Process and Emerging Goals

Chapter 3: Methodology

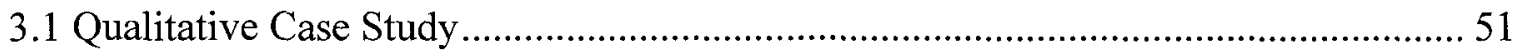

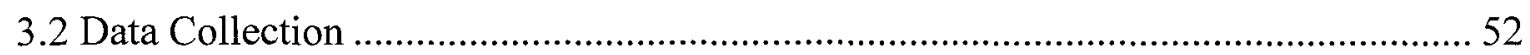

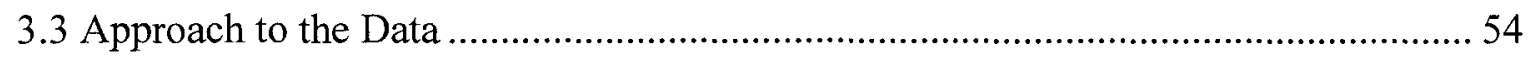

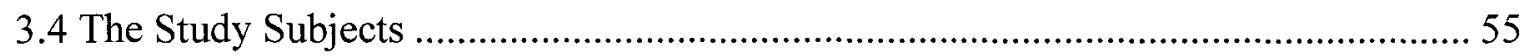

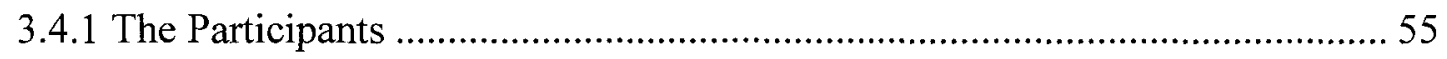

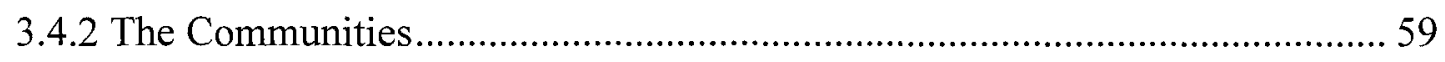

Chapter 4: Results \& Analysis $\quad 60$

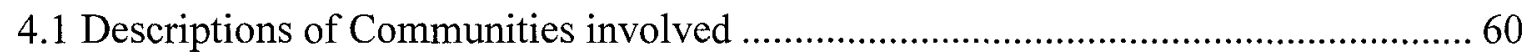

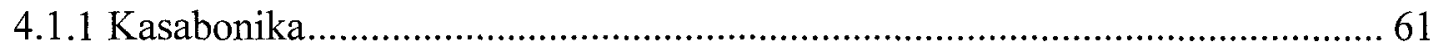

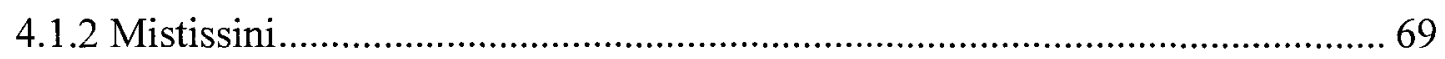

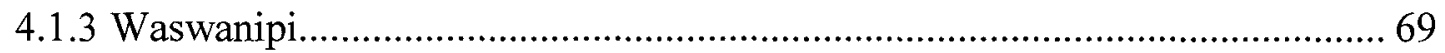

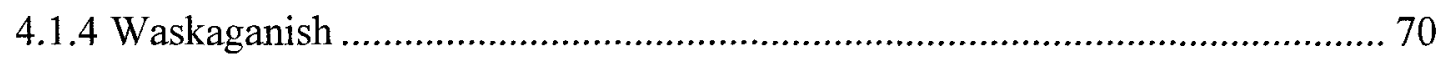

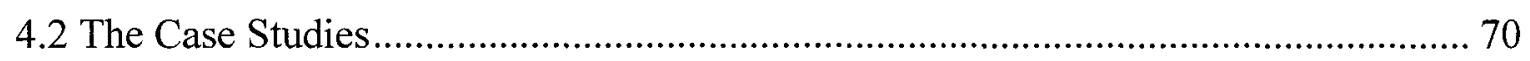

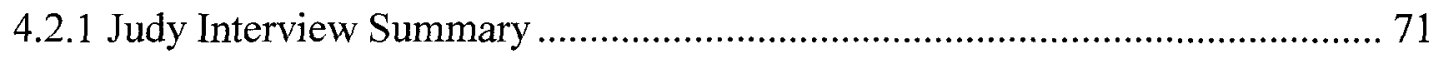

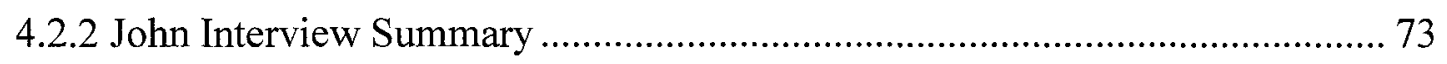

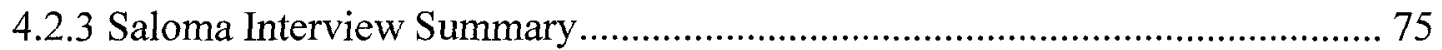

4.2.4 Pearl Interview Summary ........................................................................ 78

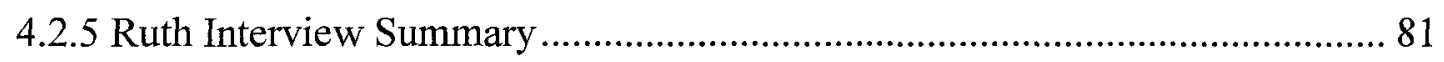

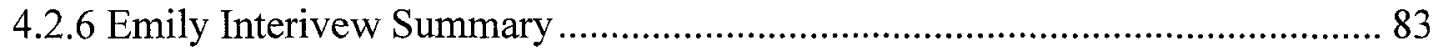

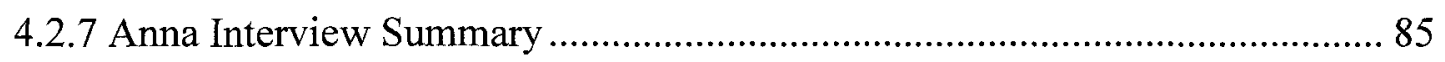

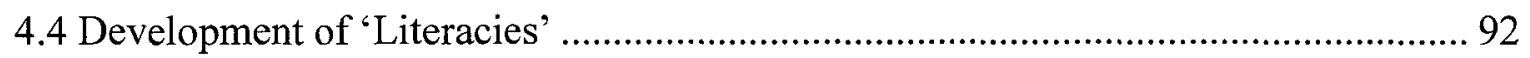

4.4.1 Participants who Attended Residential Schools ................................................ 93

4.4.2 Participant who Attended Community Schools............................................. 88

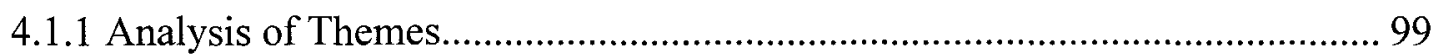

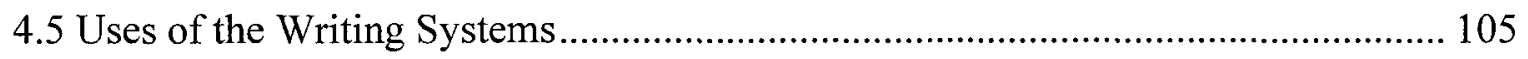

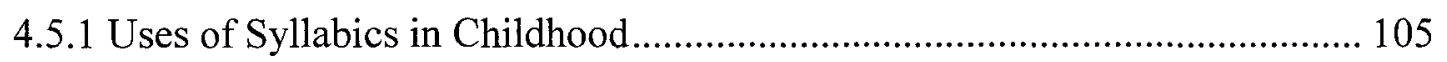

4.5.2 Uses of the Writing Systems in Daily Life .................................................... 106 


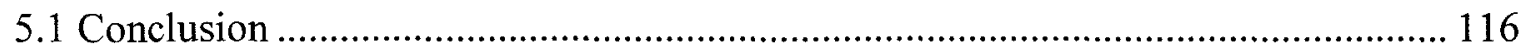

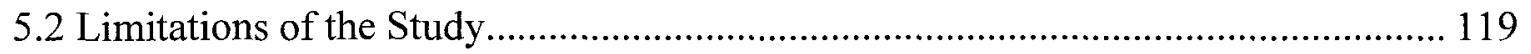

5.3 Suggestions for Further Research ........................................................... 119

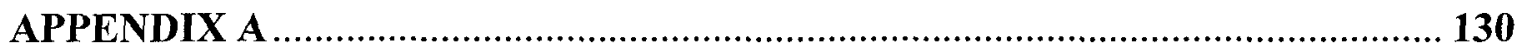




\section{List of Tables}

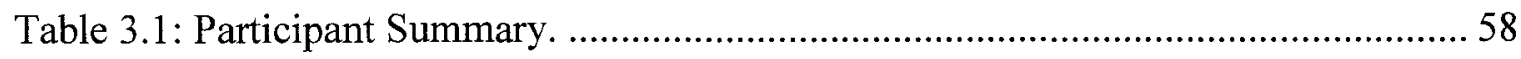

Table 4.1: Participants who attended Residential Schools ................................................ 94

Table 4.2: Participants Who Attended Community Schools............................................. 98

Table 4.3: Participant Examples of Reading in Daily Life.......................................... 110

Table 4.4: Participant Examples of Writing in Daily Life............................................ 113 


\section{List of Figures}

Figure 2.0: Hornberger's Continuum of Biliteracy ..................................................... 20

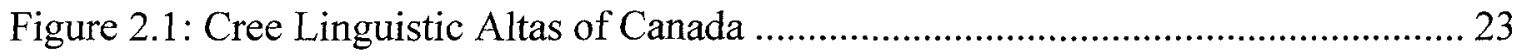

Figure 2.2: Geographical Map of Northern Quebec....................................................... 24

Figure 2.3: Geographical Map of Northern Ontario........................................................ 25

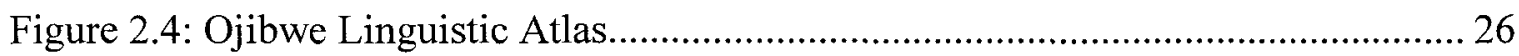

Figure 2.5: Ellis' Standardized Roman Orthography for Cree. .......................................... 34

Figure 2.6: East Cree Syllabic Chart............................................................................ 48

Figure 2.7: Traditional Cree Beadwork Resembling Syllabic Characters........................ 49

Figure 2.8: Ojicree Syllabic Chart Used in the Classroom............................................... 50 


\section{Chapter 1: Introduction}

At the turn of the $19^{\text {th }}$ century, syllabic literacy rates in northern Ontario and Quebec are thought to have been among the highest in the world despite the absence of 'institutional' support (Murdoch, 1985, Berry \& Bennett, 1989). Since then, many of these languages have been steadily eroded by the devastating legacy of Canada's residential school system and the encroachment of English and French into everyday living in even the most isolated of communities. There is a 'generation gap' between past and present in the collective knowledge of many Canadian Native language speakers in their experience of spoken and written languages. This gap, a consequence of the residential school system, has, to some degree, been bridged by the individuals who managed to learn the syllabic script outside of formal schooling and now are active members of education and resource programs to ensure its survival. Achieving literacies in their ancestral languages, some have become language professionals and are depended upon as scribes, translators, and teachers in their communities. These individuals have a unique relationship with the written forms of their ancestral languages. The central focus of this thesis is to approach understanding the nature of this relationship by investigating 
the connection between Aboriginal literacy and identity ${ }^{1}$ for two Canadian Native groups: Ojicree and (East) Cree.

Today, language literacy is an important topic of inquiry because it touches upon pressing issues of language preservation and may provide insight for decisions currently being made by Native school boards and education authorities. At a time when most Canadian Aboriginal languages are not expected to survive past the next two generations (Norris, 1998, Heimbecker, 1997), efforts have intensified to protect these languages through education and curriculum development. Mandatory Native language classes, which include Aboriginal literacy as an integral part of their curriculums, have been developed in an effort to expand knowledge of Native writing systems. The hope is to strengthen the identity of Aboriginal youth by teaching reading and writing as a way to ensure cultural continuity and the legitimization of their ancestral language. Recent research into the relationship between literacy and identity seems to support the mandate of this effort, as "literacy practices are one expression of the knowledge, values, and behaviors of any group" (Kucer, 2009:221). The thesis will address three research questions designed to explore the connection between identity and Aboriginal experiences of literacy:

1. How do Ojicree and (East) Cree L1 speakers conceptualize the relationship between their identity and literacy in their ancestral language?

\footnotetext{
${ }^{1}$ The title of this thesis was given to me by an Ojicree participant. Its English meaning may be approximated to Aboriginal Identity Way of Life.
} 
2. How have Ojicree and (East) Cree individuals come to learn the written form of their language?

\section{What is the current role of written Ojicree and (East) Cree in northern communities where English is considered the second language?}

The three research questions will also assist in documenting knowledge about Aboriginal literacies in Canada.

Statistics Canada has no information regarding the current number of Ojicree and (East) Cree who are able to write in their ancestral language. In addition, the current role of Aboriginal written language for individuals and communities is also unstudied (Burnaby, 2002). Though there is some academic work concerned with historical accounts of the development of various Aboriginal orthographies (Berry \& Bennett, 1995, Walker, 1968, Drapeau, 1985, McCarthy, 1995, Burnaby \& Anthony, 1985, Burnaby, 2002), little attention has been paid in general to Aboriginal people's actual experience of literacy in their languages. Further, the perspectives of Ojicree-English and (East) Cree-English biliterate people regarding the two scripts ${ }^{2}$ have not been documented and may also prove valuable to curriculum designers. In particular, those at the Kwayaciiwin Education Resource Centre and the Cree Language of Instruction Program (C.L.I.P.) may be interested in the results of this study. The importance of current practices of written Ojicree and (East) Cree and the processes involved in an individual learning to write in his/her ancestral language may also inform the question of

\footnotetext{
${ }^{2}$ The two general scripts to which I refer are syllabic and roman. There are standardized and nonstandardized versions of each for the East Cree. Variations of the two scripts are used by both language groups discussed in this study.
} 
how the use of written language differs between Ojicree, (East) Cree, and English communities when thinking about the new curriculums and the promotion of Native writing systems in Canada.

There are seven participants interviewed in this study: four attended residential schools where they were forbidden to read, write, or speak their language, and three attended community schools where they were not taught their language until it was implemented as a language of instruction in the intermediary grades. Each of the participants has acquired Aboriginal literacy skills making them a minority in their communities. Highly skilled readers and writers of their ancestral languages, the participants each brought a great deal of insight into the way written language is learned and functions in their respective communities. They are now teachers/language specialists involved in education programs and part of the larger Aboriginal language revitalization movement currently happening in Canada.

My interest in this topic stems from personal experience teaching grade 7 at Chief Simeon McKay Education Centre in Kasabonika, Ontario, where I lived and worked for one school year. The thesis includes a personal narrative description of Kasabonika, designed to provide context for understanding the way the language functions on the reserve, and how, in every way, the language and writing systems are embedded in the culture and Aboriginal identity of this community. The Kasabonika Lake First Nations feel passionate about their language and they take great pride in having maintained it, though there are fears about its future. I am encouraged by the children of Kasabonika, 
whose love of their Native language was evident to me and who are now growing up at a time when it is at risk of extinction. I am optimistic that through education, the number of students who graduate fully bilingual and biliterate will increase from year to year.

\subsection{Overview of the Paper}

The study consists of an examination of the experience of Aboriginal literacies through qualitative analysis of seven case studies. Chapter 2 is a literature review divided into three sections designed to inform the three aforesaid research questions. 2.1 examines recent literature concerned with the relationship between Aboriginal identity and literacy and provides a theoretical framework for the first research question; 2.2 discusses key terms used ('literacies', 'biliteracy', and 'bilingual communities') and provides a theoretical framework for the two secondary questions; and, 2.3 addresses issues related to Ojicree and (East) Cree writing systems. The methodology is described in Chapter 3 and involves one-on-one interviews conducted with three Ojicree-English and four (East) Cree-English biliterate and bilingual participants. Chapter 4 examines results and provides an overview of the participant responses. A thematic analysis of the data is then presented, showing connections between the literature review and the discussion section. Chapter 5 explains the limitations of the study, concludes, and discusses implications for further research. 


\section{Chapter 2: Literature Review}

The literature review is divided into three sections designed to inform the research questions and provide a theoretical framework for each. 2.1 examines recent literature concerned with the relationship between Aboriginal identity and literacy and provides a theoretical framework for the primary research question; 2.2 discusses key terms that include: 'literacies', 'biliteracy', and 'bilingual communities', and creates a theoretical framework to the second and third sub-questions; 2.3 is intended to provide background information to the reader and addresses issues related to Ojicree and (East) Cree writing systems. In this section, a background to the emergence of the syllabics and other written forms of Ojicree and (East) Cree is provided (a brief linguistic description of the two scripts is also included). In addition, there is a review of what is understood about the

uses of the writing systems today. A general history of the teaching and learning of Ojicree and (East) Cree, including the effects of the residential schools on language knowledge, is also given. 


\subsection{Aboriginal Identity and Literacy}

The inherent links between language, culture and identity are most poignantly expressed in the opening quote of this paper by Elder Eli Taylor who explains that the Indian way of life is inextricably embedded in their language - that there are no English words to replace their understanding of the connection between "man and nature, the Great Spirit, and the order of things". He says: "without our language we will cease to exist as a people". Indeed, the assertion of the absolute necessity of maintaining Native languages as a way of ensuring that Native children grow up with strong Native identities is expressed in virtually every Native curriculum document and Native School Board website. The most powerful academic article that I have read in this area is from Hallet, et al. (2007) whose preliminary investigations gesture to the link between Aboriginal language knowledge and band-measured youth suicide rates. Results from their study indicate that those bands with higher levels of language knowledge had fewer suicides than those bands with lower levels (Hallet, et al. 2007). Thus, the human costs associated with language loss can in some way be tied to identity loss. Other social-psychological literatures gesture to the apparent links between language and culture:

That language is often the central criterial attribute for group identity is evident even from a cursory review of intergroup relations in numerous countries around the world including Canada, Russia, Spain, Belgium, India, Malaysia, Finland, etc. (see Fishman, 1989; Giles, 1977; Ros, Cano \& Huici, 1987; Liebkind, 1982; Bourhis, 1984). Moreover, much of the social psychological research cited above suggests that language use and identity appear to be related reciprocally: language use influences the formation of group identity and group identity influences patterns of language attitudes and usage. (Sachtev, 1995) 
It is clear that Elder Taylor's affirmation is supported by academic literature across disciplines.

In the areas of northern Ontario and Quebec that are specific to this study, language researchers have commented on the difficulty of 'getting' Native participants to distinguish between the spoken language and the written. One example from Berry \& Bennett (1989:39): "It was obvious from our early work in the area that people tended to confuse the issues of script and spoken language" such that "despite our persistent efforts to disentangle the two strands of script and speech, people would still forget and tell us, that is was important to learn to read the syllabic script, 'because it's the language for the Indian people, the same as whites have to learn their language"". This trend is also commented upon by Burnaby (2002) in her review of the literature on Aboriginal writing uses. She says that for Aboriginal people, their language and script are one and the same, in fact, because of nature of the script, the conception that a written syllable does not 'stand for the sound, it is the sound' is perfectly logical (Burnaby, 2002, Taylor \& Olson, 1995). Thus, it also seems likely that a relationship will exist between Native language literacy and identity.

The primary focus of this thesis to examine the relationship between Aboriginal literacies and identity. Identity, as defined from the perspective of social psychology, is often associated with a "stable, internal state of being" (Lewis, 2007: 4) and is the part of oneself that remains constant as an individual moves through different social settings. Recent literature has also identified that individuals "typically holds membership in 
multiple groups or interpretive communities - that is, has multiple social identities" and that "because these various memberships are accompanied by various literacy forms and functions, the individual may possess multiple literacies as well" (Kucer, 2009: 221). In regards to the unique cases of the Ojicree and (East) Cree, who live in isolated communities, the membership to the outside group is limited (to some degree) and often mediated through some form of technology. The idea is meaning and language that are built and used are always framed by the social identity (e.g., ethnic, cultural, gender) of the individual and the social context in which the language is being employed such that "readers and writers engage in multiliteracies rather than a single literacy." (Kucer, 2009: 6). Thus, literacy as a means of thinking about identity becomes particularly interesting in the unique case of Ojicree and (East) Cree cultures in Canada.

Literacy researchers and educators, particularly those adopting a socio-cultural perspective, are increasingly interested in the ways in which literacy is a key site for identity work (Merchant, 2009). As mentioned in the introduction, literacy practices are expressions of the "knowledge, values, and behaviors of any group" (Kucer, 2009:6). Kucer (2009) notes that: "with time, experience, and apprenticeship, the literacy practices of any individual come to reflect group norms and values" (Kucer, 2009: 221). Similarly, Gee (1999) surmises that "language and literacy are elements in larger wholes: elements in multiple and socioculturally diverse 'ways of being in the world' ... which are meaningless if taken out of those forms of life" (Gee, 1999:122). The approach by Kucer (2009) and Gee (1999) suggests that specific literacy practices are seen as ways to display 
membership and are part of the overall "identity kit" (Gee, 1999) of an individual. In connection to the unique case of the language situation of the Ojicree and (East) Cree, their literacy practices may, on a micro level, reflect in some way the changes that their 'ways of being' in the world have changed during the past decades. In such a case, Leu's (2000) notion that an individual is always "becoming literate rather than [is] literate more accurately describes our ongoing relationship with written language" (Leu, 2000). The unique language situation and the isolation of the four communities involved in this study is an opportunity to examine the application of these theories in new ways. The language change, coupled with the influx of technologies, may also translate into ways in which literacies in these four communities have changed through applications by that are used in mainstream Canadian culture.

One of these applications is the teaching of literacy in schools, which are typically cultural sites for childhood identity development. The applications of literacy teaching may:

1) affirm, build on, and extend the way in which language is used in the child's home;

2) may require adaptation in how thought and language are used as regulatory systems;

3) or may directly contradict home language patterns

(Heath, 1983, Scollon \& Scollon, 1981)

As each group has "rules for socially interacting and sharing knowledge in literacy events" (Heath, 1982: 50), the combining of the teaching of Aboriginal literacy with a Western model of education provides an interesting site for analysis regarding how 
knowledge is produced in school contexts and how this relates to identity development.

As Kucer notes:

the nature of knowledge, its production, and its use as linked to literacy, ideology, and power are being uncovered. The educational impact of these explorations has been an increased sensitivity to the range of socially based experiences and meanings that students bring to the classroom. (Kucer, 2009:4)

Studies of the development of literacy and cultural identity, such as Stairs' (1990) work with Inuktitut children who are taught literacy in both their Native language and English ${ }^{3}$, are based in Freire's (1970) understanding of literacy as a cultural action:

The cognitive dimensions of the literacy process must include the relationships of men with their world. These relationships are the source of the dialectic between the products men achieve in transforming the words and the conditioning which these products in turn exercise on men (Freire, 1970, 36).

Freire's assertion is applicable to the case of the cultural identity of the (East) Cree and Ojicree, where these 'products' have been brought into their communities by the dominant French and English cultures and practices. Stairs (1990) applies this concept in her model for examining the role of literacy in Native cultural development by looking at the cause and effect role that literacy has on Native cultural identity:

Starting predominantly from the cause side, initial literacy teaching methods and materials are based essentially on the skill strengths and thinking biases of a dominant, external culture. Beginning reading and writing this way deeply negates the Native cultural identity by ignoring, suppressing, or conflicting with Native cognitive skills and styles...In contrast, we feel that literacy which is introduced on the effect side of the cycle can serve the bicultural goal for Native development which we are pursuing here. When Native language literacy is based predominantly on the unique cognitive capacities of the Native culture, it

\footnotetext{
${ }^{3}$ She found that children's English writing was related to the fluency of their earlier Inuktitut writing, and their current Inuktitut fluency (Stairs, 1990:114).
} 
both preserves and strengthens those internal capacities and integrates them with the external capacities of the written language. (Stairs, 1990)

In her model, she observes the introduction of literacy to a Native culture and warns literacy workers to "realize that from the earliest stages they inevitably bring applications, both individual and social, with their technology" (Stairs, 1989:36). For the Ojicree and (East) Cree, how are the technologies and conventions of the dominant English and French cultures being applied to their traditional literacies today?

More recently, Kramsch (1993)'s concept of the 'third place' discussed in 2.2.2 has been applied to the "larger social, economic and political systems" that play a part in "structuring dominant-subordinate, majority-minority relations". It is argued that "their impact on everyday experience cannot easily be predicted. Instead, the emphasis is on looking closely at "how people make sense of inequality and difference in their local situations, and at how they interpret them in the context of a range of social relationships" (Rampton, 2000). It is through the lens of this awareness of the damaging impacts of majority cultures and the literacy applications that they carry, that analysis of the participants' conceptions about their own identity as it relates to literacy, will be carried out. 


\subsection{Literacies, Biliteracy, and Northern Bilingual Communities}

\subsection{1 'Literacies' and 'Biliteracy'}

This study will proceed from the notion that the cultural functions of the Ojicree and (East) scripts are not analogous to that of English. Recognizing that literacy

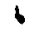
practices vary across cultures and that it is dangerous to assume an autonomous, idealized form of literacy when designing curriculum and education programs, this study will proceed from Street's (2003) notion of 'literacies" ${ }^{4}$ in which he argues that practices of literacy vary according to social context. The conception of literacy as literacies, which are multiple and highly contextualized was first pioneered by Scribner \& Cole (1981) in their studies among the Vai people of Liberia, many of whom, much like the Ojicree and (East) Cree participants in this study, acquired indigenous literacy outside of school settings. Vai literacy was found to differ greatly from that of English literacy as it is not used to produce public books or manuscripts, but rather for extensive personal correspondences, private creative uses, and public record keeping. Similarly, as 2.2.2 attempts to present, (East) Cree and Ojicree literacies are clearly distinct from those of English and French.

In addition, the working definition of 'biliteracy' will follow from Hornberger (1990:xiii) as "any and all instances in which communication occurs in two (or more)

\footnotetext{
${ }^{4}$ This notion was developed from Scribner and Cole (1981).
} 
languages in or around writing". The term 'biliteracy' was first used by Goodman, K. et al. (1979). The meaning was "assumed to be, roughly, reading (and writing) in two languages (or in a second language) (Genesee, 1980; Cummins, 1981; Valdes, 1983). A clearer definition of the word was then provided by Niyekawa (1982) who described biliteracy as "an advanced state of bilingualism where the person can not only speak two languages fluently but also read and write these two languages" (Niyekawa, 1982:98). Then Fishman (1985) described biliteracy to be "the mastery of reading in particular, and also of writing, in two (or more) languages" (Fishman, et al., 1985: 377). Each of these definitions is built upon by Hornberger: she incorporates Fishman's inclusion of two (or more) languages (or language varieties), and expands her definition from Niyekawa's to include those "less than fluent and those who are biliterate but not bilingual" (Hornberger, 2003: xiii). Hornberger's definition is more appropriate to use in an Aboriginal context because it is broader and more encompassing. Burnaby (1989) points out, than certain global assessments of reading based on the level of schooling achieved implies that "people who can only decode from symbol to sound without meaning recover, or use the two-step process of decoding from symbol to sound and then rereading for meaning, would not be considered literate" (Burnaby, xiii).

Furthermore, Hornberger's definition of biliteracy is distinguished from Heath's (1982) characterization of literacy events as "occasions in which written language is integral to the nature of the participants' interactions and their interpretive processes and strategies' (Heath, 1982: 50, 1983: 386). Hornberger (2003) explains that while Heath 
focuses on the actual 'event' of literacy, she refers to "instances, a term encompassing events, but also biliterate actors, interactions, practices, activities, programs, situations, societies, sites, worlds" (Hornberger \& Skilton-Sylvester, 2000:98; Hornberger, 2000: 362). Thus, Hornberger's definition is broader and more inclusive and will be adopted in the thesis. Each of the seven case studies chosen for the project will be referred to as 'biliterates' 5 .

\subsubsection{Aboriginal Bilingual Communities in Northern Ontario and Quebec}

Aboriginal Bilingual communities in northern Ontario and Quebec share some characteristics concerning the relationship between their language and culture and the outside world. In light of the modern day influx of technologies and the creation of road access, individuals living in these communities can be seen to embody a sort of "third place", that is "between and beyond the social order of the native culture" and that of the mainstream culture in regards to literacy learners (Kramsch, 1993). There is some variation generationally within these communities in regard to knowledge of the ancestral languages. In the community of Kasabonika ${ }^{6}$, Ojicree is generally the L1 for older speakers but is the L2 for younger speakers. In the communities of Waskaganish, Mistissini, and Waswanipi, (East) Cree is still the L1 for most of the children, although

\footnotetext{
${ }^{5}$ Two participants are actually tri-literate: East Cree, English and French. See section 3.5.1.

${ }^{6}$ The Kasabonika homepage (kasabonikafirstnation.ca) states that "the English language, both spoken and written, is the working language for most of our younger community members".
} 
the on-off reserve pattern means that some students have difficulty maintaining their language in a strong way.

In addition, many of these communities are experiencing a population boom which has, in some cases, compounded the effects of the generation gap in language knowledge created by the implementation of residential schools (detailed in section 2.3.9). Statistics Canada reports that the "Aboriginal population is growing quickly, at a rate that outpaces that of the rest of the Canadian population" (Zukewich \& O'Donnell, 2006). In some cases, the shorter generation means a higher percentage of Aboriginal children are born to young parents who are products of the generation gap in language knowledge created by residential schooling. The richest form of Canadian Aboriginal languages are with the Elders ${ }^{7}$. In addition, impacts of satellite TV, DVDs, and the internet, which bring French and English language and culture into the homes, have contributed to this climate of rapid language shift in many northern communities. Consequently, the younger generations face obstacles to gaining a good foundation in their mother tongue as it was traditionally acquired in the home.

The northern communities of interest in this study have all responded the language situation by taking control of their own education through the development of the Cree school board in Quebec which serves the nine East Cree communities including the ones my participants come from: Waskaganish, Mistissini, and Waswanipi; and the

\footnotetext{
${ }^{7}$ There are many language specialists and individuals in all four communities who have excellent language and literacy skills. In addition, children who underwent Cree as a Language of Instruction Program (C.L.I.P. ) in East Cree commnities were said to "speak like elders" and have better language skills in their first and second language than the ones who did not have CLIP. (M.O. Junker, p.c.)
} 
Sineonokway Education Authority that just serves Kasabonika, Ontario. While (East)

Cree remains the L1 in James Bay for most of the children, the Ojicree language is being learned in the northern schools by some students as an L2. The phenomenon of language shift has created challenges for the local schools:

Indigenous students' backgrounds are...varied and complex. They may enter school speaking the Native language as a primary language, have a passive knowledge of the language, or have no knowledge of the language at all. Their variety of English is also complicated by the variation of English spoken within indigenous communities which are typically modified by the structures and use patterns of the heritage language. (McCarty, 2003:150)

In regards to Aboriginal literacy, Burnaby (1989) notes that it is likely that there is "no native community in Canada in which literates in the Native language are in the majority" (Burnaby, 1989: xiii). In addition, some reports suggest that the acquisition of Aboriginal literacy is not consistent among the specific cases of Ojicree and Cree in northern Ontario, despite the implementation of education programs in the 1970 s to teach it (Ningewance, 1993). Unfortunately, there is a lack of literature available to better describe the present situation and Statistics Canada has no information regarding the number of Ojicree/(East) Cree who are able to read and write their language.

The literature widely reports that only 3 Aboriginal languages are likely to survive past the next century ${ }^{8}$ : Ojibwe, Cree, and Inuktitut (Norris, 1998). This statistic is misleading, as section 2.3.1 shows, because these three 'languages' actually encompass a huge variety of speakers and dialects that are not mutually intelligible. All Aboriginal

\footnotetext{
${ }^{8}$ Cree, Ojibwe, and Inuktitut are also the three Canadian Aboriginal languages that are most often written in the syllabic script (Foster 1982).
} 
languages in Canada face significant challenges now and in the future ${ }^{9}$. The Assembly of First Nations (1990) states that, "it is apparent that the vast majority of First Nations are relying on the school system to instruct their children in their Aboriginal language" (AFN, 1990: 66). Hope lies in the Aboriginal-controlled, bilingual and trilingual education programs that operate at the local level in many of northern communities for the transmission of language knowledge to the younger generation.

\subsubsection{Theoretical Framework}

This study proceeds from the notion that the cultural functions of the Ojicree and (East) Cree scripts (in both forms) are not analogous to that of English. As discussed in section 2.2.1, the study will proceed from Street's (2003) notion of 'literacies'. The research conducted will be guided by a theoretical framework introduced by Hornberger (2003) as the 'Continuum of Biliteracy' which suggests understanding interrelationships between bilingualism and literacy through "the importance of contexts, media, and content through which biliteracy develops" (Hornberger, 2003: 35). Hornberger's nine continua (see Fig. 2.0) characterize contexts for biliteracy (macro-micro, oral -literate, monolingual-bilingual), the development of individual biliteracy (production - reception, oral-written, L1-L2), and the media of biliteracy (simultaneous- successive, exposure,

\footnotetext{
${ }^{9}$ In a 1990 Assembly of First Nations report, the Education secretariat reports that of the 151 First Nations in Canada surveyed, $25 \%$ of bands have declining languages, $30 \%$ have endangered languages, and $11 \%$ have critical languages.
} 
similar-dissimilar structures, convergent-divergent scripts). The framework encourages the consideration of a single point on the continua as inextricably connected to all other points. The content analysis of the first two sections of the interviews (the development of 'literacies' and the participant uses of the scripts) will be guided by an awareness that the context of biliteracy for these participants is extremely complex and interconnected with factors such as relationships with the dominant English and French cultures. The nature of these relationships, the role of media such as Television and computer technology will be incorporated into analysis. Furthermore, a personal narrative description of daily life in Kasabonika is included in Chapter 4 to give some level of context into a life that is foreign to the dominant English and French cultures of Canada. 


\section{Context of Biliteracy}

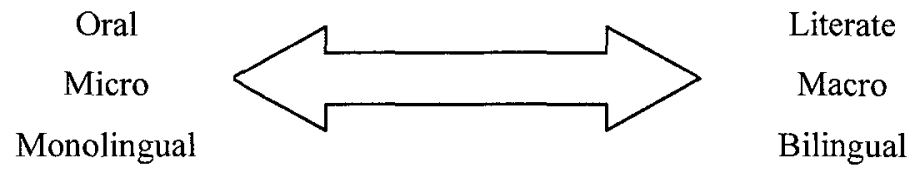

\section{Development of Biliteracy}

Production

Oral

L1

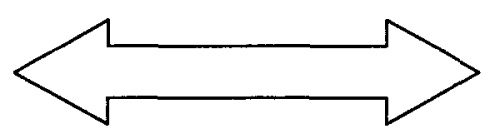

\section{Content of Biliteracy}

Simultaneous

-Successive

Similar

Convergent
Reception

Written

L2

Exposure

Dissimilar

Divergent

Figure 2.0: Adapted from Hornberger's (2003) 'Continuum of Biliteracy' 


\subsection{Issues Related to Aboriginal Writing Systems in Northern Ontario and Quebec}

This section will review issues relevant to the development of the Aboriginal writing systems used in northern Ontario and Quebec. The section begins by clarifying the geographical and linguistic boundaries between the two groups discussed in the study: Ojicree and (East) Cree. Unfortunately, there is a lack of specific information regarding the development and spread of syllabics and roman scripts among the Ojicree, so much of the literature reviewed in this section refers explicitly to Cree scripts used in Ontario and Western provinces where there is contact with the Ojicree $(2.3 .2,2.3 .4)$. This is also true of the state of the respective languages today (2.3.6). In terms of the development of Aboriginal control of education and the teaching and learning of the syllabics (2.3.8, 2.3.10), discussion mostly centers on examples from northern Quebec communities because current information available regarding the Ojicree is more limited ${ }^{10}$.

\subsection{1 'Ojicree', '(East) Cree', 'Cree', and 'Ojibwe': A Clarification of Terms}

It is appropriate to open this section with a discussion about the use of the terms 'Ojicree', '(East) Cree', 'Cree', and 'Ojibwe' as they appear in this thesis. It has been my experience living in Kasabonika, Ontario that the residents strongly self-identify as

\footnotetext{
${ }^{10}$ There is some research that describes the movement towards Aboriginal control of education in northwestern Ontario and the development of the Shibogama Education Authority (Long, 1999). Teacher recruitment and job satisfaction is also addressed by Long (2003).
} 
Anishininiimowin or 'Ojicree"11. Thus, in the context of this participant-centred paper, 'Ojicree' will refer to both the people and language of the Kasabonika community members. Similarly, I use the word '(East) Cree' to refer to the language and people from Waskaganish, Mistissini, and Waswanipi, Quebec. I will use 'Cree' to refer to Cree linguistic group in general, across Canada (See Fig. 2.1 Cree Linguistic Atlas), and 'Ojibwe' to refer to the general linguistic group the Ojicree belong to (See Fig. 2.3 Ojibwe Linguistic Atlas). Although the Ojicree and (East) Cree belong linguistically to the same Algonquian language family, there are important geographical and linguistic boundaries between the two groups.

As observable in the Cree Linguistic Atlas (Fig. 2.1), the term 'Cree' refers to peoples from a vast geographical area and huge linguistic spectrum ${ }^{12}$.

\footnotetext{
${ }^{11}$ The 2001 Canadian Census reports that there are 9,875 speakers of Ojicree in Canada.

${ }^{12}$ The 2001 Canadian Census reports that there are 80,075 speakers of Cree in Canada. However, many Cree dialects are not mutually intelligible. See Cree Linguistic Atlas (Fig. 2.1) and the on-line Cree-Innu linguistic atlas: www.atlas-ling.ca.
} 


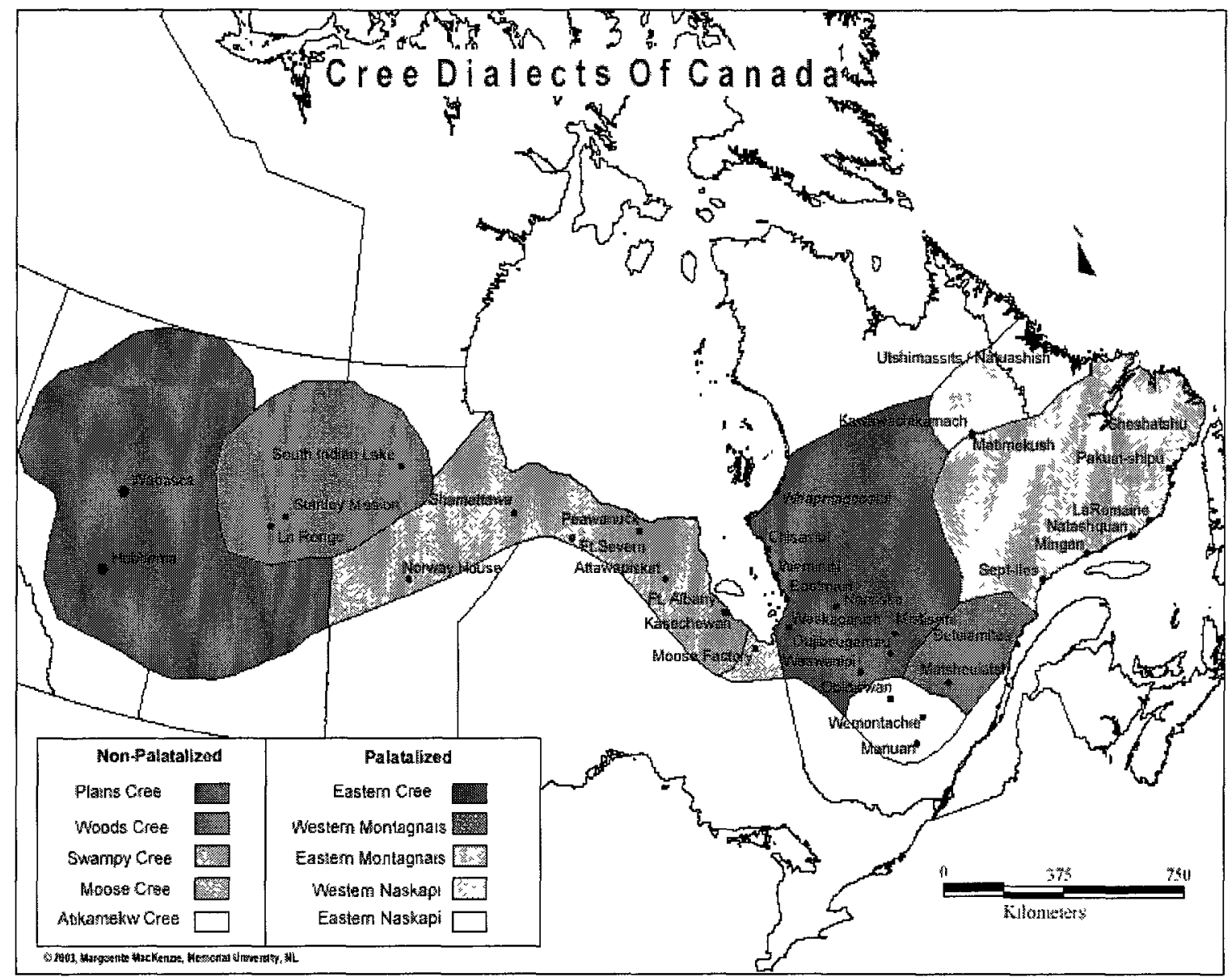

Figure 2.1 Cree Linguistic Atlas (http://www.eastcree.org/cree/en/grammar/\#)

The dialects of Cree spoken in northern Quebec are different from the dialect spoken in northern Ontario: Swampy Cree and Moose Cree. The latter are situated in close proximity to the Ojicree community of Kasabonika (compare location of Kasabonika in Fig. 2.3 with Cree linguistic Atlas Fig. 2.1). The (East) Cree participants in this study from Waswanipi, Mistissini, and Waskaganish, Quebec, speak the linguistically designated dialect of East Cree. East Cree is described by linguists as having two dialects: Southern and Northern (Mackenzie, 1980, Zhou, 2010) which have distinct 
(standardized, modern) orthographies. The Southern East Cree dialect may be further divided into two sub-dialects: Coastal and Inland (Junker \& Mackenzie 2003, Mackenzie, 1980). While all of the (East) Cree participants in this study speak the Southern dialect of (East) Cree, there is a difference in the sub-dialects spoken in their home communities (Fig. 2.2).

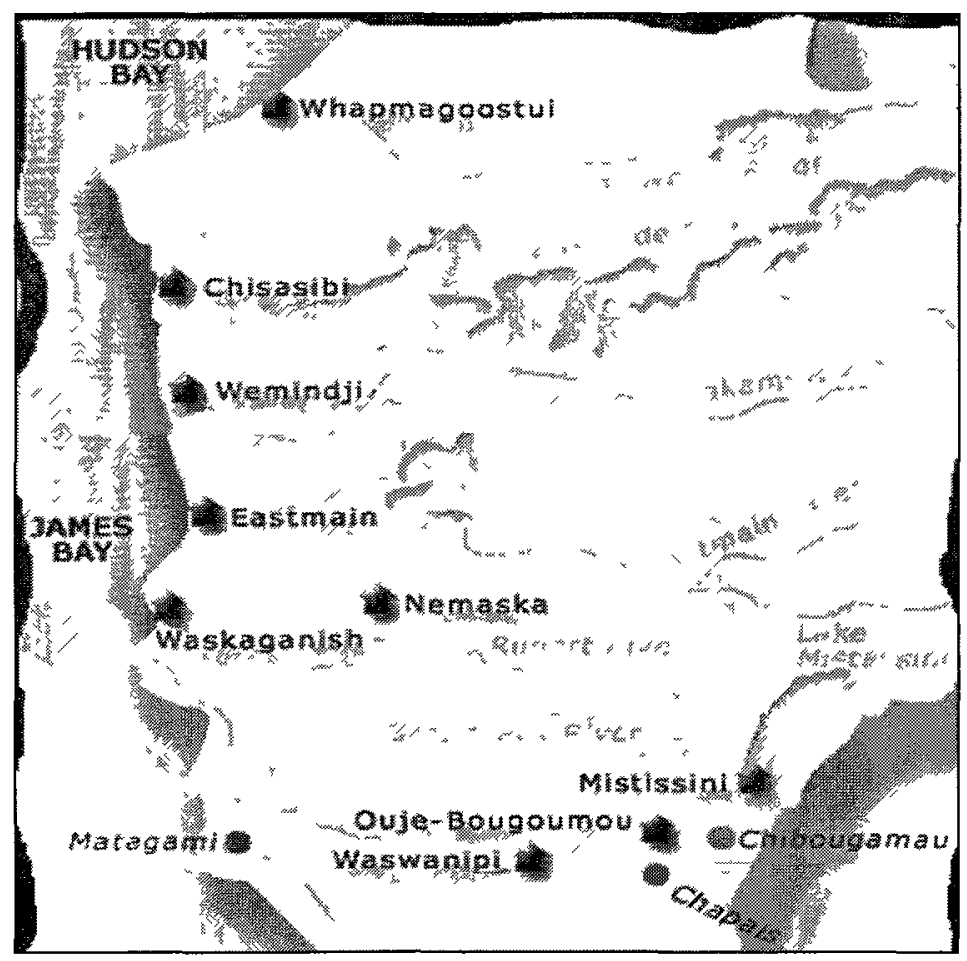

Fig. 2.2 Geographical Map of Northern Quebec

Linguistically, the two (East) Cree participants in this study from Waskaganish speak the Southern-Coastal dialect (Ruth and Pearl), while the two from Mistissini and Waswanipi speak the Southern Inland dialect (Emily and Anna). 
The Ojicree have sometimes been placed under the umbrella of 'Cree' geographically $^{13}$ (Berry \& Bennett, 1991), despite significant social and linguistic differences The Ojicree participants in this study are from the community of Kasabonika, Ontario in northern Ontario (see Fig 2.3) which is situated between the geographical regions of Ojibwe to the south and the Cree speaking regions to the north, where Swampy Cree is spoken (compare geographical location of Kasabonika to Cree Linguistic Atlas 2.1 and Ojibwe Linguistic Atlas 24 )

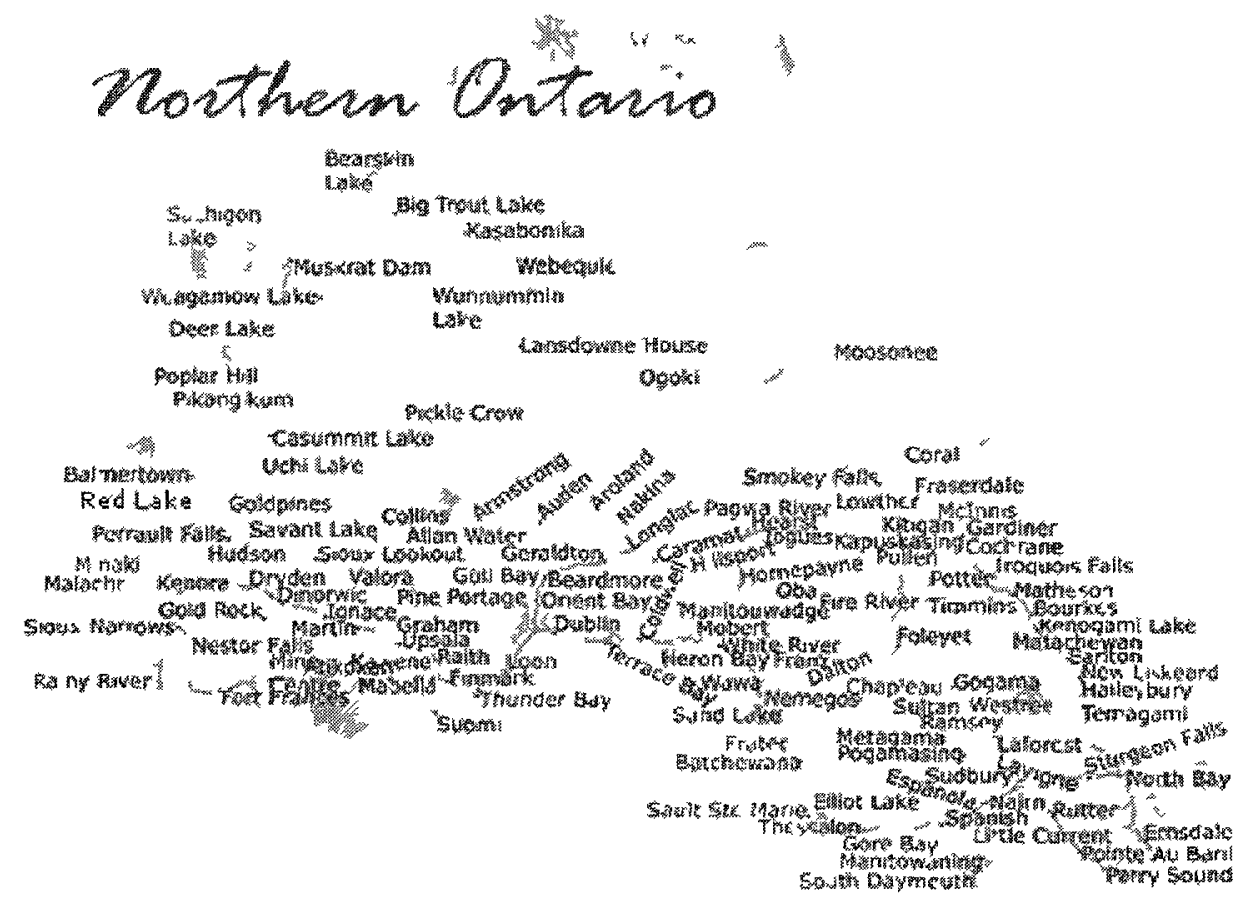

Figure 2.3: Geographical Map of Ontario

\footnotetext{
${ }^{13}$ The Natıve North American Almanac (Champagne, 1994) incorrectly desıgnates the major cultural area of Ojıcree speaking regıons (such as Kasabonıka) as "Cree"
} 
Linguistically, Ojicree is considered to be a dialect of Ojibwe (Valentine, 1994), sometimes described as "Severn Ojibwe" or "Northern Ojibwe" (Nichols, 1975). This linguistic dialect is spoken in areas of northern Ontario and Island Lake, Manitoba (see Fig. 2.4). The specific linguistic sub-dialect of the Ojicree participants from Kasabonika is classified as Eastern Big Trout (Nichols, 1976).

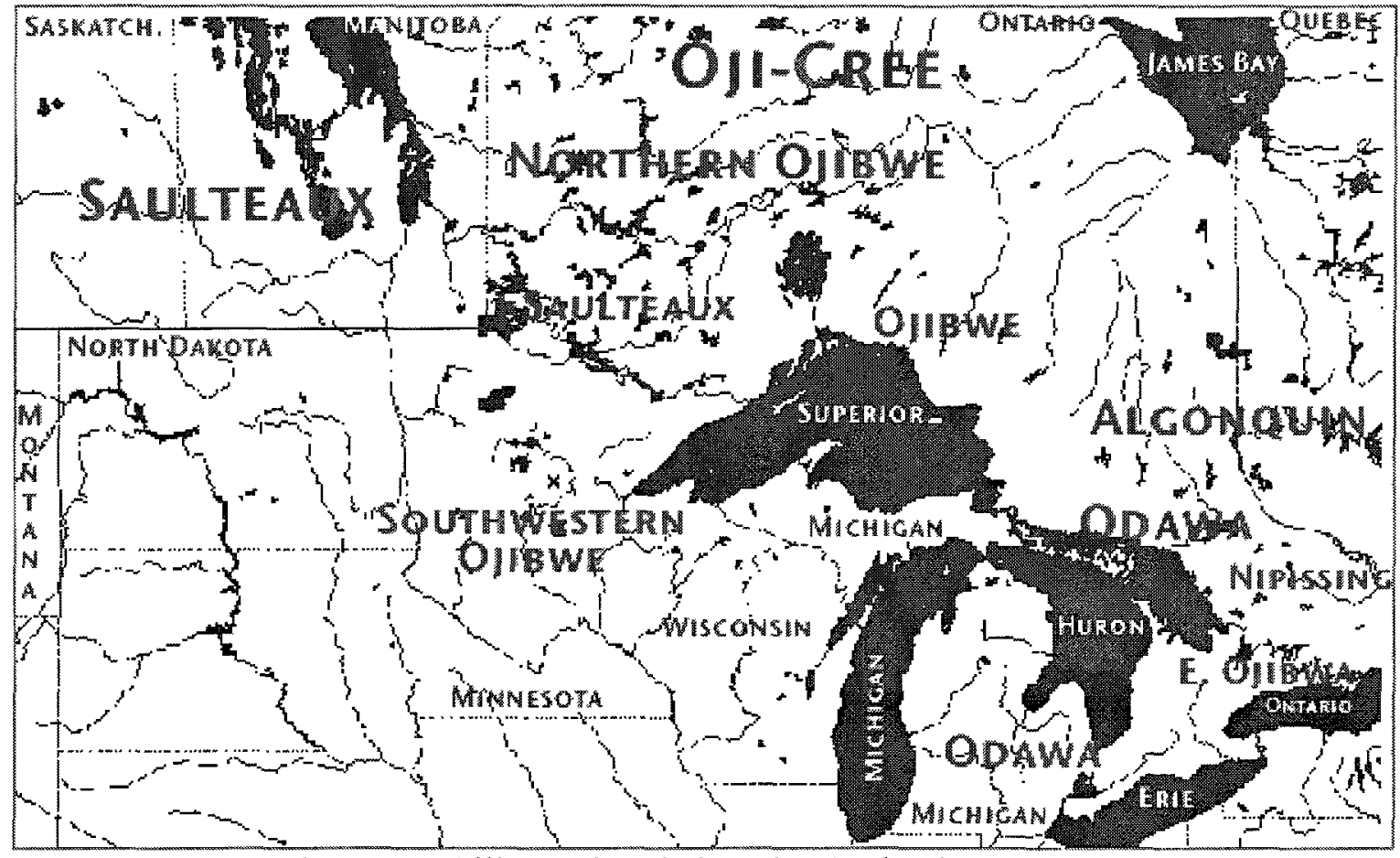

Figure 2.4 Ojibwe Linguistic Atlas (Valentine, no date)

Valentine (1994) discusses the linguistic relationship of Ojicree to the Cree and Ojibwe "language complexes" in Ontario in the following way:

Although sometimes described as a separate language, Severn Ojibwa is most accurately described as a dialect of the larger Ojibwe language complex, with a number of distinctive innovations, in addition to an increment of vocabulary 
borrowed from Cree and a modest amount of Cree morphology. (Valentine, 1994: 46).

The closeness between Ojicree and Ojibwe may be exemplified in the relationship between the ways these two groups self-designate. The Ojicree refer to themselves as Anishinini (which means 'ordinary person') while a similar term, Anishinaabe (which means 'ordinary man'), is widely used as a self-designation across the Ojibwa dialect continuum (Valentine, 1994). Cree people will refer to themselves as variants of innu or іуии (iinuu/iiyiyiu in East Cree) (See www.atlas-ling.ca) ${ }^{14}$.

The central focus of this thesis is to examine the relationship between identity and literacy among participants who share a social role in their respective communities. Though there are differences between these groups, certain characteristics are shared by all of the participants that make the consideration of their responses as a group appropriate (this is discussed further in the Methodology section 3.5.1). For the purposes of exploring the historical accounts of the development of the scripts used in the four communities, much of the literature presented is specific to Cree syllabics in northern Ontario (where divisions between the Ojicree and Swampy Cree have not been drawn). This is due to a lack of information concerning the development and spread of the Ojicree scripts, and a relative abundance of literature available on Cree syllabics. As Berry and Bennett (1991) note, the two groups (Ojicree and Cree) are sufficiently similar in a broad and general way to be considered together when examining the spread of syllabics. In

\footnotetext{
${ }^{14}$ It is not my intention to prescribe a linguistic label to either the Ojicree or the (East) Cree, but to help make it clear to readers which group I am referring to throughout the thesis.
} 
addition, sections 2.3.6 and 2.3.10 on the history of teaching and learning Aboriginal language literacy and education will largely centre on the emergence of the Cree School Board and its policies in areas of northern Quebec.

\subsubsection{The Cree Syllabary: A Background}

The Cree syllabic script is attributed by most academic sources to its development in the early 1840s by Rev. James Evans, a British Wesleyan missionary (Pilling 1891, Young 1899, McLean 1932[1849]; Hutchinson 1988, Lewis, 2001, Burnaby, 2002, Nichols, 1986). It is believed that prior to the development of the Cree syllabics, written communication and recording of information was achieved through:

the use of pictographs, petroglyphs, notched sticks, and wampum...which served the social, political, cultural, and spiritual needs of the pre-contact period. Only remnants of this period of literacy remain for most examples have perished or were not recorded accurately by European travelers and missionaries in their written observations of the New World. (Battiste, 1985:8)

According to historical documents, missionaries in the early 1800 s needed to translate biblical texts into a form of Ojibwe (Lewis \& Dorais, 2003). In 1839, Evans was invited to join a committee in St. Clair mission (near Sarnia, Ontario) whose mandate was to find a solution to the "problem of written Ojibwe" (Lewis \& Dorais, 2003). Half the members of this committee were missionaries and half were native speakers of Ojibwe. In 1836, this committee came up with a script that used symbols to represent syllables. The script developed by the committee was eventually rejected by the Toronto Bible Society because it would have been "too expensive to print books written in [the] new characters" 
(Lewis \& Dorais, 2003). In addition, some educators felt that the learning of two writing systems would be too confusing for students (Lewis \& Dorais, 2003). James Evans was later appointed superintendent of Methodist missionaries in the Hudson's Bay territory in 1840. He moved to Norway House ${ }^{15}$ accompanied by two Ojibwe collaborators: Peter Jacobs (Pahtahsega) and Henry Bird Steinhauer (Sowengisik). The three remained in Norway house for six years where they adapted the syllabic script to the Cree phonology.

According to James Piling (1841), Evans and his Native collaborators designed the system to be acquired rapidly while accurately reflecting the phonemic structure of the language. The result of this achievement was the creation of the Cree syllabic script, in which each symbol is associated with a sound that may be thought of as a consonant in English (Berry \& Bennett, 1991:92). The vowel quality of each character is indicated by its orientation corresponding to "south", "north", "east", and "west". Though there are actually 7 vowel sounds in the language, Evans relied on "other methods besides orientation to indicate the three additional vowels" (Berry \& Bennett, 1991). Berry \& Bennett (1991) note that the number four has a religious or semi-religious value for many Aboriginal groups the incorporation of 'four' into the script was an excellent "psychological fit'. Many scholars, including Burnaby (2002) have commented on the suitability of the new script for the population it was designed for.

Acceptance of the new script "made possible a mode of writing in which the relationship between speech and symbol reflected the preference for metaphorical

\footnotetext{
${ }^{15}$ The variety of Cree spoken in Norway House is called Swampy Cree.
} 
expression found in a wholistic society" (McCarthy, 1995:66). The script was likely inspired by Samuel Taylor's shorthand (which Evans had studied) developed in 1786 (Butler, 1951) and is thus highly economical, in that it uses a minimal number of characters (Berry \& Bennett, 1991). As Taylor and Olson (1995) comment, the use of the syllabic script saves both time and materials 16 and this was a "significant consideration in a hunter-gatherer community" (Taylor \& Olson, 1995: 61). As Suzanne McCarthy (1995) asserts, the design of the syllabics was an extension of a pre-existing cultural pattern.

Syllabics were adopted by the Cree as the chosen script and its survival to present day is a testament to its status as a cultural icon. The speed and ease by which the script spread among the Cree population is noted:

by the time the Anglican and Catholic churches continued the work left off by Evans, they found that the syllabary was already used widely among Cree communities beyond missionary influence. Their decision to accept syllabics went against their usual practice of transcribing native languages in an alphabet. (McCarthy, 1995:73)

The rapid spread led to an eventual decision by the churches to support the script, and, in 1861, the first Bible was published in London in the Cree syllabic script. By the end of the $18^{\text {th }}$ century, virtually every adult Cree speaker was literate in their language (Rogers, 2005).

\footnotetext{
${ }^{16}$ The first materials, according to Taylor \& Olson (1995) that were used to write syllabics were birchbark, charcoal, and animal blood.
} 


\subsubsection{Indigenous Origins of the Cree Syllabics}

Although the rapid spread of the Cree syllabics is usually credited to its original developer, James Evans, alternative beliefs exist that place its origin in Cree legend (Nichols, 1991). Others suggest its origination can be seen in the traditional quill and bead work designs ${ }^{17}$ of the northern Woodlands (Valentine, no date, Murdoch, 1985, Nichols, 1991). The results of a number of surveys conducted by Berry \& Bennett (1989) in the Ojicree speaking communities of Kasabonika and Big Trout Lake and the Cree speaking communities of Attawapiskat and Fort Albany explain the importance of the syllabics as a cultural icon because of its visible distinction from other world scripts and its unique feature of marking vowels by orientations based on the directions. The overview of their study comments on the participant's "tendency to assert that both language and script were give to Native people in primordial times by the Great Spirit and have been handed on from generation to generation ever since" (Berry \& Bennett, 1989:39-41). Other residents expressed a belief that the script was not actually invented by a missionary but that it was adapted from existing "Indian symbols" (Berry \& Bennett, 1989). Some, who were aware of the rumour of the 'white' origin of syllabics, suggested that James Evans obviously must have had considerable help from Native speakers of the language and it was these assistants who actually developed the script. Indeed, Walker (1996) notes that James Evans was married to a Cree native speaker. It is also pointed out in the study by residents that in many places syllabic literacy preceded the arrival of

\footnotetext{
${ }^{17}$ See Fig. 2.4 shows a photo of traditional Cree beadwork resembling syllabics at the end of this chapter.
} 
missionaries. In any case, Cree and Ojicree speakers are clearly responsible for the rapid spread of the written form of their language and preserving it.

\subsubsection{Modern Syllabics}

The variety of syllabics in existence today in northern Ojicree and (East) Cree communities differ from the original script developed by James Evans in 1847. James Horden, an Anglican missionary living in Moose Factory, worked on adapting Evan's syllabics to the local dialect used in the James Bay region. Having undergone many changes, the modern (East) Cree syllabic chart (Fig. 2.6 at the end of this chapter) ${ }^{18}$ and the Ojicree syllabic chart (Fig. 2.7) are examples of current versions that evolved from the original script. The chart contains columns or "series" that contain either a set of syllables with the same vowel, or a set with the same initial consonant. Modern convention in the writing of the syllabic scripts incorporates the use of 'finals' or reduced letters which are used in many Canadian Aboriginal languages written in the syllabic script, including both Ojicree and $\mathrm{Cree}^{19}$. Finals are represented in the right-most column of the East Cree Syllabic Chart (Fig. 2.6) and the Ojicree Syllabic Chart (Fig. 2.8). Finals ${ }^{20}$ are usually placed after a syllable to indicate a final consonant. There are also Diacritics that are used in many Canadian syllabic scripts to indicate whether the vowel is

\footnotetext{
${ }^{18}$ Fig. 2.7 shows a variation of the Cree syllabary currently being used in Ojicree schools.

${ }^{19}$ The ways in which these two groups share or differ in their use of finals is unknown.

${ }^{20}$ In some Cree cases, a reduced letter will be used to represent an initial consonant sound.
} 
long or short. It is likely that there is differentiation between the writing practices of speakers of Ojicree and the (East) Cree dialects regarding their use of finals and diacritics. Though it is clear that the (East) Cree writers use finals and diacritics to achieve preciseness in their writing, the specific practices of the Ojicree ${ }^{21}$ are unclear and there is little literature available to inform this question. In many dialect areas including East Cree regions, there are now standardized syllabics spellings.

\subsubsection{The Roman Orthography}

In addition to the syllabic script, one can transcribe aboriginal languages using an orthography borrowed from the colonial languages (French or English) by transliteration of syllabics into roman characters. Many variations of this orthography exist today for both Ojicree and Cree, for example the standardized version developed by Ellis (1975) (Fig. 2.5). Some Algonquian languages only use roman orthography: the Innu in Quebec and the Ojibwe in the United States, for example. They have developed modern standardized roman orthographies (M.O. Junker, p.c.).

\footnotetext{
${ }^{21}$ In some ways the Ojicree syllabic writing practices are more ambiguous, perhaps attributable to their close linguistic relationship to the Ojibwe who tend to favor the roman orthographies. Further study in this area is needed to properly describe Ojicree writing conventions.
} 


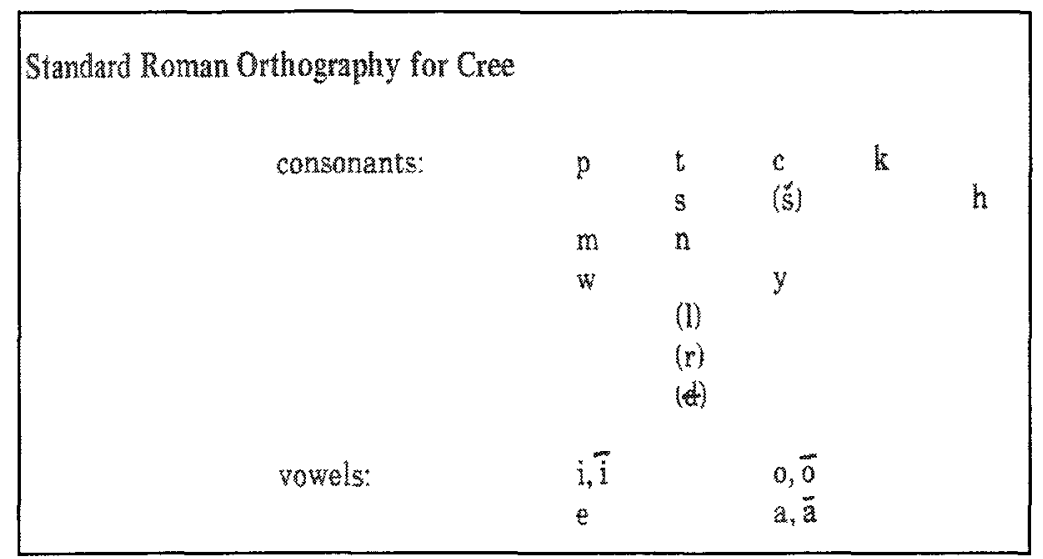

Fig. 2.5 Standard Roman Orthography for Cree, Ellis (1975)

It has been suggested by some, today, that the roman orthography may be beneficial to learners in Canada. There are two reasons for this: 1) technology is already available to support roman characters on cell phones and keyboards and this technology is easy to use, and 2) there will be a higher level of language transfer for student learners who will likely already be familiar with the alphabet letters, though there is no linguistic evidence this is the case. As Burnaby \& Anthony (1985) note, both writing systems (syllabic and roman) have drawbacks. Syllabics can be difficult to learn because "crucial distinctions are marked only by the rotation of a character" (Burnaby \& Anthony, 1985:72). Conversely, the "problems with roman is that characters represent phonemic units rather than syllables, the words tend to be long, and sound values may be confused with those of a roman orthography for another language" (Burnaby \& Anthony, 1985:72).

Arguments made by some for the place of the roman orthography have been responded to with high emotion and intense disagreements in Native communities (Hinton, 1994). As discussed throughout this paper, the syllabics are symbols of 
Aboriginal identity and it is not likely that they will be replaced in favour of roman characters in Native School systems in northern Ontario and Quebec:

In every way syllabic literacy seems to authenticate Cree society, it is hardly surprising that there has been strong resistance to its replacement by a roman orthography. (McCarty, 1995)

It is noteworthy that Aboriginal identity appears to be especially strongly tied to orthographies which are distinctly different from the roman, alphabetic system of most European languages (Burnaby, 2002:22)

The strong community loyalty to syllabics makes the role of the roman orthography (if any) in both education and Ojicree and (East) Cree culture unclear. In the specific case of (East) Cree, as noted by Burnaby \& MacKenzie (1985), roman writing has been "brought in by outsiders and is used mainly by them for their own purposes" (Burnaby \& MacKenzie, 1985:63). Roman characters can be directly transliterated into syllabics, and automatic conversion tools exist for word processors (Jancewicz \& Junker, 2008). Typing in East Cree syllabics, for example, can be achieved in two ways, either with a syllabic keyboard, or using the standard roman keyboard which a program that converts roman instantly to syllabics (so that you type in roman but see syllabics- for a demonstration see: http://www.eastcree.org/cree/en/resources/videos/\#). The use of roman orthography is evident in the academic community and the development of some Cree language resources uses both roman and syllabic orthographies ${ }^{22}$. The appearance of both

\footnotetext{
${ }^{22}$ An example would be the collaborative work done by linguists and native speakers, in the creation of the "Cree Conversation Manual" and the "East Cree Dictionary Project" which include roman and syllabic orthographies, in addition to translations into English and French.
} 
orthographies makes these resources accessible to teachers and speakers of related languages who do not use the syllabics.

Though discussion of the place of roman orthography in education and culture is contentious, as Burnaby notes in Promoting Native Writing Systems in Canada:

The development of skilled mature readers requires extensive practice on a wide array of materials and in the absence of such material, perhaps the needs of the mature reader with respect to orthography choice are the least urgent to consider. (Burnaby \& Anthony, 1989:124)

\subsubsection{Ojicree and Cree Literacy Today}

Statistics Canada unfortunately has no information regarding the number of Aboriginals who are able to read and write in their ancestral language (in either syllabic or roman writing systems). The most recent statistics available are from Ningewance (1992) who conducted a study for the Northern Nishnawbe Education Council in 1993. She found that only $31 \%$ of the Ojicree students, $28 \%$ of the Ojibwe students and $20 \%$ of the Cree students could read syllabics, despite the incorporation of literacy programs offered in the school. In Fort Severn, the single Cree community in the study, the student literacy rate was only $20 \%$ despite the fact that these students have the highest fluency rate and have a very competent syllabics teacher" (Ningewance, 1992-3:15). In addition, Berry \& Bennett (1990) found statistics indicating that younger people (under 20 years of age from Big Trout Lake) were unable to read the syllabic script despite syllabic instruction in schools. There is no information currently available about the number of Cree or Ojicree who are literate in the roman orthography. 
There are many factors that have likely contributed to this decline from the end of the $18^{\text {th }}$ century statistic that began this paper. Burnaby (2002) suggests three reasons for the decline of Aboriginal writing systems today:

1) The precipitous decline or even extinction of the languages themselves.

2) The role of residential and or compulsory schooling.

3) Writing Aboriginal languages served certain purposes as a technology so that when other forms of communication such as the telephone became available, it sometimes replaced writing in Aboriginal languages.

This being said, efforts have intensified though curriculum development in Native education programs which have mandated the learning of syllabics as a goal. The Anihshininiimowin Language Arts program developed by Kwayaciiwin Education Resource Centre has included goals for their programs suggesting that the curriculum should:

stress literacy as well as fluency. It is very important that literacy skills continue to be developed in the upper grades thereby producing students who can read and write Anihshininiimowin at an academic level, similar to their skills in English literacy.

Clearly, the goal of this new curriculum is to educate students to be biliterate in Anihshininiimowin and English at an academic level. An understanding of how the written language is used in these communities today will aid educators when making appropriate goals about how to achieve this. 


\subsubsection{The Uses of the Scripts}

Though Native languages in Canada are known historically to be predominantly oral languages with a rich oral tradition ${ }^{23}$, the use of the syllabic script was conducive to the nature of the traditional hunter-gatherer society. From historical documents, we know loosely that the syllabics were used as the medium of communication over long distances between communities and in giving directions to hunting areas. Until the $19^{\text {th }}$ century, published material in syllabics tended to be of a religious nature (Bible, hymns, psalms) (Rogers, 2005). During the time of residential schools, there is evidence that:

some Rupert House families, literate in syllabics, taught their children to read syllabics before they went to school so that they could communicate by letter. In other cases, children taught themselves to read and write syllabics once they were at school. (Burnaby \& Mackenzie, 1985: 65-66)

In the past 100 years, Aboriginal literacies have adapted to changes in ways of life.

Today, an adequate account of current literacy practice amongst Native language literates is not available and, specifically, the current role of written Cree and Ojicree in northern communities is largely undocumented (Burnaby, 2002). Information about the current uses of the texts is dated, as noted: "the most common areas of use are reading and writing for personal communication, and reading as part of religious observance. In addition, there are also some magazines, newspapers and, occasionally, government documents which are written in a Native Language (Burnaby \& Anthony, 1989:123). We

23 Although evidence exists that there were alternative methods of recording information discussed in section 2.3.2. 
do know that specific to the case of Cree in northern Quebec there has been an increase in the amount of secular material published in the East Cree syllabics, such as schoolbooks, sections of popular magazines, and government documents. The bible and hymn books written in syllabics still exist, and modern versions have been translated in different languages and dialects, and are read today in many Aboriginal community churches as part of the service. However, modern technology like telephones and bush radios, are now replacing the traditional need for letter writing and reading skills in syllabics. Settlement people who have access to electronic means of sending messages over distances seem to prefer these methods to letter writing.

In her introduction to Promoting Native Writing Systems in Canada, Burnaby asserts that: "Native people have wanted to develop literacy in their languages to serve such purposes as recording, preserving, and disseminating cultural information, increasing communication among speakers, and using written language as a symbol of group unity and political uniqueness" (Burnaby, introduction). Language shift in northern bilingual communities is happening so rapidly and the push to preserve the knowledge of the Elders who hold the richest form of the language has intensified. Fogwell (1994) identifies the role of literacy in protecting this knowledge for future generations: "the Elders tell us that writing the language, writing down the stories, the history, the knowledge, the wisdom, the traditions, is the preserving role of literacy" (Fogwell, 1994: 245). As a consequence to the rapid language shift we know is 
occurring (see section 2.2.2), it is likely that the uses of the script are also changing rapidly. The information that we have from the $1980 \mathrm{~s}$ and $1990 \mathrm{~s}$ is no longer current.

Current research is lacking in several major areas. The first is an examination of the current daily uses of written Ojicree and Cree. Do they write letters to relatives? Do they keep diaries or write poetry in their language? Do they give written directions to a place in their language? How does their uses of written Ojicree and (East) Cree compare to their uses of written English? The second is whether modern computer technology ${ }^{24}$ supports their use of their chosen written orthography or hinders it? Do Ojicree/ (East) Cree-English biliterates use this technology to communicate and do they use a roman or syllabic? Are they using roman because technology is forcing them to? What are their perceptions about the role that technology plays in relation to their literacies?

\subsubsection{The Learning and Teaching of Aboriginal Writing Systems}

As Burnaby (2002) notes, the persistence of Aboriginal individuals learning to read and write Aboriginal languages on their own or within informal family and community settings, despite the presence of institutionalized support, is noteworthy in itself and a testimony to the inherent value that the scripts hold for them. Prior to the generation gap of individuals who grew up during or after the implementation of

\footnotetext{
${ }^{24}$ There are fonts that have been developed for East and West Cree and Naskapi available from eastcree.org. These fonts are a subset of the Unified Canadian Aboriginal Syllabics (UCAS) complied with input from native and community based users (Jancewitz \& Junker, 2008).
} 
residential schools, reading and writing syllabics was understood in a general way to be transmitted by relative-to-relative through one-on-one instruction and use of the syllabic chart. For individuals who were cut off from their families and sent away to residential schools, the learning process might have been different. Unfortunately, there have been no recent studies that look at the ways in which these individuals were able to achieve literacy in their Native language.

The teaching of syllabics includes implicit understanding that there is no 'right' or 'wrong' way to write because people wrote as they speak (Taylor \& Olson, 1995). There is no accepted or standardized spelling Cree and Ojicree which reflects a tendency in the culture to avoid defining the 'right' and 'wrong' way of doing something (McCarty, 1995). Some reports indicate that a fluent speaker could become literate in a matter of hours, and conversely, a non-speaker could also learn to read the script without understanding it. Formal schooling was not a requirement to acquire the script. As Mackenzie (1985) and Valentine (1994) note, advanced skill in reading and writing in syllabics tended to be developed as a specialty among some, and was not expected of everyone.

\subsubsection{Residential Schools: The "Generation Gap" in Aboriginal Language Learning}

The 'generation gap' is highly significant because of the impacts on collective language knowledge for generations following those who were forced to attend. In residential schools, it was common practice to beat or punish Aboriginal students for 
speaking or writing in their language: "being reprimanded for speaking a Native language within minutes of entering the school was not uncommon; in some cases physical punishment took place immediately" (Grant, 1996:189). This forbiddance affected an entire generation of speakers deeply. Aside from the physical and psychological assaults, the students were taught that their ancestral languages were somehow 'primitive' and were devalued. As Haig-Brown (1991) concludes, "this generational control has had devastating effects on the children whose parents attended residential school. Many of them have never learned their language" (Haig-Brown, 1991: 122). In recent years, the Canadian government has recognized the damage caused by their implementation residential schools: "the repercussions of this has been devastating for all Aboriginal languages in Canada and are recognized as deeply damaging to Native identities and cultures in Canada" (CBC News, 2008). Aboriginal people did not have control of their own education until the 1970s and 1980s. As noted, many generations of children now grow up with parents who cannot speak, read, or write in their ancestral language and so the chain of traditional means to pass on cultural knowledge in the collective memory has been broken.

In their survey completed by community members from Big Trout Lake, Kasabonika, Attawapiskat, and Fort Albany, Berry \& Bennett (1989) ${ }^{25}$ noted the generation gap among the Ojicree and Cree between those who were children in the years following WWII and the following generation. The statistics show that nearly every male

\footnotetext{
${ }^{25}$ Community members from Big Trout Lake and Kasabonika speak Ojicree (see Fig. 2.4). Community members from Attawapiskat and Fort Albany speak Swampy Cree (See Fig. 2.1).
} 
under 45 (at the time of the study) is somewhat literate in English and that nearly every male over 45 is literate in syllabics. For women, the cut off age is 30: nearly every woman over 30 was reported as being able to read syllabics, while nearly every woman under 30 was able to read English. The study notes that biliterates in their 40 s were taught to read by a relative and tend to favour the syllabic script. Berry \& Bennett (1989) also note that a much higher percentage of women are biliterate than men which was attributed to the higher number of males who attended residential schools and that women were more likely to maintain an interest in their own scripts outside of schools.

\subsubsection{Aboriginal Control of Aboriginal Education: The Cree School Board}

Language maintenance and revitalization efforts through education in northern Ontario and Quebec intensified since the National Indian Brotherhood's Indian Control of Indian Education policy paper (1972) and signing of the James Bay Northern Quebec Agreement (1975) by the Quebec Cree. Since the late 1960s there has been rapid rise of programs to teach Native languages in schools across Canada (Burnaby, 1985a). Federal control over Native education in the 1970s gradually began to diminish and Cree slowly began to be used as a medium of instruction in parts of northern Ontario and Quebec. During this time, Aboriginal language use was clearly in the decline. The 1981 Canadian census indicates that those who self-identified to be of Aboriginal ancestry with an Aboriginal language as a mother tongue dropped from $75.7 \%$ in 1961 to $57.1 \%$ in 1971

(Burnaby \& Beaujot, 1986) which precipitated an accelerated call to action. There are 
two important events noted by MacKenzie (1985) that ensue at this time: 1) the introduction of Cree syllabics as a subject of instruction in East Cree Schools, and; 2) the beginning of political organization and negotiations which led to the James Bay Agreement.

In 1972 the first Cree teachers were hired in the James Bay region to teach reading and writing in syllabics for four coastal schools ${ }^{26}$ in response to the document: Indian control of Indian Education (1972) by the National Indian Brotherhood. This document sets out the central requirements for the "role of Aboriginal languages as the medium and subject of instruction in education for first-and second-language learners" (Burnaby \& Mackenzie: 1985):

What we want for our children can be summarized very briefly: ...to reinforce their Indian identity...to provide the training necessary for making a good living in modern society. (National Indian Brotherhood, 1972:3)

There were requirements for the new Native language teachers that were hired to teach reading and writing in syllabics for coastal schools in the James Bay region: they had to be literate according to community standards, they had to be available for year round employment, and they had to be approved by the community (Mackenzie, 1985). The group of teachers hired at this time were not required to have experience in teaching adults or children, speak English, or have attended schools themselves. In the spring of 1973, the Quebec regional offices at the Department of Indian and Northern Development (DIAND) formed the Amerindianizaton team consisting of DIAND administrators and

\footnotetext{
26 "All of which were in the Abitibi administrative district" (Mackenzie, 1985).
} 
linguists to conduct six-week teacher training courses. In 1978, the Cree Regional Authority formed the Cree School Board. During this time, the issue of standardization is first raised, and, in 1979 the Curriculum Development Team and the Amerindianization team begins working on orthography standardization and training of technolinguists (MacKenzie, 1985). Between 1981 and 1993 the teacher training programmes were transferred to McGill University and continued to certify local people as fully credentialed teachers and literacy in Cree continues to be taught as a subject.

In December of 1988, the council of Commissioners of the Crees implemented its education plan by creating a Cree Language Policy, and, in 1992 it was agreed that pilot Cree-medium program would be set up in Chisasibi and Waskaganish (Burnaby \& MacKenzie, 2001). In accordance to the UNESCO declaration that children learn best through instruction in their first language, Cree was used as the medium of instruction up to Grade 2. In their review of the Grade One Cree Language of Instruction Program, Burnaby, et al. (1994) discuss the success of the program but list some issues to be dealt with including "the need for more literature in Cree". The Cree Language of Instruction program pilot continued to address these challenges and later became mandatory in all schools in the board where there were sufficient qualified personnel to staff it (MacKenze $\&$ Burnaby, 2001).

\subsubsection{A Note on the Decision Making Process and Emerging Goals}

In their discussion of the process of Cree decision making about the place of their language in classroom instruction, Mackenzie \& Burnaby (2001) described the view of 
Cree parents who "could see the point of using oral Cree in school to explain concepts and do classroom management, [but] they were not as sure that literacy in Cree first would be appropriate" (Mackenzie \& Burnaby, 2001:206). The perspective that was expressed in the early stages of development appears to have changed with the mandate of the CLIP programme at present where initial literacy in Cree is a central component. Mackenzie \& Burnaby (2001) ask the question of what happened during the process of decision making that changed the minds of these parents to accept the CLIP program? They surmise that:

1) People were able to see the orthography and dictionary development projects as having an intrinsic value in Cree literacy that had not been there before.

2) As teachers and others gained skills in literacy through the orthography workshops and adult literacy classes, perhaps some of their confidence in these skills impressed the parents

3) Perhaps the unusual nature of the writing system came to be associated by the Cree with the unique value of the language itself. (Burnaby \& Mackenze, 2001)

It appears that the decision making process, thus, has contributed to the way that Aboriginal literacy is valued in northern communities like Chisasibi and Waskaganish. As Berry \& Bennett (1990) note in their study of the Cree and Ojicree communities of Kasabonika, Big Trout, Attapaskat, and Fort Albany: "over 95\% [of parents] said they wanted their children to learn the script" (Berry \& Bennett, 1990:38), mentioning that a few parents stressed the usefulness of syllabic literacy in getting jobs, in translating for relatives, in reading letters for aged relatives. One thoughtful person said that knowing syllabics would help his children "use a Native turn of thought". 
The final education model that is settled on appears to strive for two approaches to learning as ideal in the case of the (East) Cree by combining a system of Western education with traditional values generated at the community level while recognizing the distinction between the languages:

We must acknowledge that native languages, being oral languages, are the foundation of an oral culture and that this cannot be compared to the literate culture of French or English that has dominated our communities and our classrooms... Our oral cultures existed by holistic knowledge of the traditions of oratory and storytelling... On the other hand, the literate culture of French or English that know it is compartmentalized knowledge and it is acquired by 'education'...it incorporates a different value system. From our observations and experience, we are able to combine the two because we cannot deny the impact of non-native society on our lives and cultures. (Bobbish, 1996:247)

Today, Native school boards and education authorities across Canada are adopting curriculums that are designed to incorporate more focus on Native language, including reading and writing. 


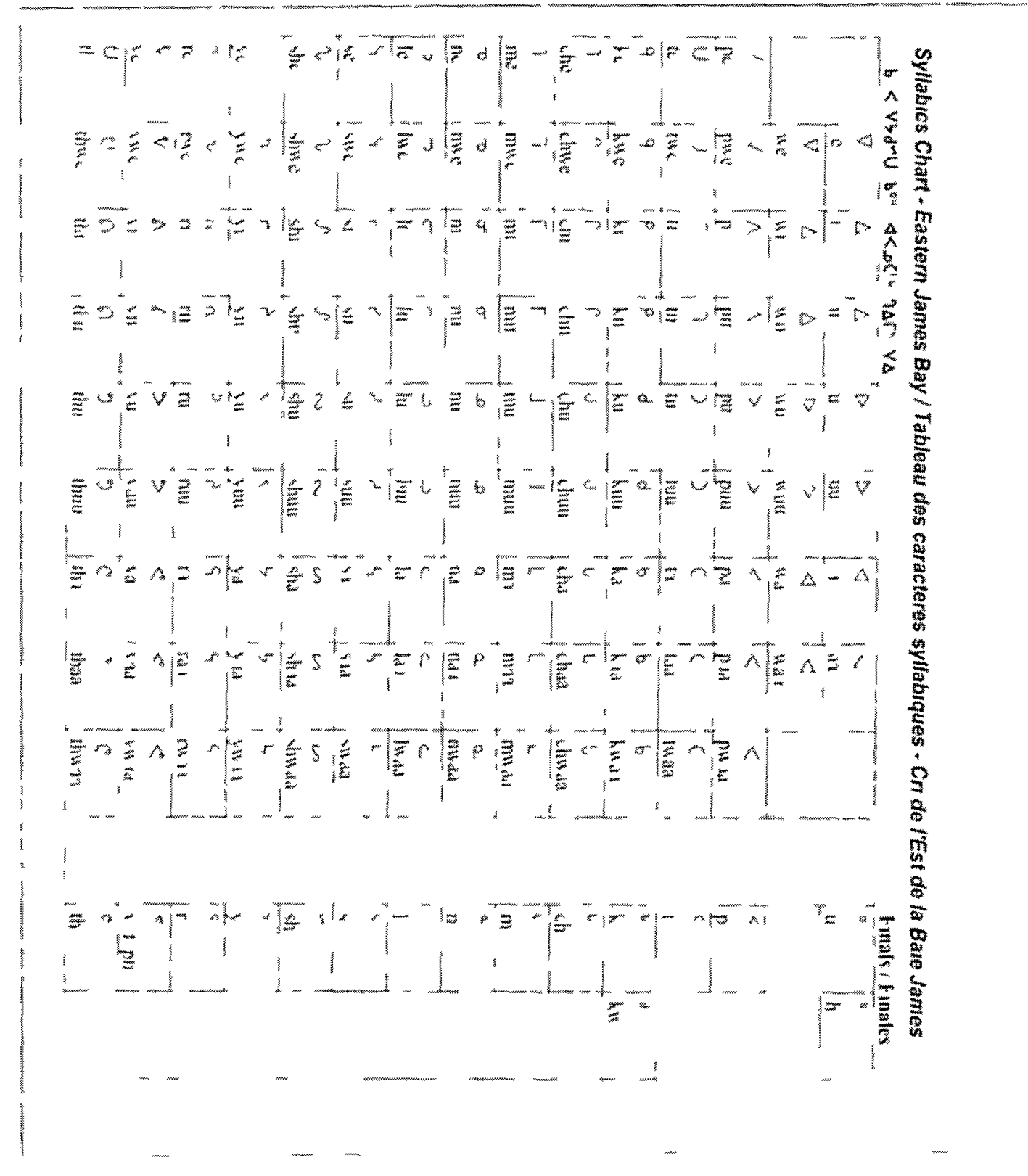

Figure 2.6 The Cree Syllabic Chart ${ }^{27}$

${ }^{27}$ Source "The Cree Conversation Manual" by Blacksmith, L et al, 2004 


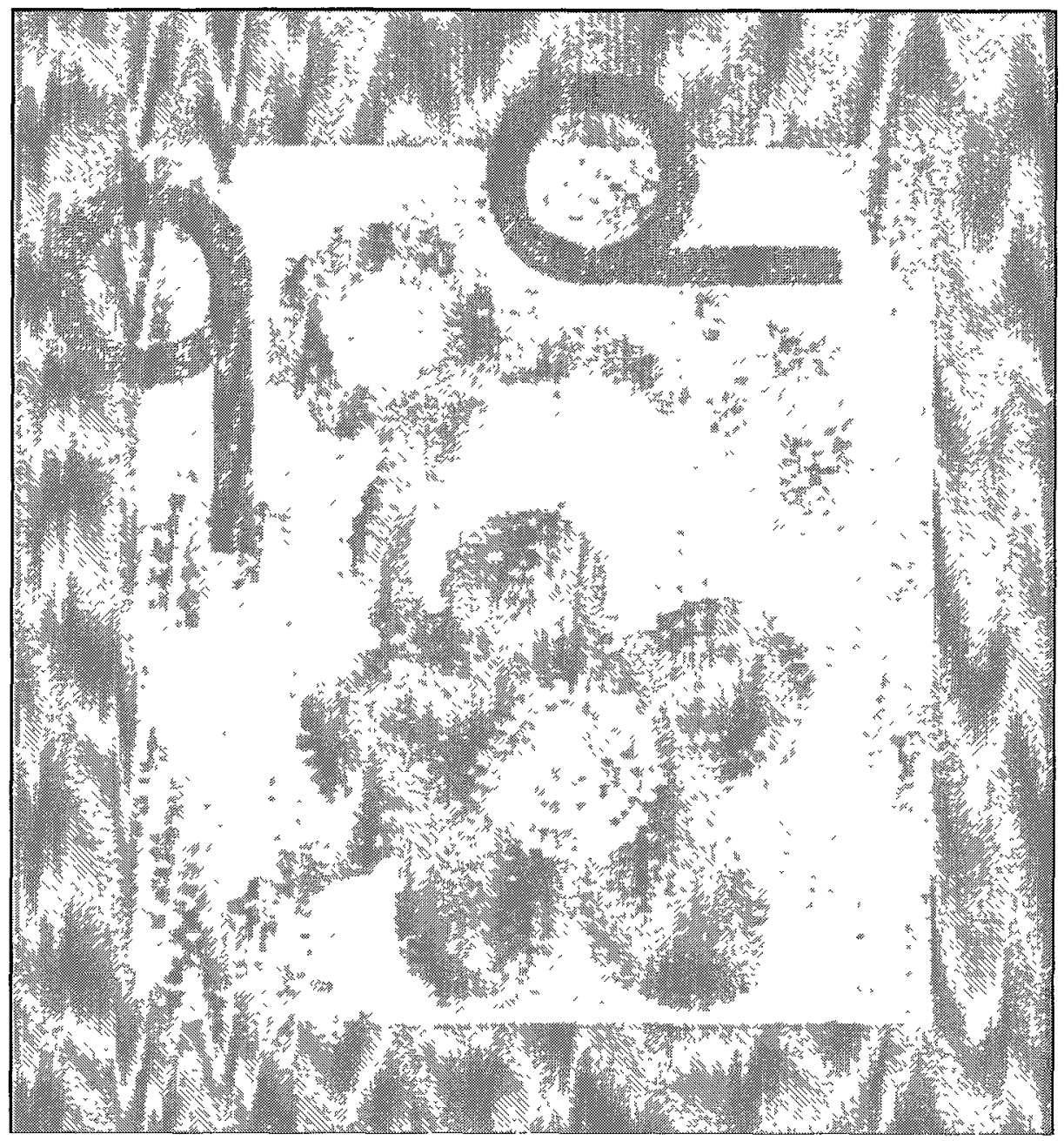

Figure 2.7 Traditional Cree Beadwork Resembling Syllabic Characters (Valentine, no date) 


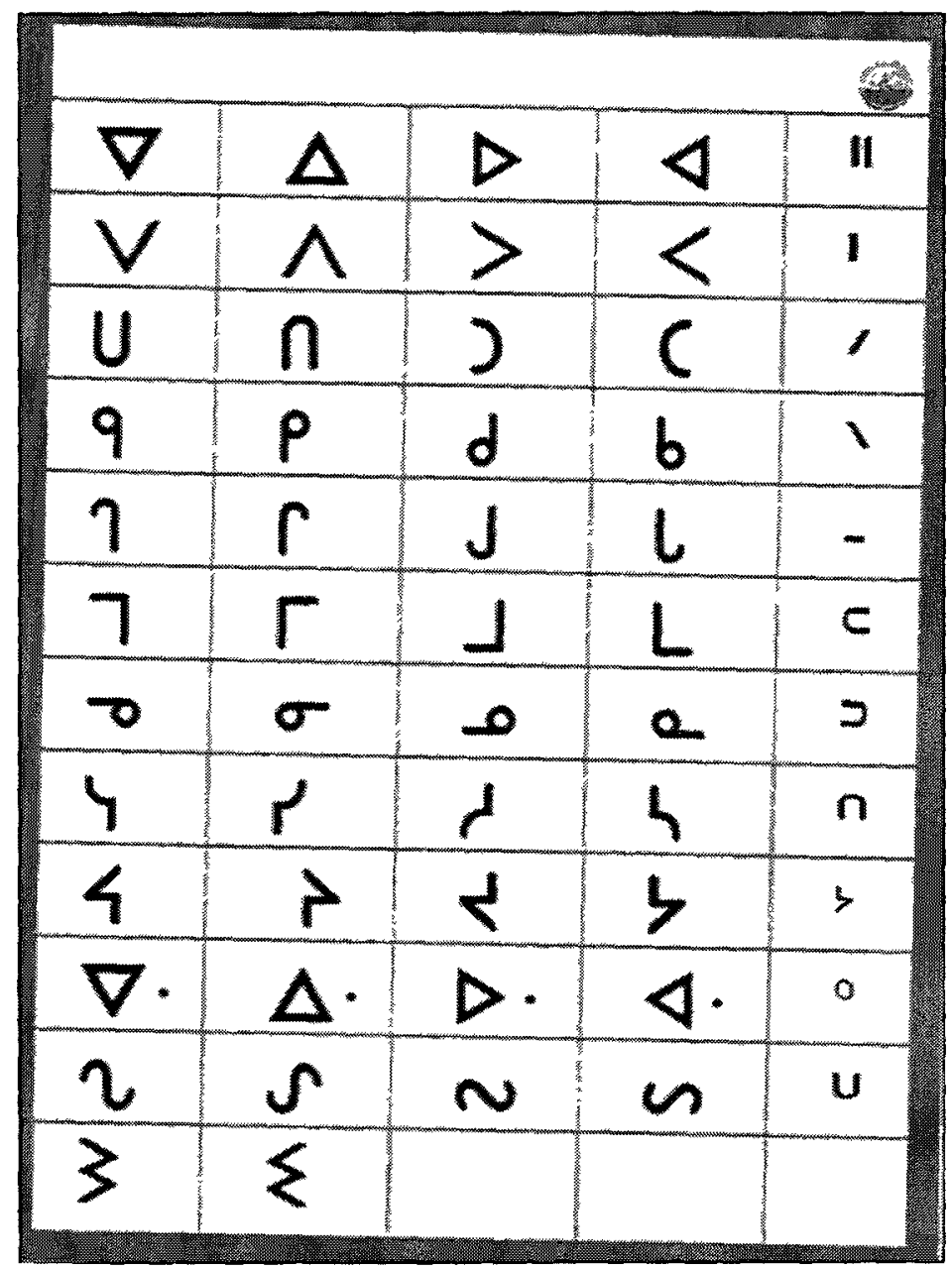

Figure 2.8 Ojicree Syllabic Chart Used in the Classroom 


\section{Chapter 3: Research Methodology}

The research methodology is a qualitative case study. A rationale for the qualitative research method and the two sets of participants is detailed in section 3.1. The description of the data collection is described in 3.2 and the approach to the data is discussed in 3.3. 3.4 discusses the study subjects and describes the participants (3.4.1) and their home communities (3.4.2).

\subsection{Qualitative Case Study}

Denzin and Lincoln (2008) argue that "qualitative investigators think they can get close to the actor's perspective through detailed interviewing and observation" and - that "quantitative researchers are seldom able to capture their subjects' perspectives because they have to rely on more remote, inferential empirical methods and materials" (Denzin \& Lincoln, 2008: 16). In short, a qualitative researcher attempts to "minimize the distance between him- or her-self and those being researched" (Creswell, 1994: 6). A qualitative approach is selected for this study because the nature of the research is to seek out the participant's perspectives on their experience of Aboriginal literacy. It was appropriate for me to listen to the story offered by the participants, rather than relying on a more generic means of gathering information. Also of importance was to provide a 
forum for them to speak about these issues through open-ended interview questions, rather than asking them to detail their personal experiences and perceptions in an English questionnaire.

The specific qualitative method adopted in this research is the use of multiple case studies. As Yin (2009) explains, case study is an empirical inquiry that:

1) Investigates a contemporary phenomenon in depth and within its real-life context, especially when

2) The boundaries between phenomenon and context are not clearly evident. (Yin, 2009: 18)

The phenomenon under investigation is the perspective of Ojicree and (East) Cree individuals on their experience of literacy in the context of their respective cultures and identities. The use of multiple case studies in this research has been employed for the purpose of increasing variation and representativeness (Duff, 2008). Although the two groups of participants (Ojicree and (East) Cree comprise two separate linguistic groups, they share broad characteristics with regards to their positions in their respective communities as bilingual and biliterate teachers and language specialists.

\subsection{Data Collection}

There are two methods of data collection. The first method involves my personal field notes describing the community of Kasabonika taken during my 10 month stay there. These notes are the basis of the narrative description provided for this community (4.1.1.) I have never visited the communities of Waskaganish, Mistissini, and Waswanipi so the information provided about these communities (4.1.2., 4.1.3., 4.1.4.) is gathered 
from their websites. The second method involves one-on-one interviews with the seven participants. The interviews focus on three areas of interest and were delivered in the following order: the participant's experience of learning written forms of (East) Cree/Ojicree, the use of (East) Cree/Ojicree written language and reading in daily life, and, the relationship between written forms of (East) Cree/Ojicree and aspects of identity, and (for a complete list of interview questions, see Appendix 1). All seven interviews contain generally the same questions, although in some cases, because of time limitations, some questions were omitted. This is also the case where I felt the participants had already responded to a question earlier in the interview. The interviews were conducted and transcribed by myself and lasted approximately 20 minutes. The interviews with the Cree participants took place during the break times of the dictionary compilation sessions (a collaborative effort between members of the Cree Language of Instruction Program C.L.I.P. and Dr. Marie-Odile Junker) in June of 2009 at Carleton University. Each participant was escorted by myself to the CKCU radio station in the Tory building where the interviews were recorded by the radio staff. The interviews with the Ojicree speaking participants took place in the library at Chief Simeon McKay Education Centre in June of 2010 and were recorded by the school resource person, Norman Semple on a video camera (although only sound was recorded). 


\subsection{Approach to the Data}

As Creswell (1994) notes, a qualitative methodology requires inductive logic and "categories emerge from informants, rather than are identified a priori by the researcher" (Creswell, 1994: 7). The initial results (4.2) include a summary of all of the participant responses. The transcripts are then analyzed according to the three sections of interest. 4.3 presents participant perspectives on the connection between their identities and Aboriginal literacies. Content analysis is used to examine emergent themes in this section of the interview transcripts. Qualitatively, content analysis can "involve any kind of analysis where communication content (speech, written text, interviews, images ...) is categorized and classified" (Devi, 2009:2). The transcripts are analyzed using the conceptual content analysis method: "conceptual analysis can be thought of as establishing the existence and frequency of concepts - most often represented by words of phrases - in a text" (Devi, 2009:2).

4.4 examines participant perspectives on the development of their Aboriginal literacies. In this section, the transcript data provided by the two groups of participants (Ojicree and (East) Cree) are sub-divided into two categories and presented as such: 1) those who attended residential schools; and 2) those who attended community schools. 4.4 focuses on understanding the current uses of reading and writing Ojicree/ (East) Cree and English in the four communities. Although this section was originally intended to examine current uses of the languages, some participants spoke about the ways they used their written language in the past, and thus a distinction is delineated between old/modern 
syllabics and standard/non-standard roman scripts. Thus, 4.5 is presented in two sections: 4.5.1 Past uses of syllabics, and 4.5.2 Current uses of syllabics, roman, and English reading and writing.

\subsection{The Study Subjects}

\subsubsection{Participants}

There are seven participants: three are Ojicree and four are (Eats) Cree (all participants consider English to be their L2). The Ojicree participants all identify their home community as Kasabonika, Ontario (although one participant was originally from Big Trout Lake) and self-identify as speakers of the Ojicree language. The (East) Cree participants represent two dialectal groups of East Cree. Two participants are from Waskaganish, Quebec, and speak the Southern-Coastal East Cree dialect. The remaining two are originally from Nemaska (before the hydro project forced their relocation). One now resides in Waswanipi, Quebec, and the other is in Mistissini, Quebec. These two participants speak the Southern-Inland East Cree dialect. Four of the seven participants attended a Canadian residential school where they were not allowed to speak their language or learn to read it. The other three participants did not attend residential schools because they fall into a different age bracket. Instead, they attended a school in their home community where they were taught to read and write primarily in English and later, often outside the school, in Ojicree/ (East) Cree. 
The first four participants were initially identified to me by Dr. Marie OdileJunker (my initial supervisor for this project) from a group of collaborators working on the compilation of the East Cree dictionary in conjunction with Carleton University. The project received full ethics clearance from the Carleton's Research Services and the participants were approached by Dr. Junker and myself with an information letter about the study. The first four participants are all female and are all curriculum designers for (Cree Language of Instruction Program) C.L.I.P. All work or have worked as language teachers in the Cree School Board. In addition, these women play a resource role in their communities as translators, scribes, and language professionals. Several of the (East) Cree participants were taught by the late Annie Whiskeychan, a well known language activist and teacher in the community of Waskaganish. Each participant is known to be an excellent reader and writer of both (East) Cree syllabic and roman scripts, as well as English (one of the participants also speaks French).

In addition, there are three participants from Kasabonika, Ontario, who are Native language instructors at the local school, Chief Simeon McKay Education Centre. I met these participants when I was working at the community school as the grade 7 teacher. At the end of the school year I approached two teachers and the vice-principal with the same letter of information for the study after renewing my ethics clearance. These participants may also be classified as among the most literate in their communities. Of the Kasabonika participants, there is one male and two females. Each instruct daily 
Native Language classes in the local school at both the elementary and high-school levels and are respected in their communities as experts in both written ${ }^{28}$ and spoken Ojicree.

The following chart summarizes the characteristics of the participants. First names will be used to identify the participants (all the participants agreed to be identified). I am deeply grateful to the participants for their participation in my study.

\footnotetext{
${ }^{28}$ In both the syllabic and roman scripts
} 


\begin{tabular}{|c|c|c|c|c|c|}
\hline $\begin{array}{l}\text { Participant } \\
\text { Name }\end{array}$ & Male/Female & $\begin{array}{c}\text { Approximate } \\
\text { Age }\end{array}$ & Home community & $\begin{array}{l}\text { Language } \\
\text { Spoken }\end{array}$ & $\begin{array}{c}\text { Type of } \\
\text { Early } \\
\text { Schooling }\end{array}$ \\
\hline John & Male & $60+$ & Kasabonika & Ojicree & Residential \\
\hline Judy & Female & 39 & Kasabonika & Ojicree & $\begin{array}{c}\text { Community } \\
\text { School }\end{array}$ \\
\hline Saloma & Female & 39 & Kasabonika & Ojicree & $\begin{array}{c}\text { Community } \\
\text { School }\end{array}$ \\
\hline Ruth & Female & 58 & Waskaganish & $\begin{array}{l}\text { East Cree: } \\
\text { Southern } \\
\text { (Coastal) }\end{array}$ & Residential \\
\hline Pearl & Female & 43 & Waskaganish & $\begin{array}{l}\text { East Cree: } \\
\text { Southern } \\
\text { (coastal) - }\end{array}$ & $\begin{array}{c}\text { Community } \\
\text { School }\end{array}$ \\
\hline Emily & Female & $58-60$ & $\begin{array}{c}\text { Nemaska (originally) } \\
\text { now in Waswanapi }\end{array}$ & $\begin{array}{l}\text { East Cree: } \\
\text { Southern } \\
\text { (Inland) - }\end{array}$ & Residential \\
\hline Anna & Female & 56 & $\begin{array}{c}\text { Nemaska (originally) } \\
\text { now in Mistissini }\end{array}$ & $\begin{array}{l}\text { East Cree: } \\
\text { Southern } \\
\text { (Inland) }\end{array}$ & Residential \\
\hline
\end{tabular}

Table 3.1: Participant Information 


\subsubsection{The Communities}

The northern communities of northern Ontario and Quebec relevant to this study include Kasabonika, Waswanipi, Waskaganish, and Mistissini. Each of these communities share characteristics that have contributed to the survival of their ancestral language despite great challenges (see section 2.2.2). Their geographical isolation from major cities in southern Ontario and Quebec has somewhat limited the intrusion of nonAboriginal influences in the past. A description of each community is presented the beginning of Chapter 4 to provide context for analysis. The description of Kasabonika is a personal description, based on my own field notes taken during my time living in that community. 


\section{Chapter 4: Results and Analysis}

The results are divided into three sections. 4.1 offers a context for analysis through descriptions of the 4 home communities of the participants in this study (the description of Kasabonika is presented as a personal narrative). 4.2 provides a summary of the responses from each of the seven interviews. This initial, case-by-case description has been included because of the wealth of information that each participant provided. 4.3 discusses the participants' conceptions of the relationship between their Aboriginal literacy and identities. 4.4 analyzes the literacy development of the participants who attended residential schools (4.4.1) and those who attended community schools (4.4.2), concluding with an analysis of themes present in this section of the interviews (4.4.3). 4.5 identifies the participants' childhood recollections of the uses of syllabics (4.5.1) and presents their current daily uses (4.5.2).

\subsection{Description of Communities Involved}

This section provides a context for analysis through a personal narrative description of Kasabonika written from field notes taken during my time there (4.1.1). There is also information provided about the other three communities, Mistissini (4.1.2), Waswanipi (4.1.3), and Waskaganish (4.1.4), in the study based on information available their websites (as I have never personally visited these communities). 


\subsubsection{Kasabonika ${ }^{29}$}

Kasabonika is a fly-in community in northern Ontario that has a mostly Aboriginal population of around 1,000. Historically, Kasabonika became a satellite community of Big Trout Lake in the early 1970s. It is located 448 kilometers northeast of Sioux Lookout in northwestern Ontario and is situated in a lake fed by the Asheweig River. Access to the community with heavy equipment is limited to a few months a year via a winter road. The traditional language used by the elder community members is Ojicree. English is considered the second language but is the working language for most younger community members. The only non-Aboriginal residents are the nurses, the owners of the local Northern Store, the teachers, and the building engineer. Occasionally, land surveyors, construction workers, tourists, and government people will visit and stay at the local hotel. Kasabonika has the following communications available: mail, internet, satellite TV, telephones, newspaper, and local radio.

I arrived on the island on August $27^{\text {th }}, 2009$. On the first day of class I asked what the 'Kasabonika' means. Dale, a student, told me the name means 'place of many lakes'. He said the people chose the island location for several reasons: it is more convenient to land a float plane, it is a natural protection against forest fires, and it provides some degree of protection from bears and wolves. I spent a great deal of time walking around during my off hours. I noticed over the months that the island breathes, changing its size and landscape as the water rises and falls with the seasons. Mining

\footnotetext{
${ }^{29}$ Kasabonika First Nation website: http://www.kasabonikafirstnation.com/
} 
operations on the island constantly alter its terrain. Kasabonika is often still, and quiet. People walk around the community using shortcuts, and you can hear their steps before you see them. Often they take the shortest path to where they are going, without worrying about walking over someone's lawn or stepping foot on a neighbor's property without permission. Once I was going to the video store. I walked way up and around on the main road. A little girl chased after me and told me (pointing) to "take the short cut' through the backyards of the houses. The kids would notice things like this from the white people. "Look at that white guy," said Dale, "he is going to walk all the way around. He He". It takes 40 minutes to circle the island, walking on the main road. The Elders walk too, sometimes carrying giant bags of groceries and stepping slowly, evenly, toward their homes. People walk around at all hours. Even in the night, children would walk by my window. They said it was boredom, or they just didn't want to go home. Sometimes on Saturday nights you could hear the music from the community centre's jamboree, and laughing.

The sky is always magnificent, every time of the day. The houses are small, and, as I understand, sometimes not well heated. Big families live together in small houses and often shared rooms. There is a shortage of housing and a long waiting list for the new homes being built ${ }^{30}$. Someone told me that the Band didn't give housing to single mothers. The homes are often single storey, all roughly the same size, and there are problems, I think, with mould in some. The sewage plant is just now being revamped to 
accommodate the population increase. I never went into a local's house, except for the coffee house across from me, which was a table in the doorway with the TV always on and a relaxed and easygoing feeling. There were a few churches in the community. I went to the Anglican - although it was like no Anglican Church I had ever been to in Toronto where I grew up. They had Bible study, and the choir would sing hymns in Ojicree. The books I saw in the pews were in English, but someone said they have Cree Bibles there. During the service, the kids would run around the church playing with one another, while their parents and relatives sat quietly, listening. Sometimes they were so loud I couldn't hear a thing the pastor said. Mothers would have their babies there, wrapped tight in a tiknagan (Native cradle). The service was conducted mostly in Ojicree. It was lengthy, over 2 hours long. Some of my students would be there and say hello.

There is a great interest in hunting. Students came by my house once to show me the rabbit they had snared. They would go hunting before class. Some of the boys in my class could talk to the geese. They made bird calls spontaneously during lessons. They could call the geese when they flew by and make them change direction and circle back. The students love things that fly. One day at gym I saw a girl just staring straight up in the air. "What are you looking at?" I asked her because I could not see anything. "Hawk" she said. And I looked around and everyone was staring at it. The crows in Kasabonika are the largest I have ever seen. There are many stray dogs in the community that are shot in the winter. A man goes around and shoots all dogs that aren't tied up, and 
then takes their bodies to the dump. People told me that "They make the wolves come on the island. They will be killed anyway by the wolves." And then I would hear the wolves at night and know it was true.

The island is connected to the mainland via bridge ${ }^{31}$. When I was there, the bridge was so weathered (missing planks and rotted wood) my heart would skip a beat to go rumbling over it in a vehicle. The airport and the dump are located just off the island, across that bridge. People would fish off of it. The water moves fast there so the fishing is good. My students would climb up and walk along the top of it with their fishing poles. And I would lose my mind with worry. And trucks would go by and shake it; I still hear the sound of it. They knew everything about fishing. Dale did. When I caught my first fish I was afraid to take it off the hook, and Dale said: "The Elders say if you don't take your own fish off the hook, you'll never cast again," but in Ojicree.

The community school was built at the physical centre of the island and has a current student population of 304. The school has functional library, computer lab, and gym facilities. The class sizes are large, but tend to shrink as the year progresses, especially in the upper grades. Each class has a Native Teaching Assistant and Tutor escorts for particular students who need individual help. On the first day I could not believe the kids who walked through the door of my classroom. Every one in a hoodie, the boys with hats bearing logos like "NYC", "LA", all in gold like gangsters. Some boys were interested in rap music. They wrote their own lyrics after school. They wrote

\footnotetext{
${ }^{31}$ All of the homes are located on the island itself.
} 
about 'Reza Lyfe'. And the girls all quiet. Really quiet, but they seemed to scream "don't embarrass me!". They would write things in the margins of their workbooks about their little dramas - sometimes in English, sometimes in Ojicree, written phonemically in roman. And then I heard them talk and would laugh at the things they said. So funny English mixed with Ojicree. I would say something to the class, some inane remark, and Dale would say: "Too-ke-kee-zagan" (it's amazing!), and I would laugh at myself. The kids would play with eachother in words: "ko-kom-ma" (your granny!) and the other would say "toh-toom-na" (your old granddad!) and the other would say "Jiisk-naa" (your butt!) and I would laugh hysterically when I finally understood.

The class was just chaos, I don't know if it was because they were in grade 7 . But they were crazy full of energy. And their favourite class, I think, was Native language. Judy would come in and they would all yell: "Judy!" as if she was saving them from death through boredom. And I would go to the library and put my feet up, happy. They loved to talk their language. The ones that could. Some of them did not speak it so much, but I think they understood it. They knew the slang, that's for sure. Some would write little things to each other in roman, little notes. They didn't want to teach me at first, I think because they would talk back in their language. I never complained on this, I was happy they were speaking it. When I started keeping my own little dictionary, I would press them for the correct spelling. I couldn't hear the sounds properly, it always sounded different every time I heard it, a ' $k$ ' or' $t$ ' would be added. 'Just spell it how it sounds!" they would say. Dale explained once "you can spell it either way, but this is 
more correct". Dale always got the Native Language Award. Now I see they write in slang (using roman) I think on Facebook and MyKnet to each other. They could also write their names in syllabics.

The community came together many times. There were suicides when I was there. The whole community mourned. It is still recovering from the murder that happened two years back. The whole community cried, I think, when this happened. So much sadness, so deeply felt. When I say the 'whole community', it is different from what is meant when you hear those words about a neighborhood, or a town down south. The 'whole community', like every single person, would go to the airport when the body is flown back from autopsy. Every single person was involved in the funeral procession. It was strange for me to understand at first, that they were all related. There were nine 'Andersons' in my class, many cousins, two siblings. When something happened to someone, it was the relative of someone else. It affected everyone. The local radio played a significant role in keeping people connected. It was mostly in Ojicree, and I don't know what they were saying, but often news would travel fast and I would say: "How do you KNOW that?" and they would just look at me and say "it was on the radio". I didn't listen enough, and it was mostly in Ojicree. Anyone could be on the radio. I think the station was always unlocked. You could just go in and say something, I think. Or play music.

There were many serious problems with drugs and alcohol. Some people made home brew (Kasabonika is a dry reserve). I know some of my students sniffed gas, but 
they told me they stopped that, and I pray it is true. The school resources on solvent abuse included a video in Inuktitut with English subtitles that I showed them. It was translated. To me it sounded the same as their language. "We don't understand anything from this!" they said. They all knew who did what; I think it was impossible to keep a secret in Kasabonika. The kids knew everything. If I walked somewhere, if I visited someone, my students would know about it. There is a high unemployment rate in Kasabonika; many of the people are on welfare. The cost of living is high because all the food and supplies have to be flown in by airplane. The alternative is eating game meat: moose and fish mostly, some caribou. People would come by to sell things to me. Necklaces, earrings, moose meat, fish. I went up there with only my boots. The kids made fun and asked why I wore them. I said, "because I don't have other shoes". And then that night, I got a knock, someone wants to sell me running shoes. Or I would come home and want to watch a movie, and then the phone would ring: "Do you want to buy a movie?". They had current movies at the video store, the same as at Blockbuster. Getting a movie for the class on Fridays was always a good bribe. They loved movies. Their favourite was Avatar.

There was a great belief in superstition. There was talk that the island was haunted by a 'jeepers creepers' - a black bird that would travel from roof to roof. Dale saw it over an airplane when he was hunting. A girl saw it in the school. The pastor came to bless the school the following week with holy water. The social counsellor explained all this to me, that some people say the island is haunted. That he believed it. 
The kids did not ever want to say something was going to happen in the future for sure. They would tell me what they were going to do on the weekend, but then explicate in their journals: "that's a maybe." I think they believe that if you say for sure or talk about something too much, it won't happen. One student got mad when I gave him a detention. I put his name on the board and wrote 45 minutes beside it. He was annoyed and upset and kept repeating "There's no chance, no chance for me!". And these words bugged me. This started something in the class; I would insist "There's always a chance!". That I didn't want to hear anybody say there wasn't a chance ever again. I invented that you could 'redeem' yourself if your name was on the board. Then when kids got their name up there, they would say "Can I redeem myself?", and I would say, "You can always redeem yourself". So a detention was never for sure, the future is always a maybe.

They also love hockey. I have never seen anybody skate like the kids in my class could. Dale looked like a bird on the ice, swooping in and around his classmates. Hockey was big. When they announced on the PA system that the arena was open to public skating, a cheer went up in the school, and I have never seen them so happy as when they were skating, or going to skate. I didn't know what was going on in the NHL playoffs when I was up there. The most important playoffs were between the communities. Webequie vs. Kas. And they had an amazing arena. The level of hockey was outstanding.

In Kasabonika, people, landscape and language are all one. The collective presence of the community infuses the landscape. Wherever you go in Kasabonika you 
are never alone, even if there are no people to be seen. The sense of connectedness is palpable. You might be walking along and then suddenly someone is there with you, or a group of children appear and surround you. None of the houses are marked, the roads have no names, but everyone still knows where they're going. The function of the language is not bureaucratic. It is, in its essence, an orientation. And the economy of the syllabic script is reflected in the children's logical advice to take the shortest path to your destination. The names of the animals, the way to hunt and fish, are all in the language of the Elders. The movements of the people are a language that can be read. All are part of a structure and cannot be separated from the place and context. One can sense that the landscape and movements of people are language and the language is them.

\subsubsection{Mistissini $^{32}$}

Mistissini is the largest Cree community at 4,000 and has been accessible by road since 1970. The Cree School Board and the Cree Construction Company have their head offices here. French explorers and traders entered the area in the $17^{\text {th }}$ century and by the second half of that century, a trading post was established on Lake Mistissini. The location of the post shifted from time to time until 1821 when the Hudson's Bay Company established it at the present village site.

\footnotetext{
${ }^{32}$ Cree Nation of Mistissini website: www.mistissini.com
} 


\subsubsection{Waswanipi ${ }^{33}$}

Waswanipi is an isolated northern community in northern Quebec. The name means 'light by water' which refers to the traditional method of luring fish at night time using torches. It is located along Route 113 and has a population of 1,473 (2006 Canadian census). The spoken language in this community is East Cree: Southern Inland dialect.

\subsubsection{Waskaganish ${ }^{34}$}

Waskaganish, called in the old days Rupert House, was founded in 1668. It is a community of 2,000 and has been accessible by road since 2001 . The spoken language in Waskaganish is East Cree: Southern Coastal. Waskaganish was the first Hudson's Bay Company trading post established in the James Bay area and is one of the oldest settlements in Canada.

\subsection{The Case Studies}

The following provides an introduction to each of the seven case studies. Each of the seven participants provided a great deal of information and it was not possible to include everything in the analysis sections. The seven interview summaries provide particulars regarding the participants' occupations and their general responses to each of

\footnotetext{
${ }^{33}$ Waswanipi Cree First nation website: http:/www.waswanipi.com/

${ }^{34}$ Cree Nation of Waskaganish website: www.waskaganish.ca
} 
the 3 sections of the interviews (perceptions of the relationship between their Aboriginal literacy and their identities; development of 'literacies'; and, childhood and adult uses of their written languages).

\subsubsection{Judy Interview Summary}

Judy is currently a Native language teacher at Chief Simeon McKay Education Centre (CSMEC) in Kasabonika, Ontario, and has teaching experience in all grades, from elementary to high school. Her first language is Ojicree. She is also bilingual and biliterate in both Ojicree and English. In terms of her literacy development, Judy attended the community school in Kasabonika (before CSMEC was built) where she was taught to read, write, and speak in English during the elementary grades. Native language classes were implemented in Kasabonika in the 1970s. Although she can't remember exactly how she learned to read and write in her language, she is able to recall that she was literate in syllabics (roman was not taught at this time) upon the completion of her grade 8 school year. Judy describes the teaching of syllabics in her childhood at school:

Basically what my instructors did was tell us legends and they would write the legends down on the blackboard while we would basically copy down from the blackboard, there weren't really worksheets there was just writing, writing and writing. (Judy)

She also spoke about a female teacher she had who was important to the development of her love of the language because of the "way she taught". Judy's parents were literate in the syllabics as well as her grandmother who used to send her to the store with a 
shopping list: "Yeah, but she wouldn't have the finals there, so I kinda had to try to make out what she did she only used the main symbols there - not the finals ${ }^{\prime 35}$. She said she cannot recall if her Grandpa was literate or not, although she believes he 'probably was'.

In terms of the current uses of the written language, she finds she mostly uses her Ojicree reading and writing skills through her work as a teacher in preparing lessons and worksheets. She says she uses the roman orthography sometimes for emails, but she uses the syllabic keyboard for preparing worksheets. However, there are occasions outside of the school that she might use her written syllabics, such as giving directions or a note to an older person. She also explains that she reads newspapers/magazines written in Ojicree syllabics because she is interested in the translations from Ojicree to English and vice versa. When she does this, she often reads silently. Judy says it is not unusual for her to mix Ojicree syllabics and English when she takes notes for herself.

Judy articulates a strong relationship between her Aboriginal identity and her ability to read and write in her language. She said that having these skills was what allowed her to work as a teacher. She feels deeply that learning Native language is very important for young people:

And then from there on they would have no problems attaining whatever they want to do just because they have Native language like, in themselves, they have it, is uh, how would you say it? As a background, or I don't know, something you know that you have, like belongs to you, that can't be taken away. And like it's there to assist you like, to learn more. (Judy)

\footnotetext{
${ }^{35}$ By finals she meant that her grandmother did not know or did not include the raised characters at the end of a word (describe in Chapter 2.3.2).
} 
This being said, she did not feel that her literacy in Ojicree ever hindered her literacy in English and she says she never confused the two languages in her head. In fact, she makes use of both languages when she studies for a test. For instance, she prepared for a test in Thunder Bay by reading the material in English, and then writing it out in syllabics. Judy also talked about the importance of reading and writing as a way of 'keeping the connect' with the Elders. In her experience teaching, Judy said that she finds the use of both the roman and syllabic orthographies helpful and does not favour one orthography over another as long as the student understands. She has noticed a decrease today in the number of students literate in their native language.

\subsubsection{John Interview Summary}

John is a Native language teacher at Chief Simeon McKay Education Centre (CSMEC) in Kasabonika, Ontario in the elementary, intermediary, and high school grades. Originally from Big Trout Lake, John was brought up in the bush with his brothers and sisters by his mother. Neither of his parents spoke English, and he spoke only Ojicree until the age of 13. In addition, he also learned to speak in Cree36 from a Cree grandfather on his mother's side. John's mother taught him to read and write in syllabics at the age of 5 or 6 . His mother "didn't know anything about the roman," he says, and he picked up the roman orthography later at University during summer courses. Thus, he was literate in syllabics before being literate in English. At the age of 13, he

\footnotetext{
${ }^{36}$ John did not specify at the time which dialect of 'Cree' his grandfather spoke.
} 
was taken to residential school where he learned to speak, read, and write in English and was forbidden to communicate in his language. He is the oldest participant.

John's uses his written language daily in his work at the school. He uses both syllabic and roman orthographies to prepare worksheets and lessons for his students. In the past he used an Ojicree typewriter, though now he is aware that computer technologies have changed and that there is a way to use syllabics when typing. If he has to write for himself, he will usually do so in syllabics and then translate into English later. He reads the Wawatay newspaper in both the English and the Ojicree. In addition, he does translations from the Bible and reads his bible in Cree. John also recollected other uses of syllabics that he observed while living in the bush. He described the practice of writing in syllabics on trees as a very important tool in wilderness survival:

Another thing that's very important is if a guy is lost and knows what to do he can write a note on a tree because if there's a storm he can make a note on the tree and tell them the direction that he is heading when they find the note. (John)

John spoke very strongly about the importance of kids today learning their Native language as an alternative to getting a job if they fail to complete their education. He says that going to the bush is their only survival in such a case:

That is a very good thing for the kids to learn because they never gonna know what happens in the future because if they should fail to complete their education, they're not able to get a job because the law says they gotta have their grade 12 and then they don't know what they can do in the bush to survive then with the animals, the moose, fish and everything else, so that's what they've gotta go if they don't speak their language and they forget that they are Indians. That's their only survival if they can't get a job they've gotta survive somehow. That's what their mothers gotta tell them: If you can't get a job you have to hunt and fish at least to eat, you gotta build a shelter there's a lot of resources out there. Just build it from what you got available. That's what I used to do when I first got 
here that's how I survived. Yeah that's a very big loss if they lose their language, it will cost them their life, I think. (John)

John spoke at length about the importance of not losing the language and the role it plays in relationship to identity and survival. Knowledge of the land is connected intimately with knowledge of the Native language. He also sees a strong relationship between his Aboriginal identity and his ability to read and write. For John, knowing how to speak one's ancestral language, and be literate, is how one comes to know oneself. He sees written language in having a role in the community to preserve accounts of local history. John also spoke about his belief that the use of roman characters is the best way to teach a Native person their language today, because he feels that the students who are entering the school are all speaking English. He thinks that the roman characters provide a sort of bridging assistance to the later learning of syllabics because the students already know their alphabet when they enter school.

\subsubsection{Saloma Interview Summary}

Saloma has worked in several positions at Chief Simeon McKay Education Centre (CSMEC) including Native language teacher and social counsellor. During of 2009-2010 school year she was the vice-principal. Prior to this she was the coordinator of the Native language program and taught Native Language classes at all levels from kindergarden to high school. Her first language is Ojicree. She learned English in her community school. Saloma showed an interest in her parent's letter writing at a young 
age and observed them writing letters. She also says she learned through her grandparents how to read and write in her language. In reflection, she explains that she learned syllabics mostly in the home, and learned English mostly in school. She remembers that when she when she started learning English in schools, her syllabic reading and writing was slow for her because "it was English all day for me". She was formally schooled in syllabics when it was implemented as part of the new curriculum in her community school in the 1970 s. She remembers that before they had telephones in the community, people would send their kids with messages written in syllabics to their friends and relatives. As they wrote these letters, Saloma would observe them. She also remembers that she would give direction to her dad in syllabics. Nowadays, she says, she has noticed that telephones have replaced some of these practices.

In terms of her daily life, Saloma uses both syllabic and roman orthographies to prepare lessons and worksheets for her students. She prefers to use syllabic over roman for her personal use. Saloma says she uses her syllabics in the creation of children's songs, poems, and when she writes down Elder's stories told on over the local radio. If she hears a word she doesn't know in Ojicree on the radio that an Elder uses, she will usually write it down in syllabics:

Yeah sometimes I do. Just when I'm listening to a radio and they'll be discussing something that I was looking for a word that I couldn't translate to or something like that. I would just jot them down and use them. (Saloma)

She also uses her syllabics in cases when she cannot spell a word in English. Her preferred method of reading is out loud. Saloma is also aware of the syllabics keyboard 
and says she would probably use this keyboard if she were writing something on a computer (instead of roman).

Saloma thought there was a connection between her knowledge of reading and writing in her Native language and her identity, and she said she felt lucky because of this. She notices that more and more children are coming to school not speaking the language:

Yeah I think so. Like I am like - like I am really proud of myself that I can read and write in my language and speak it and then read and write it. I'm lucky because why I say that is I know even in this community there are parents here that speak the language but don't know how to read and write it there are so many young parents out there. And even if they don't come to school they don't learn the English and how to read and write it. Cause one time a student said to me I told him "take this home for your parent" and he said 'she can't read the English part" I said "it's in syllabics too" and he said "she can't read that either". So I just have to call her and tell her. (Saloma)

Because she got only native language at home from her parents and grandparents, she was able to get a good foundation at a young age. She says:

I think it's important for an Aboriginal student to learn his or her language. Like I know we're starting to loose our language slowly every year. So I think it's important that Ojicree be taught like the immersion programs that are in place in order to keep our language in order to survive. (Saloma)

Saloma also had comments specific to education. She felt that it was important to learn to read and write in syllabics and to learn the roman writing and reading later when the students get older because it will be easier once you learn the English language. She suggested that culture classes be offered, in addition to language classes, also conducted in the Native language. Saloma also noted that in some cases, there is not a direct translation for many words in subjects like science but that it is possible to translate 
words in English into Ojicree using a whole sentence for one word (if there were no translation available).

\subsubsection{Pearl Interview Summary}

Pearl works with the Cree Language of Instruction Program (C.L.I.P.) in Waskaganish37. She was first introduced to syllabics through the hymn book at the Anglican Church $^{38}$ in her community. At the beginning of the Cree hymn book ${ }^{39}$, there was a syllabic chart and also the alphabet. Pearl learned her English alphabet at a young age from pre-kindergarten in community school. She said that she could sound out the alphabet and taught herself

how to do the system in the syllabic chart, the reading system in the syllabic chart and I used to sound them out and that's how I first learned to read the syllabics. (Pearl).

She began to understand the syllabic reading system when she was 8 or 9 years old, it wasn't until later that she learned to write. In the $1970 \mathrm{~s}$, her first teacher, Annie Whiskeychan, "taught us how to read the syllabics" (Pearl). Pearl also specifies that Annie taught them Waskaganish Cree. Learning how to read in her own Waskaganish Cree allowed Pearl to work on comparisons between it and the Moose Cree she had originally learned from the hymn book. In addition to (East) Cree and English, Pearl also

\footnotetext{
${ }^{37} \mathrm{Her} \mathrm{L} 1$ is the (East) Cree - the Southern-coastal dialect.

${ }^{38}$ The Anglican church was one of the first two churches in her community.

${ }^{39}$ The Cree hymn book is in Moose Cree.
} 
had French classes in school, and studied it later on her own. She says that her father didn't have time to write but that he was able to read English. Her mother was able to read and write a little in both English and (East) Cree. Pearl explains that her mother learned to read and write Cree through her involvement with the church choir, "I guess she taught herself how to read and write Cree" (Pearl). When she was young, also, she would write 'funny notes' to her grandfather on her mother's side. The two people she credits with influencing her (East) Cree reading and writing was her mother and Annie Whiskeychan.

Pearl talks about her daily uses of (East) Cree literacy:

at our home there is not enough Cree. I only see the books in Cree at the office I work. There is no Cree literature in our bookshelves, there is only English and French. (Pearl)

She makes an effort to use her written (East) Cree when she is at home with her father or the Elders. She listens to them and writes down the words, later looking up the words that she didn't know in the (East) Cree lexicon. Pearl elaborates that some of the Elders use really old (East) Cree that she doesn't always understand:

My dad he's a very fluent speaker and he hardly uses English at all when he speaks and sometimes I don't understand his words so I just write them and what he's saying and then I try to understand what when I write it I understand it and then I ask him is that what you meant? (Pearl)

In this way, writing does not just serving the purpose of preserving the words of Elders; it assists her in communicating with her father and understanding his meanings. Syllabics 
are present in her community on signs, buildings, posters ${ }^{40}$, and jackets. She comments that the government-Cree 'agreements' are boring to read in English, so she makes an effort to read them in (East) Cree, though sometimes they have 'mistakes'. Her style of reading is both out loud, and silent (depending on the circumstance). On chat lines, she finds she is able to use the (East) Cree syllabics (since 2007). When texting her son and daughter, she uses the roman characters because she has to. While attending McGill University, Pearl sometimes mixed (East) Cree syllabics and English: "sometimes I would write the English words into syllabics and sometimes I would write the Cree words" (Pearl). She says she always prefers to use the syllabics over roman.

Pearl was unsure about the relationship between being able to read and write in her language and her identity. She did say that she really enjoys writing in syllabics and believes that it helps her to understand the correct pronunciation of the word. She feels that writing down her thoughts in syllabics helps her to know what she wants to say in English. In regards to the teaching of (East) Cree literacy in Cree schools, Pearl felt that it is important for everyone who is Cree to learn to write in Cree. That it will help them in the long run.

\footnotetext{
${ }^{40}$ She specified that the little advertisements about healthy eating and the studies/reports put out by the nursing station are all trilingual.
} 


\subsubsection{Ruth Interview Summary}

Ruth works with the (East) Cree language through Cree Language of Instruction Program (C.L.I.P.). She spoke (East) Cree (Southern-inland dialect) as a child, but learned to read and write the syllabics later in life from the late Annie Whiskeychan. She was taken from her parents at the age of 6 or 7 to attend residential school. In residential schools, she says: "we weren't allowed to speak my language" (Ruth). Both of her parents did not read and write (East) Cree (Her father never attended school and her mother only went up to Grade 3). Hence, Ruth spoke (East) Cree as a mother tongue, learned English in residential school, was first literate in her second language, English, and then learned to read and write her mother tongue later in life

She says that though her daily uses of reading and writing tend to be in English (TV, books, bible), in her community she speaks (East) Cree all the time: "it is the spoken language". She also is aware of signs and public posters in her community that are bilingual and trilingual (English, (East) Cree, and French). Ruth explains that she prefers to read the (East) Cree part of the poster out loud, in order to educate others. Though she is able to read the English and the French, she never reads these sections out loud. Similarly, when she has to fax things to the office in Chisasibi, she would do so in syllabics with the intention of educating the workers there. In addition, Ruth says she is

able to read the articles in IN FLIGHT magazine, although they are written in the 
northern dialect ${ }^{41}$. She also will read other magazines like the Cree Trapper's annual report and the Cree Regional Authority (with sections written in Cree). The reading style she uses is both out loud and silent. In regards to computer technology, Ruth says that she corresponds with Anna using roman orthography because she is unable to do so in syllabics. She describes the process of typing a syllabic symbol as lengthy because her fingers are used to typing in English. To get one Cree symbol there are many English letters involved on a computer keyboard. Like many other participants, Ruth will sometimes use syllabics for English words she doesn't remember how to spell.

Ruth spoke about the fact that her ability to read and write in her language has shaped her identity. At first, she doubted her ability to learn to read and write the language. She says it was Annie who encouraged her to try and taught her voluntarily. The link between Aboriginal identity and knowing how to read and write in (East) Cree was articulated by Ruth through the telling of a story:

It is like a story I will tell you this one old lady, well she is old now, probably in hundreds, Flory Marster. And she was teaching the Cree language, because when the Cree language first was taught it was taught by what we call Cree language specialists. They didn't have certificates in teaching but they were the ones who had the Cree language and they were the ones that could read and write it. So we had these Cree language specialists and she was telling us a story where once when she was teaching she asked the students to do some work. And this one boy said NO, and he was talking in English, No I'm not going to do that because I don't want to read and write Cree. I don't want to be Cree. I want to speak English, I want to read and write English. So she said I don't know how you are going to understand this but you were born a Cree. And you are supposed to be able to read and write your language. You are never going to be a white person. Even if you try to be white-you are never going to be a white person because you were born a Cree person and that was the language that was given to you so

\footnotetext{
${ }^{41}$ She prefers to read in her own dialect (East Cree Southern-inland).
} 
you have to try to learn to read and write your language. And we always talk about that. (Ruth)

For Ruth, the link between Aboriginal identity and language knowledge is inherent, and cannot be escaped. She spoke very strongly about the importance of Cree children getting a good foundation in their mother tongue and expressed concern about recent decisions to cut down the (East) Cree in Grade 3. She believes that more should be done to train Native language teachers. In general, Ruth believes that her literacy in English did not hinder her literacy in (East) Cree, and vice versa. She finds reading and writing in (East) Cree a pleasurable experience and wishes she had more time for it.

\subsubsection{Emily Interview Summary}

Emily works with the Cree Language of Instruction Program (C.L.I.P.). Her first language is (East) $\mathrm{Cree}^{42}$. She recollects that she first learned to read and write in her language while in church. She explains that she would follow along with the open hymn book as she swung her baby sister in her arms. Because she didn't know any lullabies, Emily would sing the familiar hymns and follow along with the symbols of the hymn book. Her father and grandmother also helped her to read sentences in the hymn book. She had taught herself to read and write syllabics by the age of 8 , before she went away to school. Her mother was able to read and write in syllabics and they communicated by

\footnotetext{
${ }^{42}$ She speaks the southern-inland dialect.
} 
letter while she was away. Emily remembers her mother being happy that she was able to read and write because it meant that they were able to stay in touch.

In her daily life, Emily says that she uses her (East) Cree writing, when she can, to express her thoughts because she finds it difficult to get the meaning that she wants using English. She writes her journal and grocery list in Cree (syllabics). When she is doing something to do with her grandchildren, she will also use her written (East) Cree sometimes. She always prefers to write in syllabics over roman because she feels it is easier. If she encounters a word that is not in the (East) Cree lexicon, like 'tomato', she will write it phonetically using syllabics. She says that there are bilingual signs in her community. There are also newspapers sections that she will read in (East) Cree. In order to email in syllabics, Emily explains, the person has to have the syllabics in their computer: "You cannot just chat with anybody using syllabics because not everyone has syllabics in their computer. At her work, she is required to do lots of reading, writing, and translating from English to (East) Cree.

When asked if literacy played a role in shaping her identity, Emily responded, "Yes, because it is my mother tongue, it is a part of me" (Emily). She feels that her ability to read in syllabics has helped her reading in English. She says that she enjoys reading and writing in her language. She strongly believes that it is important to teach Cree literacy in Cree schools because strengthens the identity of the children:

Well, um, some people they don't know how to read and write in syllabics the Cree people. And um, they're asked sometimes by non-Native people to write their name and they say that it's embarrassing when you're asked to write and you don't know how and you're Cree. (Emily) 
Emily expresses that the ability to write your own name, in your own language, is an important part of knowing who you are.

\subsubsection{Anna Interview Summary}

Anna works with the Cree Language of Instruction Program (C.L.I.P.). Cree is her mother tongue. She remembers that she became familiar with the syllabics when her parents were reading the bible, the hymn book and the psalm book. She would remember the shapes and play outside with woodchips or branches and make the shapes in the snow. She would write the shapes in whatever material she could find, and ask her parents "what does this mean?". She was seven when she left for residential school in Moose Factory. She left school at the age of 14 and by 17 she had learned the syllabic reading and writing system with the help of her dad. Her father was the first one that taught the (East) Cree language and culture in the school, and she began to assist him in the classroom when she was 19. Anna recalls that at the age of about 18 or 19 , the Nemaska community had to move because of the hydro project. Anna and her sister went to different communities, but they were able to communicate via letters written in the syllabics.

In her daily life, Anna will practice syllabics with her children from available materials (like The Nation magazine). Though she notes that often, these materials are written in the northern Cree dialect which makes it hard for her kids. Anna says that she 
will read her bible and psalm book in English or (East) Cree, depending on the language of the church service. She will refer to the Cree bible when she doesn't understand the English part ${ }^{43}$. She also practices her reading and writing when she makes flyers for meetings of the assembly, agendas, and display workshops. In her community, Anna sees street signs, buildings, and offices with the syllabic symbols. She will usually give directions in oral (East) Cree, though she writes her grocery lists in syllabics. Anna's personal uses of (East) Cree includes her journals and stories, though, she explains most of her literacy skills are used in a work capacity. The only time she will use the roman characters is when she does text messaging, otherwise she would not recommend the roman orthography for the (East) Crees. She says she never mixes the writing systems together.

Anna sees her Aboriginal literacy abilities as important in keeping her language:

Yes. If I can keep my language in the written part, people know where I come from whereas the other people they loose their language and when it comes to when they ask the people can you speak your language? You know, and if I said no, how do you think that would make me feel? So I can say I'm proud I can maintain my language and culture and be able to write it. For our youth today, sometimes it's hard for them to understand our Elders if the Elders have something to say like tell a story and it's hard for them understand so, they can go back to read the story that is told and go back and do a search on the words they didn't understand so it will help them. (Anna)

She has also expressed a belief about the importance of the written language in keeping a connection to the knowledge of the Elders for the children. She says that she will sometimes read English books to her grandchildren in (East) Cree; she will translate as

\footnotetext{
${ }^{43}$ The old Moose Cree version and more recently the Cree Eastern/James Bay New Testament. (http://www.biblescanada.com/catalog/1554.htm)
} 
she reads. She now holds her Cree language as extremely important because she realizes that she began to loose her language in residential schools. Through her teaching she has come to see the difference in kids who are educated in (East) Cree at a young age. She feels these students, who have mastered their mother tongue at 9 or 10 were far better learners than the ones that began to attend English schools early.

\subsection{Literacy and Identity}

The response to this section of the interview contained the most data, and responses were generally extensive. Often the participant's perspective on the connection between literacy and identity expanded to include the importance of Native language in general, both spoken and written. There were several themes that reoccur in the responses of both groups of participants, and these themes are deeply interconnected:

\section{Themes:}

1) Pride in the knowledge of their written language.

Although only two participants explicitly stated that they were proud to be able to read and write in their language, it was clear that all considered it part of who they are. This pride was expressed in several ways: one Ojicree participant said she was proud to know her written language because so many young parents in the community did not have this knowledge (of either language). An (East) Cree participant said that when she 
saw a sign in her community written in her language, she would always make a point of reading it out loud to educate others and to let them know that she could read it. This same participant said:

God created me to be a Cree person, to speak the Cree language and that if I don't use it, if I tend to speak more English then that means that I am not accepting what God gave me as a person to live of this earth. So, that's what I am glad that I've learnt to read and write, and I still have my oral language and I am really glad that I have that. (Ruth)

Another participant said that she was proud of being able to pronounce her (East) Cree correctly, which she credits to her knowledge of written (East) Cree. Of the seven participants interviewed, six agreed that their ability to read and write in their Native language has shaped their identity, while the seventh person was unsure how to respond to this question, but agreed that "in some ways yeah I feel it has shaped my identity but then again we didn't really have writing system before and I feel that writing in Cree is good so and it I don't know what to say about that" (Pearl).

2) The written language helps to understand the language better and connects them to the Elders.

Some participants expressed their answer to the connection between identity and the written language by talking about how knowing to write the language helped them speak more 'correctly' and therefore, converse more correctly with their Elders:

Um, yes, I would think so yeah, because writing in Cree it helped me understandcuz I used to use slang Cree before when I was younger, but when I learned to write the standard Cree it helped me understand the word like how the Elders used to pronounce it before, that's what I see today happening to my children too, 
broken, like broken Cree, like broken English, like slang Cree. And sometimes I correct them and I tell them that's not what our grandfather used to say, or our grandmother. (Pearl)

Both Ojicree and (East) Cree participants commented on the importance of written language for communication with the Elders: "it's important for them, so they know their identity, first of all, and then to be able to communicate with the Elders, and it helps like that" (Judy). There is a general perception among the participants that the Elders have the 'old Cree' and that there is a risk that the kids could loose their connect with the Elders if they cannot understand them.

3) Language Loss is deeply felt.

All of the participants, during various parts of the interview but particularly in the identity section, expressed great sadness about the realities they see in their communities of language loss. John spoke about an Elder who had recently died in the community. She was 101 year old. He said:

Like that old lady that died recently she was over 100 years old she must have had a lot of information from their history if they asked her. They should have written it down, or record her. (John)

The poignancy of this quote exemplifies how written language can be used to preserve the knowledge of the Elders. John equates this knowledge with history. Others spoke about having almost lost her language in residential school. As Ruth says:

I learned to read and write it... and knowing that I almost lost my language it has put a lot of thinking into me because this is what makes me strong, knowing my language and where I came from and knowing my roots so that's how I know my identity" (Ruth). 
The idea of 'knowing your roots' was connected with knowledge of syllabics by three participants.

On the side of the Ojicree participants there is a deep consciousness about the lack of material available, both in the classroom and to practice reading and writing skills. The (East) Cree communities in the study have Bibles written close to their own dialects available, the Ojicree do not. Saloma says she reads her Bible in English because the Bibles used in the community churches are all written in (East) Cree:

Yes I have a Bible but I use the English. Cause the bibles and the hymn books that are used today in the churches today are all in Cree. We don't have any in our language: Ojicree. There all in the Cree language... Yeah. There's not. Almost nothing to read in Ojicree. (Saloma)

John corroborates this point when talking about the lack of history books written about the people of Kasabonika Lake. He says that other groups of Native peoples have history books written about them, and that Ojicree has nothing that he has found.

There is also a sub-theme about a deep concern for the future of the two languages. Two of the Ojicree participants comment on the growing number of "young parents'. These young parents have likely grown up not learning the script or speak the language regularly and so there is a worry that what is being taught in the school system is not being supported at home. Each participant, from both language groups, expressed a staunch feeling that Native language must continue to be taught in immersion or bilingual programs, while four of the participants commented on the importance of speaking Native language in the home. The Ojicree participants were asked if they 
believed more subjects should be taught in Native language. John, the eldest of the group felt that it should be taught one day English, one day Ojicree. Saloma felt that Native culture class should be conducted in Ojicree. Judy was reluctant to criticize the current system but said that history "could always be taught in Native language" though she wasn't sure how this would work for a subject like Math (this is because Ojicree has a numbering system that may be difficult for the teaching of a math subject (Kori Ruff, p.c.)).

4) The connection between knowing to read and write in Native Language and getting a job

Most of the participants commented on this connection and credited their knowledge of reading and writing and speaking in their native tongue to having their current job. For Ruth, this connection is particularly poignant because she did not learn how to read and write in her language before she went away to residential schools. It was later in her life that Annie approached her and asked her to work on the C.L.I.P. pilot project. She was unsure of herself and her ability to learn, this moment mark a changing point in her life when she decides to learn it because Annie asked her too. Now she plays an important role in her community as a teacher of teachers. None of the participants credited their knowledge of reading and writing in English with getting a job. 
5) That the two languages generally complement one another in the heads of the participants - Writing in Ojicree/(East) Cree helps to understand the language better - Inventive use of the language

All participants agree that their knowledge of their Native language and English generally complemented one another, with the exception of the years spent in residential school. Several participants describe incidences when they would write a word they could not spell in English in Ojicree or (East) Cree syllabics. There were also instances in which the participants said they had to invent ways to describe English concepts using Ojicree or (East) Cree words. Sometimes this would be challenging, but always possible, to find a way to describe a non-familiar concept using the ancestral language.

For science there are some words that ... when I was teaching kindergarten I did all the subjects in Ojicree. Like in my language I taught all of them in Ojicree but they were words that I couldn't like we don't have some of the words for the words in science we just have to explain what it meant using the whole sentence for one word. So stuff like that happens. (Saloma)

Saloma is expressing that all of the subjects can be taught in Ojicree. She makes it clear that process of using the language to explain an unfamiliar concept is a positive thing because it legitimizes the Native language. The language is equally capable as a medium of instruction as English.

\subsection{Development of 'Literacies'}

This section analyzes the learning experiences of the participants in regards to literacy. The analysis is divided into two sub-groups (4.4.1 Participants who attended residential schools and 4.4.2 Participants who attended community schools). Several 
themes are evident in the participant comments regarding the general experience of learning the syllabic writing systems that are discussed through the extrapolation of four key themes: The recognition of the role of teachers, the participant conceptions about the relationship between the roman orthography and the English alphabet, and the levels of interest in learning syllabics vs. the roman orthography.

\subsubsection{Participants Who Attended Residential Schools}

This sub-group contains one male Ojicree participant (John) and three female (East) Cree participants (Ruth, Emily, Anna) (see Table 4.1). 


\begin{tabular}{|c|c|c|c|c|c|}
\hline Participant & $\begin{array}{c}\text { Age Taken } \\
\text { to } \\
\text { Residential } \\
\text { School }\end{array}$ & L1/L/2 & $\begin{array}{l}\text { Orthography } \\
\text { Order of } \\
\text { Acquisition }\end{array}$ & $\begin{array}{l}\text { Method of } \\
\text { Learning } \\
\text { Syllabics }\end{array}$ & Quote \\
\hline $\begin{array}{c}\text { John } \\
\text { (Ojicree) }\end{array}$ & 13 & $\begin{array}{l}\text { Ojicree/ } \\
\text { English }\end{array}$ & $\begin{array}{l}\text { 1)Ojicree } \\
\text { Syllabics } \\
\text { 2)English } \\
\text { Alphabet } \\
\text { 3)Ojicree roman }\end{array}$ & $\begin{array}{l}\text { Taught by his } \\
\text { mother when he } \\
\text { showed interest in } \\
\text { trying to read the } \\
\text { syllabic chart. }\end{array}$ & $\begin{array}{l}\text { My mother actually told me } \\
\text { the syllabic chart sounds of } \\
\text { each letter and I when I } \\
\text { tried to read it she told me } \\
\text { more and made me read the } \\
\text { finals the finals are the } \\
\text { main thing of how you can } \\
\text { understand the writung the } \\
\text { finals of the syllabic chart }\end{array}$ \\
\hline $\begin{array}{l}\text { Ruth } \\
\text { (Cree) }\end{array}$ & $6 / 7$ & $\begin{array}{l}\text { Ojicree/ } \\
\text { English }\end{array}$ & $\begin{array}{l}\text { 1)English } \\
\text { Alphabet } \\
\text { 2) (East) Cree } \\
\text { syllabics } \\
\text { 3) (East) Cree } \\
\text { roman }\end{array}$ & $\begin{array}{l}\text { Taught by Annie } \\
\text { Whiskeychan at } 35 \\
\text { years old- Her } \\
\text { parents could not } \\
\text { read \& write } \\
\text { syllabics }\end{array}$ & $\begin{array}{l}\text { I was taught by the Late } \\
\text { Annie Whisheychan She } \\
\text { taught me the Cree } \\
\text { syllabics - the reading and } \\
\text { writing }\end{array}$ \\
\hline $\begin{array}{l}\text { Emily } \\
\text { (Cree) }\end{array}$ & 8 & $\begin{array}{l}\text { Ojicree/ } \\
\text { English }\end{array}$ & $\begin{array}{l}\text { 1)(East) Cree } \\
\text { Syllabics } \\
\text { 2)English } \\
\text { Alphabet } \\
\text { 3)(East) Cree } \\
\text { roman }\end{array}$ & $\begin{array}{l}\text { Tried to teach } \\
\text { herself at an early } \\
\text { age. Learned from } \\
\text { the hymn book and } \\
\text { her father/grandma }\end{array}$ & $\begin{array}{l}\text { When I used to go to } \\
\text { church I would join the } \\
\text { singing with an open hymn } \\
\text { book even though I didn't } \\
\text { know how to read I knew } \\
\text { the whole song And while } \\
\text { swinging my baby sister in } \\
\text { a swing I would sing I } \\
\text { didn't know how to sing a } \\
\text { lullaby so I would sing the } \\
\text { hymn and I would read the } \\
\text { symbols }\end{array}$ \\
\hline $\begin{array}{c}\text { Anna } \\
\text { (Cree) }\end{array}$ & 7 & $\begin{array}{l}\text { Ojicree/ } \\
\text { English }\end{array}$ & $\begin{array}{l}\text { 1)(East) Cree } \\
\text { Syllabics } \\
\text { 2)English } \\
\text { Alphabet } \\
\text { 3)(East) Cree } \\
\text { roman }\end{array}$ & $\begin{array}{l}\text { Tried to teach } \\
\text { herself at an early } \\
\text { age. Learned from } \\
\text { the hymn book, } \\
\text { bible. Her father } \\
\text { taught her to read } \\
\text { afterwards }\end{array}$ & $\begin{array}{l}\text { But before that I saw the } \\
\text { shapes of the syllabics } \\
\text { when my parents were } \\
\text { reading the bible, the hymn } \\
\text { book and the psalm book } \\
\text { and with these different } \\
\text { shapes of symbols I used to } \\
\text { play outside in the snow } \\
\text { with woodchips or } \\
\text { branches or strng whatever } \\
\text { I could play with the pins } \\
\text { of the bows, I used to make } \\
\text { shapes in the snow, I used } \\
\text { to make shapes on the sand, } \\
\text { play with rocks and I used } \\
\text { to ask my parents what } \\
\text { does this mean? What is } \\
\text { the letter sound? And I then } \\
\text { I learned how to write } \\
\text { 'mama' and then I wrote } \\
\text { 'baba' and then I learned } \\
\text { how to write my name and } \\
\text { that's how I first learned } \\
\text { how to write words with } \\
\text { the symbols }\end{array}$ \\
\hline
\end{tabular}

Table 4.1 Participants who attended Residential Schools 
All of the participants in this sub-group, except for Ruth, learned the syllabic characters before they left for residential schools where they then learned to read and write in English. They learned the standard orthography for (East) Cree and Ojicree later in their lives for example when they began working with (East) Cree programs. Two of the participants were first introduced to the syllabic script through opening the pages of the hymn book in church. It would be interesting to find out whether the hymn book was in their own language/dialect or in Moose Cree. They were able to follow along the symbols with the singing during church service. John, Anna, and Emily all were taught by a grandparent or by their father/mother in an informal setting. They all learned to read and write in their language (in syllabics) before English. Ruth learned the English writing system first and then (East) Cree syllabics and (East) Cree roman later in her life from the late Annie Whiskeychan. The parents and grandparents of the participants in this subsection who were literate could read and write only in syllabics.

Anna and Emily spoke about how they sometimes wrote letters to keep in touch with relatives. Emily talked about writing to her mother in (East) Cree syllabics from residential school:

She would write back in the syllabic, she didn't know how to read and write English. So she said she was happy that I could write to her using syllabics (in Cree?) yeah, she said otherwise she wouldn't have anybody to read my letters to her in English if I had written in English. (Emily)

For Emily, the only way to communicate with her mother was in (East) Cree through the syllabics. Similarly, Anna said she would write letters in (East) Cree syllabics to her sister. It is likely that they did not use the standard orthography in their childhood letter 
writing. The siblings moved to live in different communities when their home community of Nemaska was dissolved in 1970 because of a hydro project and the closing of the Hudson Bay trading post. Anna was able to stay in touch with her sisters through letter writing. She would write to her sister using syllabics. In addition, the role of Residential schools in the loss of language was also mentioned by the participants who were forced to attend. While John only mentions briefly that he attended residential schools, Ruth reflects that:

I got into trouble for speaking my own language and when I think back to what happened in residential school I realize that I almost lost my language because I didn't have the written and the reading, I only had the oral.(Ruth)

The participants were asked if their knowledge of English helped or hindered their learning Ojicree or (East) Cree and vice versa. Of the participants who attended residential school, 3 said that in some way English hindered their learning because of residential schools. Anna said:

I found that it slowed me down because I kind of lost my language when I went to school because we were not allowed to speak our language in residential school so when I came back it was kind of hard to understand my parents what my parents were telling me. (Anna)

Ruth also made a similar comment that it hindered her for a while in residential schools but that she did not confuse the two languages in her head.

\subsubsection{Participants Who Attended Community Schools}

This sub-group includes one (East) Cree and two Ojicree participants (Table 4.2). Each of these participants considers their first language to be either Ojicree or (East) Cree 
and had the benefit of schooling in their Native language at some point, although all were taught English-only in the elementary years of community schooling. Consequently, they all learned to write in English, their second language, before writing in their own language. This being said, all three participants familiarized themselves with the syllabic chart and tried to teach themselves, prior to the implementation of Native Language programs. This was achieved in a number of ways: Saloma showed an interest in her parent's letter writing at a young age and observed them, her interest precipitated their teaching of her; Pearl taught herself to read in Moose Cree from the chart at the beginning of the church hymn books which contained both the English letters and the syllabics. 


\begin{tabular}{|c|c|c|c|c|}
\hline Participant & L1/L2 & $\begin{array}{c}\text { Orthography } \\
\text { Order of } \\
\text { Acquisition } \\
\end{array}$ & $\begin{array}{c}\text { Method of } \\
\text { Learning } \\
\text { Syllabics } \\
\end{array}$ & Quote \\
\hline Judy & $\begin{array}{l}\text { Ojicree/ } \\
\text { English }\end{array}$ & $\begin{array}{l}\text { 1)English } \\
\text { Alphabet } \\
\text { 2) Ojicree } \\
\text { syllabics } \\
\text { 3)Ojicree roman }\end{array}$ & $\begin{array}{l}\text { Taught to read and } \\
\text { write in community } \\
\text { school when it was } \\
\text { implemented in } \\
\text { grade } 7 / 8 \text { (she was } \\
13 / 14 \text { ) }\end{array}$ & $\begin{array}{l}\text { I can't recall when I learned really } \\
\text { learned how to read and write but I did } \\
\text { know how to read and write in the } \\
\text { Native language by the time I finished } \\
\text { grade } 8 \text {. Basically what my instructors } \\
\text { did was tell us legends and they would } \\
\text { write the legends down on the } \\
\text { blackboard while we would basically } \\
\text { copy down from the blackboard, there } \\
\text { weren't really worksheets there was just } \\
\text { writing, writing and writing. }\end{array}$ \\
\hline Saloma & $\begin{array}{l}\text { Ojicree/ } \\
\text { English }\end{array}$ & $\begin{array}{l}\text { 1)Ojicree syllabics } \\
\text { 2)Ojicree roman } \\
\text { 3)English } \\
\text { Alphabet }\end{array}$ & $\begin{array}{l}\text { Taught to read by her } \\
\text { parents/grandparents. } \\
\text { Through observing } \\
\text { her parents write } \\
\text { notes at; learned to } \\
\text { write syllabics when } \\
\text { it was implemented } \\
\text { in grade } 7 / 8 \text { she } \\
\text { was } 13 / 14\end{array}$ & $\begin{array}{l}\text { Well when I was younger I just } \\
\text { observed my parents. The whole time I } \\
\text { would speak in my own language and } \\
\text { when my parents were writing notes or } \\
\text { letters I would just observe them. Both } \\
\text { of them taught me how to write in my } \\
\text { language... I learned how to read in } \\
\text { write through my grandparents too. }\end{array}$ \\
\hline Pearl & $\begin{array}{l}\text { (East) } \\
\text { Cree/ } \\
\text { English }\end{array}$ & $\begin{array}{l}\text { 1)(East) Cree } \\
\text { syllabics } \\
\text { 2)English } \\
\text { Alphabet } \\
\text { 3)(East) Cree } \\
\text { roman }\end{array}$ & $\begin{array}{l}\text { Taught herself } \\
\text { through the } \\
\text { syllabic chart in the } \\
\text { hymn books at her } \\
\text { church around age } \\
8 \text { or } 9 \text {. Then was } \\
\text { taught by Annie } \\
\text { Whiskeychan. }\end{array}$ & $\begin{array}{l}\text { I always attended church with my } \\
\text { grandmother. It was an Anglican } \\
\text { church is was also one of the first two } \\
\text { churches in our community. In the } \\
\text { hymn books, there where Cree hymn } \\
\text { books mostly in Moose Cree. And } \\
\text { there in the beginning of the page it had } \\
\text { the syllabics and also the alphabet. } \\
\text { And then there I used to sound out the } \\
\text { alphabet. I taught myself how to do the } \\
\text { system in the syllabic chart, the reading } \\
\text { system in the syllabic chart and I used } \\
\text { to sound them out and that's how I first } \\
\text { learned to read the syllabics... And then } \\
\text { in the } 70 \text { 's my first teacher was Annie } \\
\text { Whiskeychan. And she taught us how } \\
\text { to read the syllabics. And then I } \\
\text { learned how to read in Waskaganish } \\
\text { Cree. In our own dialect. }\end{array}$ \\
\hline
\end{tabular}

Table 4.2 Participants who attended community schools. 
Two of these participants (and one from the other sub-category) credit their learning to a female teacher who inspired them to learn the language. Two (East) Cree participants (Pearl and Ruth) credit their ultimate learning of the written language later in life to Annie Whiskeychan.

\subsubsection{Analysis of Themes}

Several themes are apparent in the participants' self reflections of their literacy development related to the process of learning and perceptions about the orthographies. These include the recognition of the role of teachers, the participant conceptions about the relationship between the roman orthography and the English alphabet, and the levels of interest in learning syllabics vs. the roman orthography for their language.

\section{Theme 1:}

\section{"The Way We Were Taught": Annie Whiskeychan \& Others}

Many participants credited their learning to family members and to individual teachers who both taught and inspired. Two of the (East) Cree participants spoke about their (East) Cree teacher, the late Annie Whiskeychan, who deeply impacted (East) Cree language teaching, particularly in Waskaganish, through her work with the Cree School Board and on her own as a translator, interpreter, and teacher. Both Pearl and Ruth speak about how their abilities to read and write were influenced by Annie. Ruth, who did not learn to read and write in (East) Cree as a child, and whose parents also did not know the script, was asked by Annie to teach in (East) Cree when the (C.L.I.P. pilot project was 
implemented. Ruth initially said no to this opportunity because she could not read or write in (East) Cree:

But then it was Annie again that said we would like you to do it because your one of the people that first started to teach and you have a lot of experience in teaching and we are asking you to do it and I will teach you how to read and write Cree. That's what she told me and that's what she did. We had some lessons in her office where she was working and she would teach us, voluntarily teach us. But then later on she did teach some Cree language courses for teachers from other communities. (Ruth)

In this way, Annie did more than just teach the language, she gave her the confidence to learn the language by taking the time to voluntarily teach her to read and write it.

Similarly, Pearl talks about how Annie "taught us" to read and write the syllabics. She says that "and then I learned how to read in Waskaganish Cree. In our own dialect".

Thus, Annie's contribution is not just that she taught others to read and write, she was one of the first to teach them to read and write in their own dialect. Several of the participants speak about the importance of reading in their own dialect (see identity section).

Judy spoke about a teacher that she had in her community school, after the implementation of Native language classes:

I liked the way they taught us. There was lady there, she was, I liked her a lot. I remember I used to just sit there and listen to her talk. I would, I don't know I just, she just, she just made an impact. (Judy)

Similarly, Anna spoke about her father:

My dad was the first one that taught me the writing system because he was the first one that taught the Cree language and culture in the school he asked me to be his assistant and so I helped him that's how I learned maybe 17, then 19 I was a teacher. (Anna) 
Though many of the participants achieved literacy in their ancestral languages through hard work and self-determination, the teachers, and the way that they were taught, also played a huge part in their confidence and motivation to learn syllabics.

\section{Theme 2:}

\section{The Alphabet $=$ Roman Orthography=English}

Two of the (East) Cree participants seemed to equate the English alphabet to the (East) Cree roman orthography. For them, there seemed to be no distinction between the two writing systems, such that writing in English letters was still writing in English, even if it was an (East) Cree word. Close textual analysis revealed a conception that writing in roman orthography equals English, while writing in syllabics equals Cree. Pearl says that she learned her alphabet in pre-kindergarten and 'that's where I learned my roman orthography" (Pearl). Yet, when she talks about how she learned to read and write in Cree, she says she learned to read syllabics around age 8 or 9 in church. A similar remark was made by Emily. When she was asked when she preferred using syllabics over roman, or vice versa, she replied:

Roman I have a hard time. It's easier to write in syllabics for me, and I find it hard to read it too in roman. (because you learned syllabics first?) Yes, I didn't know my alphabet; I had syllabics before my alphabets. (Emily)

These responses perhaps gesture to the overall disinterest in learning the roman orthography detailed below. 


\section{Theme 3:}

\section{Interest in Learning Syllabics}

Participants tended to preface the descriptions of how they learned to read or write in their language by talking about their initial interest to do so. For instance, while all of the participants identified someone who actually taught them to read the symbols, most began their story with a description of an initial interest in the script. This preexisting interest, curiosity, and/or attempt to understand the written language, was achieved mostly through observation or actively trying to decode the sounds of the symbols:

Like I said I tried to read syllabic writing. My mother actually told me the syllabic chart sounds of each letter and when I tried to read it she told me more and made me read the finals. (John)

I used to play outside in the snow with woodchips or branches or string whatever I could play with the pines of the bows, I used to make shapes in the snow, I used to make shapes on the sand, play with rocks and I used to ask my parents what does this mean? (Anna)

I really wanted to learn because my mum used to sing in Cree all the time and I wanted to sing with her as she sang...I was always a curious child. (Pearl)

Well when I was younger I just observed my parents. The whole time I would speak in my own language and when my parents were writing notes or letters I would just observe them. (Saloma)

I would join the singing with an open hymn book even though I didn't know how to read I knew the whole song. And while swinging my baby sister in a swing I would sing I didn't know how to sing a lullaby so I would sing the hymn and I would read the symbols. (Emily) 
Traditionally in the cultures of (East) Cree and Ojicree, parents and/or grandparents wait to see a child's interest in learning something, and then proceed to teach them. Observation and listening are important to the learning process in the (East) Cree and Ojicree culture. A child observes something being done, and this is noticed and fostered. The participants say they wanted to learn to read and write in their language, they had a motivation to do so that seems deeply tied to the shapes of the symbols themselves. Most participants (5/7) expressed an interest in learning or a description of how they tried to learn syllabics outside of formal schooling, either in church through the hymn book, independently, or through direct teaching from a family member. Anna gives a lengthy description of how she would try to practice memorizing the symbols and their sounds through playing with the shapes outside or inside the house ("you know the roof of the house, what sound does it make?). Pearl talks about wanting to learn the syllabics so that she could sing (East) Cree with her mother, "as she sang" which is similar to Emily who decoded the symbols in her hymn book through her pre-existing knowledge of the song. Emily and Pearl's method of learning is different than Anna's and is connected to the sounds of the syllables.

\section{Theme 4:}

(Dis)Interest in Learning Roman

In regards to the attitude towards learning roman orthography, a difference in the attitude between the two groups is discernable. The Ojicree participants did not say 
anything negative about the roman orthography or their experience of learning it (John said that he was 'getting good' at it now), although, like the (East) Cree participants, they all learned the syllabics first and learned the roman orthography later through schooling. They also all preferred to read in the syllabics. However, the (East) Cree participants tended to articulate a disinterest in learning roman orthography. Ruth comments that Annie Whiskeychan "showed us the roman but she said she preferred for us to learn the syllabics because that is what we would be using to teach the children". In this comment it is clear that Ruth did not display an initial interest in learning the script, nor did her teacher place emphasis or value on learning it. It was showed 'to her'; she did not observe it with interest. In contrast to the above section which describes most participants as wanting to learn the syllabics, there seemed to be little interest among the (East) Cree participants in wanting to learn the roman script. Pearl and Ruth talk about the drawbacks of roman and their lack of motivation to learn it:

I prefer to use syllabics because I find the roman really slow I can still write in roman if I want to because I think it's faster I write faster and also I can remember but the roman I never really tried it that much. (Pearl)

Actually I never bothered with the roman because I wanted to learn the syllabics. (Ruth)

These comments of the participants concerning the roman orthography could perhaps be explained by the literature that describes the status of the syllabics as a cultural icon. Other general comments included difficulties in reading roman because of the long length of the words and the variability in the ways the vowels are represented: aa and â. 
Interestingly, one participant who spoke about the attitudes of some people that have married into her community described the interest in learning the (East Cree) language and its syllabics as lacking:

I don't think they're interested, they are the ones that want to stop the Cree being taught in school and they've lived there for 20 years they still don't speak Cree because they don't want to learn.(Emily)

This quote exemplifies the importance of 'wanting to learn' as paramount to acquiring the language, both spoken and written. All of the (East) Cree participants clearly express an interest in the syllabics, and two expressed a disinterest in the roman orthography.

\subsection{Uses of the Writing Systems}

The data gathered in this section is divided into two sections: 4.5.1 uses of syllabics remembered from childhood; and 4.5.2 uses of both syllabic and roman scripts in daily life.

\subsubsection{Uses of Syllabics Remembered from Childhood}

This section includes only descriptions of childhood remembrances of syllabics because there were no instances in the participant recollections that involve roman orthography. During the childhood of the participants, the uses of syllabics appear to primarily serve a functional role. John, the oldest participant, describes using syllabics in the bush growing up:

Yeah, it's really amazing how we did those things in the bush even if we didn't have a writing paper. Just glaze the tree right down to the wood, Just write the 
words very clear you can write your note and it can stay a long time rather than hanging a piece of paper and some bird or animals gonna pick it up [laugh] ...that's very important if a guy is lost and knows what to do he can write a note on a tree because if there's a storm he can make a note on the tree and tell them the direction that he is heading when they find the note. (John)

John's use of syllabics clearly shows a traditionally functional role in the bush and is not analogous to the usage of modern syllabics today. The nature of this function and even the concept of 'note' are also very different from that of English. Participants also spoke about the role that reading and writing in syllabics played in their ability to communicate over long distance before the introduction of the telephone and bush radios in their communities (see examples from 4.4.1). The only published texts that were available in the childhoods of the participants were of a religious nature; there is often an association between reading syllabics during church service. Thus, church literacy is another functional role of literacy in the past.

The functional role that syllabics played during the childhoods of the participants is deeply significant to the abilities of families to stay connected over long distances and to certain survival strategies in the bush. The role of syllabics in the past does not seem to be especially symbolic as a representation of culture, but more as a writing medium that was integral to traditional life and served functional roles in this context.

\subsubsection{Uses of the Writing Systems in Daily Life}

It is apparent that the traditionally functional uses of reading and writing in syllabics has changed with the introduction of bush radios and telephones, and that 
syllabic uses have expanded to take on a highly symbolic role as a representation of the (East) Cree and Ojicree cultures. In addition, there the role of roman orthographies is also observable in the responses. The current roles of reading and writing in both orthographies will be analyzed separately below.

\section{Reading in Daily Life}

Both the (East) Cree and Ojicree participants said that syllabics were visible in their communities on posters and signs on the clothing, road signs, public buildings, at the airport, and at the airport. General reading materials mentioned are used for practice and include local newspapers/magazines with some sections written in syllabics (The Nation, Wawatay News, In Flight). Table 4.3 gives a summary of the daily uses of reading in Ojicree (East) Cree. The table breaks down the type of script used for each use.

Six of the seven participants expressed a general opinion that there was not enough material to 'practice on'. Some (East) Cree participants said though there are some materials and resources, often these are not available in their own dialects:

Well, at home, I practice it with my children, like we have the The Nation magazine but it's in the northern dialect. (Anna: Southern East Cree: Inland dialect)

Yes, like that that In Flight magazine and there is one section that is always in Cree and The Nation has sometimes story an Elder told like a legend. But it is all written in northern dialect. I can read it and I read it. But I prefer to read it in the Southern. (Ruth: Southern East Cree: Coastal dialect) 
I only see the books in Cree at the office where I work. There is no Cree literature in our bookshelves there only English and French. (Pearl: Southern East Cree: Inland dialect)

For the Ojicree, the lack of material to practice on is a problem compounded by the fact that what is available is not closely related to their language. Every Ojicree participant spoke about this:

Especially during class during the school year. There is material but its' mostly in Cree. The students don't speak Cree. There's not really much here. At least I haven't seen, in Ojicree. (Judy)

I know we don't have a lot of history of our own we got nothing not like other nationalities of Indians they have a lot of history books but we don't have the history not in any book anyway. (John)

Yeah. There's not. Almost nothing to read in Ojicree. (Saloma)

The consciousness of the lack of texts available in local dialects makes the 'practice' that participants speak about difficult. For the Ojicree participants, there is a clear need for more to be written for reading practice and school resources. For the (East) Cree participants, there is a need for more local texts to be created so that the material to practice on is available in the reader's own dialect. When Pearl was asked if she would buy books that were written in her own dialect, she replied: "Yes I would buy them I would buy every copy!" (Pearl).

The review of literature on current uses of reading mentions the importance of religious texts to reading because they comprise a large part of the body of literature available in (East) Cree. In regards to the bible, the two female Ojicree participants said that they read their personal bibles in English for this reason: 
Yes I have a bible but I use the English. Cause the bibles and the hymn books that are used today in the churches today are all in Cree. We don't have any in our language: Ojicree. There all in the Cree language. (Saloma)

While the lack of material to practice on was mentioned by the majority of the participants, one Ojicree participant also remarked on the lack of material available for practicing on not just in her daily life, but also as resource material for the local classrooms. While the (East) Cree are currently collaborating with Dr. Marie-Odile Junker of Carleton University to developing a website (www.eastcree.org) that includes read-alongs, sing-alongs, reference grammar, online dictionary, Cree linguistic atlas, and lessons, the Ojicree have no such resources. There is clearly an ongoing need for more material to be developed that can be used for practice. Furthermore, the presence of reading material online would aid communities in sharing their ideas, materials and resources. 


\begin{tabular}{|c|c|c|c|c|c|}
\hline 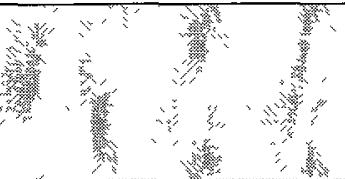 & $\begin{array}{l}\text { Phonemic } \\
\text { Roman } \\
\text { Ris }\end{array}$ & $\begin{array}{l}\text { Standardized } \\
\text { Roman }\end{array}$ & Syllabics & $\begin{array}{l}\text { Modern } \\
\text { Syllabics } \\
\text { Sylow }\end{array}$ & English \\
\hline Street Signs & & & & (:) & (ن) \\
\hline Clothing & & & & (:) & (;) \\
\hline Email, typing & (:) & (). & & (:) & (:) \\
\hline Newspapers & & (:) & & (:) & (:) \\
\hline $\begin{array}{l}\text { Cree Regional } \\
\text { Authority Reports, } \\
\text { Band reports, Cree } \\
\text { Trappers Annual } \\
\text { Report }\end{array}$ & & (:) & & (:) & (:) \\
\hline $\begin{array}{l}\text { The Nation } \\
\text { magazines, In- } \\
\text { Flight magazines }\end{array}$ & & (:) & & (:) & (:) \\
\hline Text Messaging & (:) & & & & (:) \\
\hline Books & & (:) & & (:) & (:) \\
\hline TV & & & & & (:) \\
\hline Bible & & (:) & (:) & (:) & () \\
\hline Public Posters & & & & (:) & (:) \\
\hline Facebook, MyKnet & (:) & & & (:) & (:) \\
\hline
\end{tabular}

Table. 4.3 Participant Examples of Reading in Daily Life 


\section{Writing in Daily Life}

Several of the participants mentioned that they use written Ojicree and (East) Cree for personal purposes like keeping a journal, writing down stories told by Elders on the radio, songs, etc. There was one example of a use of syllabics functioning in a traditional way offered by Judy, whose husband is a respected hunter in the community:

Like when my husband goes out hunting when he tells me of a place I usually write it in syllabics cause I don't know how it's called in English that way I can give the instructions like where he is if his skidoo broke down stuff like that I usually do that. (Judy)

The names of the surrounding landscape features are known to the hunters in Ojicree, so naturally Judy would write these in her language. This is related to the idea that the participants used the syllabic script the most when they wanted to express themselves in their mother tongue and in circumstances in which English words would not convey the intended meaning accurately.

For work I read and write in Cree, I read and write in Cree mostly because I don't really know how to write in English, the meaning that I want in the English. (Emily)

Also, an inventive use of syllabics was observed in the participant descriptions of their written usages. Many participants said that they used syllabics in cases in which, they were unsure of the spelling of the English word. This specific use is recorded on two occasions: At times when there is a word that the participant cannot translate into (East) Cree/Ojicree (such as scientific names of body parts); and secondly, at times when there 
is a word that the participant cannot spell in English. In these cases, some participants mentioned that they would write English words in syllabic characters:

Yes, I used to do that a lot when I went to McGill. I used to mix syllabics and English. So my notes are all kind of really funny. Sometimes I would write the English words into syllabics and sometimes I would write the Cree words. (Pearl)

Yes. If I write 'tomatoes' I write 'tomatoes' in syllabics. I don't know the Cree name for tomatoes. (Emily)

Yeah, I do that. Like one time I was doing body parts, like the internal body parts I was translating all of them and I came up with a couple that $i$ didn't know how to translate them I didn't know what they were called, and i just write them using the English word I use syllabics but later on I found out what they were called. (Saloma)

Several of the participants report that they generate their own materials in syllabics and roman writing for use in the classroom:

I have children's songs made up children's songs and poems in my language. (Saloma)

Some uses of different scripts are detailed below in Table 4.4. 


\begin{tabular}{|c|c|c|c|c|c|}
\hline Y & $\begin{array}{l}\text { Standardized } \\
\text { Roman }\end{array}$ & $\begin{array}{l}\text { Phonemic } \\
\text { Roman }\end{array}$ & $\begin{array}{c}\text { Old } \\
\text { Syllabics }\end{array}$ & $\begin{array}{l}\text { Modern } \\
\text { Syllabics }\end{array}$ & English \\
\hline Grocery list & & & ()) & (:) & \\
\hline Taking notes & & & & (:) & (:) \\
\hline Letters & (:) & (:) & (:) & (:) & (:) \\
\hline Email/typing & (:) & (:) & & (:) & (-) \\
\hline $\begin{array}{l}\text { Directions to a } \\
\text { place in the bush; } \\
\text { in the bush }\end{array}$ & & . & (i) & & \\
\hline $\begin{array}{l}\text { Government } \\
\text { Paperwork }\end{array}$ & & & & & (:) \\
\hline Books & & & & (:) & (:) \\
\hline Work & & & & (:) & (:) \\
\hline Songs, poems & & & & (;) & \\
\hline Journals & & & & (:) & \\
\hline Shopping list & & & & (:) & (:) \\
\hline $\begin{array}{c}\text { Stories/writing } \\
\text { down Elder's } \\
\text { stories and things } \\
\text { they say }\end{array}$ & & & & (;) & \\
\hline Chat, msn & (:) & 4 & & (;) & \\
\hline Making flyers & & & & (:) & \\
\hline
\end{tabular}

Table 4.4 Participant Examples of Writing in Daily Life 


\section{Script Choice for Teaching}

Unfortunately, I did not overtly ask which orthography the (East) Cree participants use to teach their children. Although all of the (East) Cree participants strongly said that they prefer syllabics over roman in their daily lives, only one explicated that they use syllabics in their teaching. Ruth mentioned that Annie wanted them to use the syllabics when they teach the children. In regards to the Ojicree participants, I was able to observe several Native language classes in which both the roman orthography and syllabics were used for teaching. I also was able to ask the Ojicree participants about the uses of roman orthography in the classroom. All of the Ojicree participants said that they use roman to teach the students who arrive to their class with no knowledge of their native language. In cases where the L1 is English, and the L2 is Ojicree.

John elaborated that:

The roman uses English letters and that's what I use when I teach writing with the English letters and then and kids translate it into Ojicree language. They're really good that's what helps they're really learning fast because they know the sounds of each English letter there in English classroom that's the best way to teach a Native person their Native language today all of them are speaking English. (John)

John emphasizes the role he perceives the English letters play in his students' learning of their language which is attributed to the fact that they arrive at school speaking in English. They also know their English alphabet first. Judy made similar comments to John. She spoke using the example of her niece:

Like my niece, she doesn't, well she didn't really speak Native language before in her younger years. So students like her, when they are in my class, I prefer to use roman orthography first, I read it out to them first, and they begin to read it by themselves, and then they transform it to syllabics, that's how she, I think that's 
how she, she said, her mum told me I think that's how she learned how to speak, like talk, in Ojicree. She never really understood what my parents said to her, like a simple instruction she wouldn't understand, like she would just stand there. These days she's usually using Native language or Ojicree when she talks so I think, that's what I've been doing for those kind of students there, using Roman orthography, then they begin to speak in Native language using that and then I try to get them from there, when they get to that point I try to get them to transform the roman to syllabics, so it works pretty well, pretty good, when I do that. So, I'm not against roman orthography, at least it helps the way I teach $<$ laugh $>$. (Judy)

Judy does not generalize in the same way that John does, she is careful to use an example from her own family to show the specific cases in which she would use roman orthography to help a student learn their Native language who has grown up only speaking English. In this case there is to be a difference in the attitude towards the roman orthography between John/Judy and the (East) Cree participants. The language situation between the (East) Cree and Ojicree communities is different. There are more younger people in Kasabonika who arrive at school without a strong foundation in their Native language than in the (East) Cree communities. Another possible explanation for the difference in attitudes towards roman orthography could be related to the closer linguistic relationship between Ojicree and Ojibwe. The Ojibwe of southern Ontario tend to prefer the roman script to syllabics (Valentine, 1994). 


\section{Chapter 5: Conclusion}

The final chapter of this thesis will conclude (5.1), delineate the limitations of this study (5.2) and discuss suggestions for further research (5.3).

\subsection{Conclusion}

The findings of this study gesture to the inherent importance of Aboriginal writing systems to the fabric of life in the four communities discussed. The participants all share experiences of their literacy learning that reveal similar themes including a motivation to learn the syllabic form of their language, the informal nature in which they observed and were taught the syllabic writing system, and the role of mentors (both family members and teachers) in the acquisition of syllabics. Identity, the over-reaching theme of this study, is deeply connected to Aboriginal language knowledge, both spoken and written. Most of the participants saw a link between their Aboriginal literacy and their identity, including a connection to getting a job and a feeling of pride about knowing their roots. The uses of the writing system, the processes involved in learning it in an informal setting, the traditional uses for communications with family members over vast distances, and its role in connecting children to their Elders, all traditionally serve to reinforce familial relationships. 
Though all of the participants share similar roles in their communities as Native language professionals, their responses show variation between L1/L2 vs. order of acquisition of orthographies. Some participants learned to read and write in their L2 (English) before their L1 (Ojicree/(East) Cree). What are the implications of this on identity? In the community context of the two language groups, this variation also becomes interesting when thinking about Aboriginal literacy education. In Kasabonika there is a situation in which many children speak English as their L1. What are the implications of teaching them to write in their L2 (Ojicree) first? The study also informs the question of preferences regarding the two scripts. All of the participants learned to write in their language in syllabics before the roman script and syllabics are used as the preferred means of writing (instead of the roman orthography) by all participants. However, the roman orthography is regarded as a helpful tool by the Ojicree participants in the changing times for helping the many students who come to them speaking English as a L1. The (East) Cree seemed to have a more negative view of the roman orthography. Some individuals equated roman orthography to English.

In regards to reading of the scripts within the communities in daily life, the participants listed publications that they knew with sections in their languages. They also gave examples of the symbolic uses of syllabics signs/posters/clothing in their communities. In terms of writing, many participants said they wrote journals in their language. The (East) Cree participants use syllabics for chatting online, and emailing and that they text message in roman only because technology forces them to do so. The 
Ojicree were aware of the technology to use syllabics on computers but did not seem to use it so frequently. Most of the participants spoke about the lack of material available to read in their own dialects. This was especially evident in the responses of the Ojicree, though also mentioned by the (East) Cree. The (East) Cree have had successes pooling resource material for teaching between several communities that belong to the same dialectal family (example Inland and Coastal dialects of Southern East Cree). In the case of the Ojicree, provincial boundaries and funding systems do not encourage the sharing of resources between communities that belong to the same linguistic subfamily. Perhaps by looking at neighbouring communities that belong to the same dialectal family of language (Example: Western Big Trout dialect from Big Trout Lake) language materials might be shared for education purposes.

The interviews reveal several similar overarching themes which include concern about language preservation and the importance of teaching Native language to the children to ensure a strong Aboriginal identity. By documenting these seven experiences of literacy, I hope to have demonstrated that, for these participants, reading and writing in their ancestral language is part of who they are as language professionals in their communities. They hold a part of the collective knowledge of their language that is deeply embedded in their way of life. 


\subsection{Limitations of the Study}

A major limitation of the study is that $\mathrm{I}$ was only able to interview seven participants. In addition, these seven case studies were collectively from four different communities and so the intra-community differences may not have been represented in this study. On the other hand, all my participants had in common that they were language professionals, teachers, and syllabics specialists whose living is tied to their specialty. Other community members with different economic interests might have different opinions. This being said, it was not the intent of this study to generalize the seven experiences of literacy as true for everyone in all four home communities, but rather to document some Aboriginal literacy experiences as an important part of Canadian history and to gesture to areas in which further study could be made with tentative suggestions regarding local literacy projects. The number of Ojicree and (East) Cree participants who are able to read and write in their ancestral language is comparatively fewer than those able to speak it. I feel extremely lucky to have the number of participants that I had. As an outsider of all of the communities of Kasabonika, Waswanipi, Mistissini, and Waskaganish, I feel deeply grateful to all of the participants for sharing their stories with me and trusting me to accurately and respectfully report my findings.

\subsection{Implications for Further Study}

The results of this study raise several questions. Firstly, between the two groups there were several discernable differences concerning the attitudes towards the two 
orthographies (roman and syllabic). How do teachers of Ojicree in Kasabonika address the difference in phonemes associated with the letters of the Ojicree roman orthography and the English alphabet? Also, it may be interesting to look at attitudes towards the future uses of syllabics and roman orthographies between the two communities. Do the (East) Cree/ Ojicree want the uses of syllabics to grow, or do they prefer a more symbolic usage? Further research could be conducted with focus on the various uses of standardized and non-standardized syllabics and phonemic versus standardized roman scripts.

In terms of the difficulties expressed in 'practicing' Ojicree and (East) Cree reading and writing, perhaps local literacy projects can be thought about to aid in the addressing of the issue of lack of material and teaching resources written in local dialects. Furthermore, as this study shows differences between the two groups of Ojicree and (East) Cree, it may be interesting to study ways in which communication between the two groups regarding different means of addressing some of the issues related to language teaching and learning might be beneficial to both. In addition, the study focuses on an older generation of individuals who attended schools where their language was not taught in the early years formally. Beyond the breadth of this study is how the children are learning and using syllabics and roman scripts now. It is likely that the process of a child learning to read and write in their ancestral language has now changed with the implementation of formal schooling and that they are not learning this skill in the home 
as was traditionally the case. What is the effect of this change in teaching methodology on the identity of the students?

As all of the participants in this study expressed deep interest in learning to read and write in the syllabics it would also be interesting to study if this motivation exists in the younger generation and ways in which such interest could be fostered since it seems essential for learning. Does the younger generation see value in learning syllabics? Further, it is likely that the ways in which the individuals in this study use the language is different from the way the younger generation use their language. Further study concerning how the students are using their Aboriginal literacies may also be helpful in understanding the current language situation. The students in Kasabonika use social sites such as MyKnet and Facebook to communicate with one another using phonemic roman mixed with English. What are the implications of this? In terms of technology, are computers and cell phone companies forcing these groups to use roman orthography? If so, what is being done today to address this? 


\section{Bibliography}

Assembly of First Nations (1990). Towards Linguistic Justice for First Nations, Assembly of First Nations, Ottawa.

Antone, E. (2003). Culturally framing Aboriginal literacy and learning. Canadian Journal of Native Education. 29(1), 7-15.

Battiste, Marie (2000). Maintaining Aboriginal identity, languages, and culture in modern society. Reclaiming Indigenous Voice and Vision (pp. 192-208). Vancouver: University of British Columbia Press.

Battiste, M. (1985). An historical investigation of the social and cultural consequences of Micmac literacy. In B. Burnaby (Ed.). Promoting Native Writing Systems in Canada. OISE Press: Toronto.

Berry, J. \& Bennett, J. (1989). The meaning and value of the syllabic script for Native People. Actes du vingtième Congrès des Algonquinistes. 20. 31-42.

Berry, J. \& Bennett, J. (1995). Syllabic literacy and cognitive performance among the Cree and Ojibwe people of Northern Canada. Scripts and Literacy: Reading and Learning to Read Alphabets, Syllabaries and Characters. I. Taylor \& D. Olson (eds.) Kluwer Academic Publishers: The Netherlands.

Berry, J. \& Bennett, J. (1995). The future of Cree syllabic literacy in Northern Canada. In A. Wagner (ed.) The Future of Literacy in a Changing World. Pergamon Press: Oxford.

Bobbish, J. (1996). The future of the Cree language. In J. Maurais (ed.) Quebec's Aboriginal Languages: History, Planning and Development. Clevedon: Multilingual Matters, 244-249.

Burnaby, B. (1985). Introduction. Promoting Native Writing Systems in Canada. Burnaby, B. (Ed.) OISE Press: Toronto.

Burnaby, B. \& Anthony, R. (1985). Orthography choice for Cree language in education. Promoting Native Writing Systems in Canada. Burnaby, B. (Ed.) OISE Press: Toronto.

Burnaby, B. (1998). Factors in Aboriginal mother tongue education: The Cree School Board Case. Papers of the Algoniquian Conference. 29. 62-73. 
Burnaby, B. (2000). Bicultural education in the north: Ways of enhancing traditional peoples' languages and traditional knowledge. Anthropological Linguistics. 42 (2). 282-284.

Burnaby, B. (2002). How have Aboriginal North Americans responded to writing systems in their own languages? Paper given at the Atlantic Provinces Linguistics Association Conference; St. John's: Memorial University.

Burnaby, B. \& Beaujot, R. (1986). The Use of Aboriginal Languages in Canada: An Analysis of 1981 Census Data. Ottawa: Social Trends Analysis Directorate and Native Citizens Directorate, Department of the Secretary of State.

Burnaby, B. \& MacKenzie, M. (1985). Reading and writing in Rupert House. In Barbara Burnaby (Ed.), Promoting Native Writing Systems in Canada. Toronto: OISE Press. 57-81.

Butler, E. (1951). The Story of British Shorthand. London: Pitman.

CBC News (June 11, 2008) Prime Minister Stephen Harper's statement of apology. http://www.cbc.ca/canada/story/2008/06/11/pm-statement.html $<$ Retrieved December 20, 2010) $>$

Champagne, D. (1994) Native North American Almanac: A Reference Work on Native North American in the United States and Canada. Gale Group: Detroit.

Connor, U \& Belcher, D. (2001). Appendix A. Reflections on Multiliterate Lives. Multilingual Matters Ltd.: Toronto.

Cummins, J. (1981). Biliteracy, language proficiency, and educational programs. In J. Edwards (ed.) The Social Psychology of Reading (Vol. Language and Literacy, pp. 131-46). Silver Spring, MD: Institute of Modern Languages.

Creswell, J. (1994) Research Design: Qualitative and Quantitative Approaches. Thousand Oaks, CA: Sage Publications.

Darnell, R. \& Vanek, A. (1973). The psychological reality of Cree syllabics. In R. Darnell (ed.) Canadian Languages in Their Social Context, University of Alberta Press, Edmonton, 171-192.

Denzin, N.K., \& Lincoln, Y.S. (Eds.). (2008). Strategies of Qualitative Inquiry. Thousand Oaks: Sage Publication. 
Drapeau, L. (1985). Decision-making on a standard orthography: The Betsiamites case. Promoting Native Writing Systems in Canada. Burnaby, B. (Ed.) OISE Press: Toronto.

Duff, P.A. (2008). Case Study Research in Applied Linguistics. New York: Lawrence Erlbaum Associates.

Ellis, D. (1975). A proposed standard roman orthography for Cree, Western Canadian Journal of Anthropology 45:2 1-37.

Fishman, J., et al. (1985). The Rise and Fall of the Ethnic Revival: Perspectives on Language and Ethnicity. Berlin: Mouton.

Fogwell, L. (1994). Literacy: A critical element in the survival of Aboriginal languages. Hautecoeur, J. (Ed.) Alpha 94: Literacy and Cultural Development Strategies in Rural Areas. Culture Concepts: Toronto.

Foster, M. (1982). Canada's first languages. Language and Society 7:7-16.

Freire, P. (1970). Cultural Action for Freedom. Center for Study of Development and Social Change: Cambridge, Mass.

Gee, J. (1999). An Introduction to Discourse Analysis: Theory and Method. Routledge: London.

Genesee, F. (1980) Bilingualism and biliteracy: A study of cross-cultural contact in a bilingual community. In J. R. Edwards (ed.) The Social Psychology of Reading. Silver Spring, MD: Institute of Modern Languages.

Goodman, K., et al. (1979). Reading in the Bilingual Classroom: Literacy and Biliteracy (ERIC Doc. ED 181725 ed.) Arlingtin, VA: NCBE.

Grant, A. (1996). No End of Grief: Indian Residential Schools in Canada. Winnepeg: Pemmican Productions Inc.

Grenier-Mintenko, K. (2001). en-ani-pahkaanikiishweyank: Approaching Language Change in Anishininiimowin. MA Thesis. Department of Linguistics: University of Manitoba. http://www.collectionscanada.gc.ca/obj/s4/f2/dsk3/ftp05/MQ62738.pdf.

Hack, J. \& Mellow, J. (2007). A functional analysis of the acquisition of Ojicree. Papers of the Algonquian Conference. 38. 273-288. 
Haig-Brown, C. (1991). Resistance and Renewal: Surviving the Indian Residential School, Tillacum Library, Vancouver.

Heath, S. (1982). What no bedtime story means: Narrative skills at home and school. Language and Society 11 (1), 49-76.

Heath, S. (1983). Ways with Words: Language, Life and Work in Communities and Classrooms. New York: Cambridge University Press.

Hebert, Y. \& Lindley, S. (1985). Evaluating an orthography. Promoting Native Writing Systems in Canada. Burnaby, B. (Ed.) OISE Press: Toronto.

Heimbecker, C. (1997). Bilingual Education for Indigenous Groups in Canada. In W. Corson (ed.) Encyclopedia of Language and Education in Canada. Vol. 1: Language Policy and Political Issues in Education

Hornberger, N. \& Skilton-Sylvester, E. (2000). Revisiting the continua of biliteracy: International and critical perspectives. Language and Education: An International Journal 14 (2), 96-122.

Hornberger, N. (2000). Afterword: Multilingual literacies, literacy practices, and the continua of biliteracy. In M. Martin-Jones and K. Jones (eds) Multilingual Literacies: Reading and Writing Different Worlds (pp. 353-67). Philadelphia: John Benjamins.

Hornberger, N. (2003). The Continua of Biliteracy: An Ecological Framework for Educational Policy, Research and Practice in Multilingual Settings. Buffalo [N.Y.]: Multilingual Matters.

Hutchinson, G. (1988). Evans, James, pp. 298-300 in W. Brown (Editor): Dictionary of Canadian Biography Vol. VII. Toronto: University of Toronto Press.

Junker, M. \& Luchian, R. (2007). Developing Web Databases for Aboriginal Language Preservation. Literary and Linguistic Computing. 22(2) 187-206.

Junker, M. \& Mackenzie, M. (2003). Demonstratives in East Cree. In H.C.

Wolfart (ed.) Actes du trente-quatrième congrès des Algonquinistes. Winnipeg: University of Manitoba Press: 201-216

Kramsch, C. (1993). Context and Culture in Language Teaching. Oxford: Oxford University Press. 
Kucer, S. (2009). Dimensions of Literacy: A Conceptual Basis for Teaching Reading and Writing in School Settings. $3^{\text {rd }}$ Edition. Routledge: New York.

Lewis, A. (2001). Bicenenary of Rev. James Evans. Proceedings of the Wesley Historical Society 53(3): 28-41.

Lewis, R. \& Dorais, L. (2003) Two related indigenous writing systems: Canada's syllabic and China's A-Hmao scripts. The Canadian Journal of Native Studies. XXIII: 277-304.

Leu, D.J., Jr. (2000). Literacy and technology: Deictic consequences for literacy education in an information age. In M.L. Kamil, P. Mosenthal, P.D. Pearson, \& R. Barr (Eds.), Handbook of reading research (Vol. III, pp. 743-770). Mahwah, NJ: Erlbaum.

Liu, I. (1995). Script factors that affect literacy: Alphabetic vs. logographic languages. Scripts and Literacy: Reading and Learning to Read Alphabets, Syllabaries and Characters. I. Taylor \& D. Olson (eds.) Kluwer Academic Publishers: The Netherlands.

Long, J. (1999) Local control of First Nations education: The event and the process. Papers of the Thirty-First Algonquian Conference. 31:211-223.

Long, J. (2003) Finding and keeping teachers in First Nation schools in northwestern Ontario. Papers of the Thirty-Fifth Algonquian Conference. 35:265-280

MacKenzie, Marguerite, Marie-Odile Junker, Luci Salt, Elsie Duff, Daisy Moar, Ruth Salt, Ella Neeposh, Bill Jancewicz, Alice Duff, Patricia Diamond, Pearl Weistche \& Anna Blacksmith (eds) (2004-2010) The Eastern James Bay Cree Dictionary on the Web : English-Cree and Cree-English (Northern and Southern dialects). http://dict.eastcree.org/

MacKenzie, M. (1980). Towards a dialectology of Cree-Montagnais-Naskapi.PhD Thesis. Department of Anthropology, University of Toronto.

MacKenzie, M. (1985) Spelling Reform among the James Bay Cree. In B. Burnaby (Ed.) Promoting Native Writing Systems in Canada. The Ontario Institute for Studies in Education: Toronto.

McCarty, S. (1995). The Cree syllabary and the writing system riddle: A paradigm in crisis. Scripts and Literacy: Reading and Learning to Read Alphabets, 
Syllabaries and Characters. I. Taylor \& D. Olson (eds.) Kluwer Academic Publishers: The Netherlands.

Mitchell, M. (1985). Syllabic literacy: The first year. Promoting Native Writing Systems in Canada. Burnaby, B. (Ed.) OISE Press: Toronto.

Malton, S. (1985). Six years later: The ICI dual orthography for Inuktitut, 1972-1982. Promoting Native Writing Systems in Canada. Burnaby, B. (Ed.) OISE Press: Toronto.

McCarthy, S. (1995). The Cree syllabary and the writing system riddle: A paradigm in crisis. Scripts and Literacy: Reading and Learning to Read Alphabets, Syllabaries and Characters. I. Taylor \& D. Olson (eds.) Kluwer Academic Publishers: The Netherlands.

McCarty, T. (2003) Revitalizing Native languages in homogenising times. Comparative Education. 39: 2, 147-163

McCarty, T. (2008). Native American languages as heritage mother tongues. Language, Culture and Curriculum. 21(3). 201-225.

McCarty, T. \& Leisy, W. (2009). Indigeneous youth and bilingualism: Theory, research, praxis. Journal of Language, Identity, and Education. 8, 279-290.

McLean, (1932 [1849). Notes of a Twenty-five Years' Service in the Hudson's Bay Territory. Toronto: The Champlain Society.

Merchant, G. (2009). Literacy and identity. Literacy. 43 (2) 63-64.

Murdoch, J. (1985). A syllabary or an alphabet: A choice between phonemic differentiation or economy. Promoting Native Writing Systems in Canada. Burnaby, B. (Ed.) OISE Press: Toronto.

Murdoch, J. (1985). Syllabics History: The spread of Native literacy. Education Manitoba 13(2): 9-11

Ningewance, P. (1993). Survival Ojibwe. Winnipeg: Mazinaate Press.

Niyekawa, A. (1983). Biliteracy acquisition and its sociocultural effects. Asian-and Pacific-American Perspectives in Bilingual Education (pp. 97-119). NewYork: Teachers College Press. 
Norris, Mary Jane (1998). Canada's Aboriginal Languages. Canadian Social Trends. Statistics Canada Catalogue \# 11-008.

Patrick, Donna. (2003). Introduction. Language, Politics, and Social Interaction in an Inuit Community. New York: Mouton de Gruyter.

Pilling, J. (1891). Bibliography of the Algonquian Languages. Washington: Smithsonian Institution, Bureau of Ethnology.

Rampton, B. (2006). Language in Late Modernity: Interaction in an Urban School. Cambridge: Cambridge University Press.

Rogers, H. (2005) Writing Systems: A Linguistic Approach. Malden, MA: Blackwell Publishing.

Sachdev, I. (1995). Language and identity: Ethnolinguistic vitality of Aboriginal Peoples in Canada. The London Journal of Canadian Studies. 11(41).

Scribner. S. \& Cole, M. (1981). The Psychology of Literacy. Cambridge: Harvard University Press.

Scollon, R. \& Scollon, S. (1981). Narrative Literacy, and Face in Inter-Ethnich Communication, Norwood, NJ: Ablex.

Stairs, A. (1989) The developmental context of Native language literacy: Inuit children and Inuktitut education. Promoting Native Writing Systems in Canada. The Ontario Institute for Studies in Education: Toronto.

Statistics Canada (2001). Languages in Canada: 2001 Census. Heritage Canada and Statistics Canada. Catalogue no. 96-326-XIE.

Street, B. (2003). What's 'new' in new literacy studies?: Critical approaches to literacy in theory and practice. Current Issues in Comparative Education. 5(2).

Taylor, D., Caron, M., \& McApline, L., (2000). International Journal of Bilingual Education and Bilingualism. 3(4). 283-295.

Taylor, I., \& Olson, T. (1995). Scripts and literacy: Reading and learning to read alphabets, syllabaries, and characters. Kluwer Academic Publishers Group: The Netherlands. 
Taylor, D \& Wright, S. (2003). Do Aboriginal students benefit from education in their heritage language?: Results from a ten-year program of research in Nunavik. The Canadian Journal of Native Studies. 23(1), 1-24.

Usborne, E., et al (2009) Bilingual education in an Aboriginal context: Examining the transfer of language skills form Inuktitut to English or French. International Journal of Bilingual Education and Bilingualism. 12(6). 667-684.

Valentine, R. (no date) Ojibwe and Cree syllabic writing. U of Wisconsin-Madison. http://imp.lss.wisc.edu/ irvalent/glolangiss/pdfs/syllabics.pdf. $<$ date retrieved: $12 / 01 / 2010>$

Valentine, J. (1994). Ojibwe dialect relationships. $\mathrm{PhD}$ dissertation, University of Texas, Austin.

Venezky, R. (1995). How English is read: Grapheme-phoneme regularity and orthographic structure in word recognition. Scripts and Literacy: Reading and Learning to Read Alphabets, Syllabaries and Characters. I. Taylor \& D. Olson (eds.) Kluwer Academic Publishers: The Netherlands.

Valdés, G. (1983) Planning for biliteracy. In L. Elías-Olivares (ed.) Spanish in the US Setting: Beyond the Southwest (pp. 259-62). Arlington, VA: National Clearinghouse for Bilingual Education.

Walker, W. Notes on Native writing systems and the design of native literacy programs. Anthropological Linguistics. 11 (5).

Walker, W. (1996) Native Writing Systems, pp. 158-184 in I. Goddard (Editor): Handbook of North American Indians Vol. 17 Languages. Washington: Smithsonian Institution.

Yin, R. (2009). Case Study Research. California: Sage Ltd.

Young, E. (1899) The Apostle of the North Rev. James Evans. New York: Fleming H. Revell.

Zhou, L. (2010). Morpho-Semantics of East Cree Motion Verbs: A Corpus-Based Study. M. A. Thesis. Ottawa: Carleton University.

Zukewich, N. \& O'Donnell, V., (2006) Aboriginal children's survey. Family, Community and Child Care. 8. 2006. 


\section{Appendix A}

Participant Name:

\section{Interview Questions}

Participant Age:

Participant Gender:

Home Community:

\section{Literacy Development}

How did you learn to read and write in Ojicree-Cree?

How did you learn to read and write in English?

How did you learn to read and write in French?

Did you learn roman orthography or syllabics (or both)?

Did your mother read and write Cree? Father? Other family members?

Who most influenced your Cree reading and writing?

\section{Literacy in Daily Life}

What do you read in Ojicree/Cree? English?

Do you read the bible in English//Cree/Ojicree?

Do you see written forms of Cree on signs, buildings in your community or wear clothing that has written forms of Cree on it?

When you read the poster do you read the English or in Ojicree/Cree.

Do you ever give written direction to a place in Cree?

Do you read newspapers in Ojicree/Cree? Other publications? Legal reports?

Do you use the English translation to do this?

Do you read it out loud or in your head?

Do you text message/email in Ojicree/Cree?

Do you text message in roman because you can't in syllabics?

Do you ever write letters, poetry, songs in Ojicree/Cree for yourself?

Is there a time you prefer using syllabics over roman? Roman over syllabics?

When you type, what do you use to type?

Do you ever use a mixture of Ojicree/Cree/English for yourself when you are writing/taking notes? Why?

If you are writing a shopping list, is it in Cree/Ojicree or English?

\section{Literacy and Identity}

Do you feel that being able to write in Cree/Ojicree has shaped your identity? Why?

Do you feel your literacy in English helped or hindered your learning Cree/Ojicree?

Do you see writing in Cree/Ojicree as a pleasurable experience?

Do you think it is important to teach Cree/Ojicree literacy in Cree/Ojicree schools?

Why?

Which orthography do you think should be taught in Cree/Ojicree language classes? Why? 